NIST

PUBLICATIONS

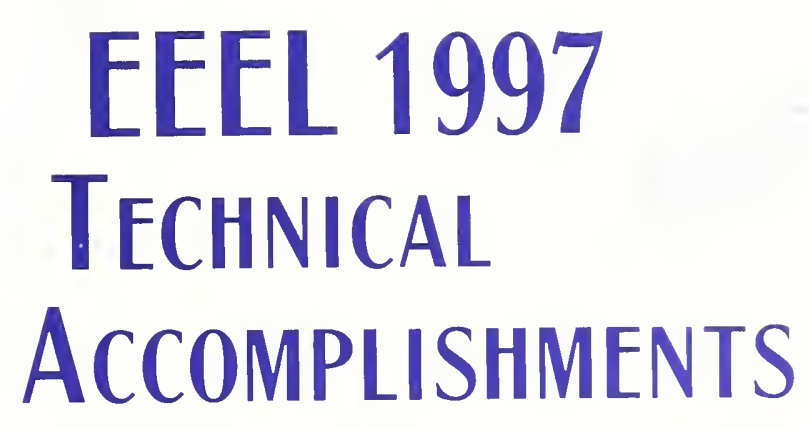

TECHNICAL

ACCOMPLISHMENTS

\author{
Advancing Metrology for \\ Electrotechnology to Support \\ the U.S. Economy
}

$Q C$

100

.456

N0.6106

1997

\section{United States Department of Commerce} TECHNOLOGY AdMINISTRATION

\section{NIST}




\section{National Institute of Standards and Technology}

As part of the Commerce Department's Technology Administration, the National Institute of Standards and Technology (NIST) works to promote U.S. economic growth by working with industry to develop and apply technology, measurements, and standards. NIST carries out its mission through a portfolio of four major programs:

$\sqsupset$ Measurement and Standards Laboratories that provide technical leadership for vital components of the nation's technology infrastructure needed by U.S. industry to continually improve its products and services;

- a rigorously competitive Advanced Technology Program providing cost-shared awards to industry for development of high-risk, enabling technologies with broad economic potential;

$\sqcup$ a grassroots Manufacturing Extension Partnership with a nationwide network of local centers offering technical and business assistance to smaller manufacturers; and $\square$ a highly visible quality outreach program associated with the Malcolm Baldrige National Quality Award that recognized continuous improvements in quality management by U.S. manufacturers and service companies.

In fiscal year 1998, NIST is operating on a budget of about $\$ 790$ million with nearly 3,300 staff members at its sites in Gaithersburg, Maryland, and Boulder, Colorado. News and general information about NIST programs and services are available on the World Wide Web at htp://www.nist.gov, or you can call general inquiries at (301) 975-3058 or e-mail: inquiries@nist.gov.

Any mention of commercial products is for information only; it does not imply recommendation or endorsement by the National Institute of Standards and Technology nor does it imply that the products mentioned are necessarily the best available for the purpose. 


\section{ELECTRONICS AND ELECTRICAL ENGINEERING LABORATORY}

NATI 0 NAL INSTITUTE $0 \mathrm{~F}$ S T A N D A R D S A N D TECHNOLLG

\section{EEEL 1997 \\ TeChNical Accomplishments}

Advancing Metrology for
Electrotechnology to Support
the U.S. Economy

NISTIR 6106

William M. Daley, Secretary

Technology Administration

Gary R. Bachula, Acting Under Secretary for Technology

National Institute of Standards and Technology

Raymond G. Kammer, Director

December 1997 



\section{Table of Contents}

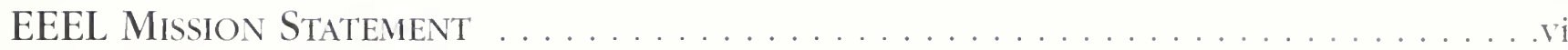

Foreword - A ProfILE of EEEL $\ldots \ldots \ldots \ldots \ldots \ldots \ldots \ldots \ldots \ldots \ldots \ldots$

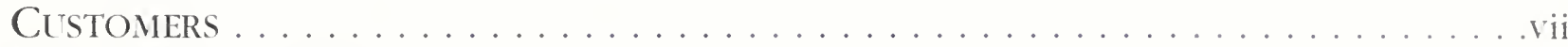

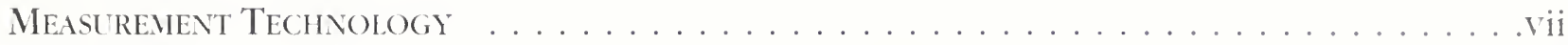

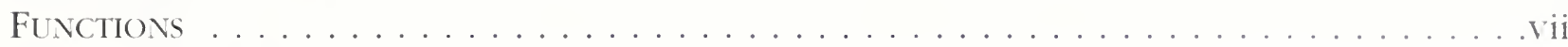

INTERACTIONS WTTH INDUSTRY . . . . . . . . . . . . . . . . . . Viii

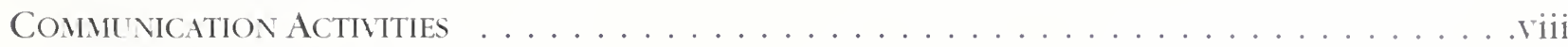

Participation in Indestritbased Planning Actintties . . . . . . . . . . . . . . viii

JoInt ACTIVtTIES . . . . . . . . . . . . . . . . . . . . . . . . . ix

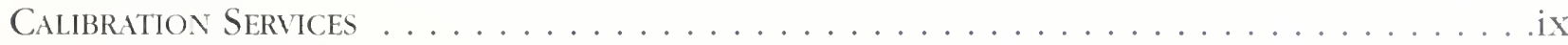

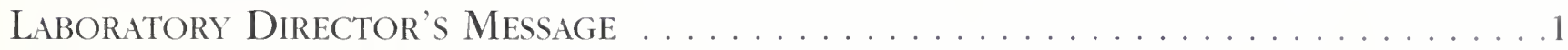

Deputy Director's Message: Measurements, Science, Standards, and

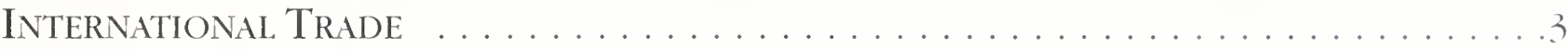

SELECTEd FY 1997 TeCHNICAL ACCOMPLISHMENTS . . . . . . . . . . . . . . .

ChAPTER 1 - SEMICONDUCTORS ......................................

1.1 Technique to Characterize long-Term Reliability of Gate Oxides Will Sale

Over an Order of Magnitude in Testing Tine . . . . . . . . . . . . . .

1.2 Improved Industry-Driven SRMs Now Avallable to Users $\ldots \ldots \ldots \ldots$

1.3 New Technique Improves Performance of Silicon RF Chips . . . . . . . . . . . 10

1.4 Single-Crystal CD Reference Materlals for Next Generation Lithography . . . . 11

1.5 Methodology for Validation of Compact Microelectronic Package

Therilal Model Proves Vlable . . . . . . . . . . . . . . . . . . . . . . 12

1.6 Finite Element Model of SCM Enables More Accurate Two-Diniensional

Dopant Profiling in MinUtes . . . . . . . . . . . . . . . . . . . . $\ldots$

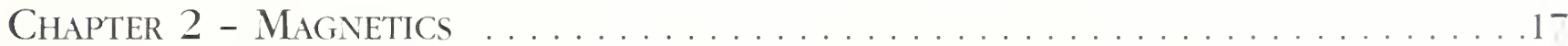

2.1 Ultra-Fast Magnetic Measurements Provtide Unprecedented Temporal.

Chapter 3 - Superconductors . . . . . . . . . . . . . . . . . . . . . . . 19

3.1 Unique Measureinents Sinulate fatigle Degradation of Futt re

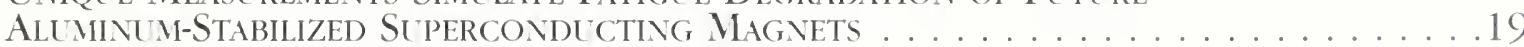

Chapter 4 - Low Frequenct . . . . . . . . . . . . . . . . . . 21

4.1 Wide-Band Salipling Voltieter Provtdes High Accl Racy Alovg With

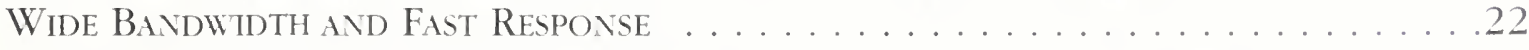

4.2 Speclal Test Developed for New Commerclal Fused-Silica Capacitalce

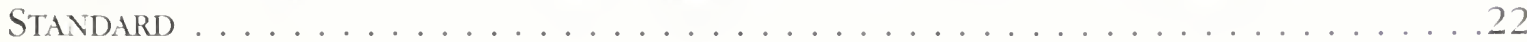

Chapter 5 - Microwaves . . . . . . . . . . . . . . . . . . . . . . 25

5.1 Attractive, New Measureilent Service for Vector Network ANalyzer (VNA)

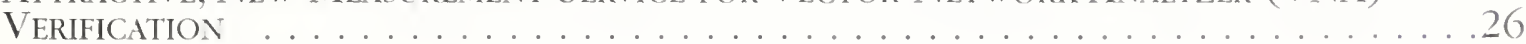


5.2 Algorithil for Probe-Position Error Correction Expands Use of Current Planar ScanNing Ranges from Maximum Frequency of

$30 \mathrm{GHz}$ to Freqlencies from $500 \mathrm{GHz}$ to $1000 \mathrm{GHz} \ldots \ldots \ldots \ldots \ldots \ldots$

5.3 International Collaboration Brings Researchers to Better

Understanding of Multiconductor Transmission Lines . . . . . . . . . . . . . . . 27

5.4 Wr-28 Noise-Temperature Measurement Service Developed to Support

Eimerging Technologies for Military and Commercial Applications . . . . . . . . . 28

5.5 Development of Infrared/Microwave Holography Antenna Measurement

TECHNIQUE . . . . . . . . . . . . . . . . . . . . . . . . . . . . . . . .

5.6 Develophient of Microwave Characterization Ability Meets National

Metrology NeEd . . . . . . . . . . . . . . . . . . . . . . . . . . . . . . . . . . 29

5.7 High-Temperature Capability for Characterizing EM Properties

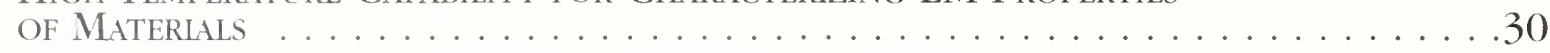

5.8 NiST Develops Method to Permit Direct Measurement of Thin-Film

Properties . . . . . . . . . . . . . . . . . . . . . . . . . . . . . . . .

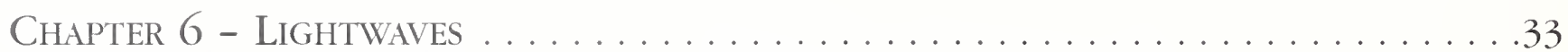

6.1 iniportant Polarization Behavior Revealed in Surface-Emitting

LASER ReSEARCH . . . . . . . . . . . . . . . . . . . . . . . . . . . . . . . . . . . . . . . .

6.2 Multimode Fiber Measurements Support Gigabit local Area Networks . . . . . . 34

6.3 New System for Polarization-Dependent Loss Measurements . . . . . . . . . . . . 35

6.4 Tools to Support Semiconductor Modeling, Manufacturing, and

Characterization . . . . . . . . . . . . . . . . . . . . . . . . .

CHAPTER 7 - VIDEO . . . . . . . . . . . . . . . . . . . . . . . . . . 39

7.1 Characterization of Flat Panel Displays Supports Standard Development _ . . . 40

7.2 Nist digital Video Compression System Test Patterns in Use by Industry . . . . . .41

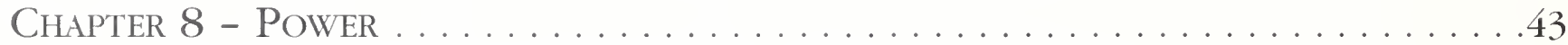

8.1 Research Focused on Calculations of Magnetic-Field Measurement-Error

Distributions Close to EleCtrical APPLIANCES $\ldots \ldots \ldots \ldots \ldots \ldots \ldots \ldots \ldots$

8.2 New Calibration Service Provides Customers with Faster, More-Economical

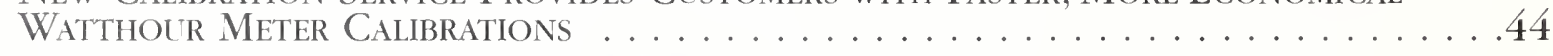

8.3 IEeE Publishes Guide for Measurement of Quasi-Static Magnetic and

ELECTRIC FIELDS . . . . . . . . . . . . . . . . . . . . . . 45

Chapter 9 - Electromagnetic Compatibility . . . . . . . . . . . . . 47

9.1 EMC Measurement UnCertainty Analysis and Antenna Calibration

IMPROVEMENTS . . . . . . . . . . . . . . . . . . . . . . . . . .

9.2 NisT's New Model Enables Absorber-Lined Chamber Evaluation Using

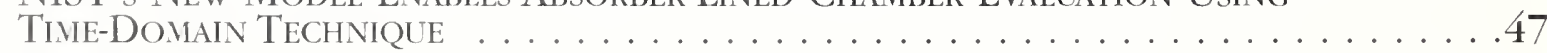

Chapter 10 - Electronic Data Exchange . . . . . . . . . . . . . . . . . . . . . . 49

10.1 FaCtory Information NeEds Identified for Crucial, NeXt-Generation

Mantfacturing Productivtty . . . . . . . . . . . . . . . . . . . . . . . . . . .49

Chapter 11 - National Electrical Standards . . . . . . . . . . . . 51

11.1 The Kilogram:A New Definition? . . . . . . . . . . . . . . . . . .51

11.2 Major Step Taken Toward Achieving aC Voltage Measurements Using

Pulse-Driven Array of Josephon Junctions . . . . . . . . . . . . . . . . . 52

11.3 Revolutionary Advance in X-Ray Energy Measurement . . . . . . . . . . . . . . 53 
Programs Matrix-Managed by EEEL . . . . . . . . . . . . . . . . . . 55

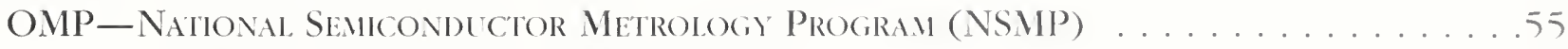

Autonateid RGa Calibration SYSTEM . . . . . . . . . . . . . . . . . . 55

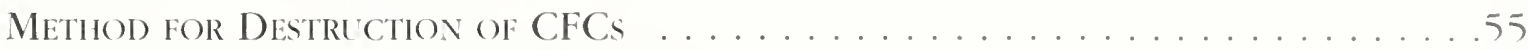

Chip View Dol bled by New SEM Stage . . . . . . . . . . . . . . . 55

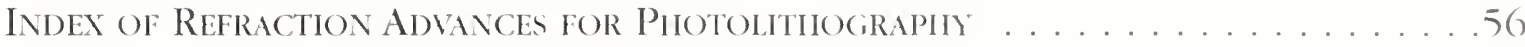

Polarized Signatures may lead to Tinier Chims _ . . . . . . . . . . . . . . . 56

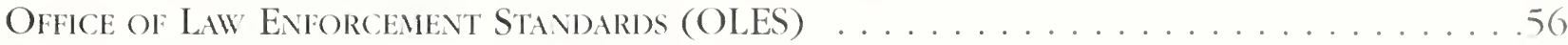

Donestic Colnterterrorisn Progran . . . . . . . . . . . . . . . . . . . . . 56

FORENSIC LABORATORY HANDBOOK . . . . . . . . . . . . . . . . . . . $5^{-}$

NHTSA PL Blication . . . . . . . . . . . . . . . . . . . . . . . . . . 5-

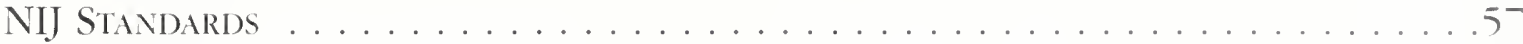

EEEL AWARDS AND RECOGNITION . . . . . . . . . . . . . . . . . . . 58

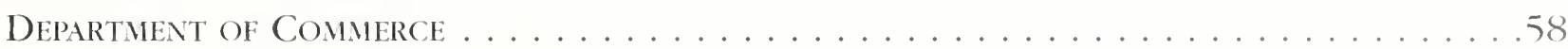

Gold MEdal . . . . . . . . . . . . . . . . . . . . . . . . . . . . . . . 58

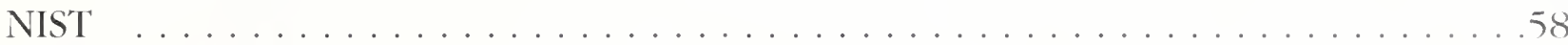

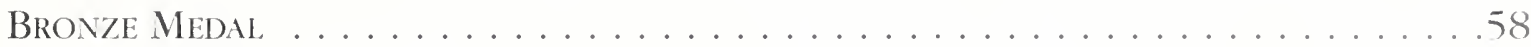

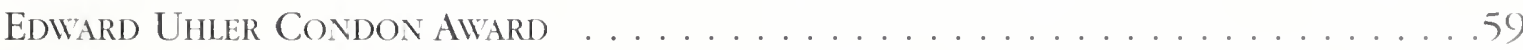

AMERICAN PHYSICAL SOCIETY (APS) … . . . . . . . . . . . . . . . . . . . 59

APS FELLOW . . . . . . . . . . . . . . . . . . . . . . . . . .59

INTERNATIONAL UNION OF RADIO SCIENCE (URSI) . . . . . . . . . . . . . . . . . . . 59

Yolng SCIENTIST AWARd . . . . . . . . . . . . . . . . . . . . . . . 59

INSTITUTE of Electrical and EleCtronics ENGineERs (IEEE) . . . . . . . . . . . . . . 59

IEEE FeLLows . . . . . . . . . . . . . . . . . . . . . . . . . . . . 59

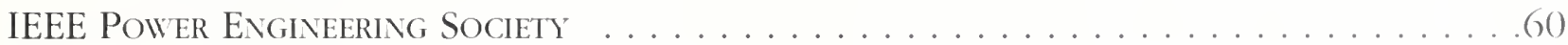

1997 Working Grolt ReCOGNITION AWARD . . . . . . . . . . . . . . . . . .60

Microbean ANALYSIS SOCIETY . . . . . . . . . . . . . . . . . . . . . . . 60

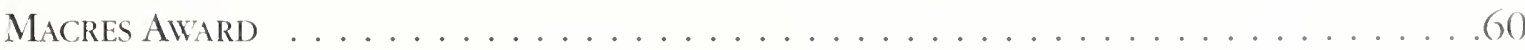

National ACAdEMY of ENGINEERING (NAE) . . . . . . . . . . . . . . . . 61

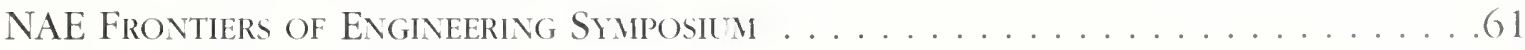

National Conference of Standards Laboratories … . . . . . . . . . . . . 61

DR. AlleN V.ASTIN AWARD . . . . . . . . . . . . . . . . . . . . . . . . . 61

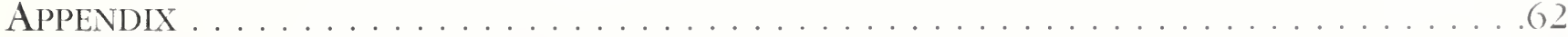

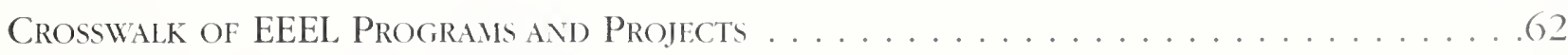

EEEL FY 1997 RESOltrCES _. . . . . . . . . . . . . . . . . . . . . . . . . . . . 66

EEEL FY 1997 CRADAs . . . . . . . . . . . . . . . . . . . . . . . . . . . 66

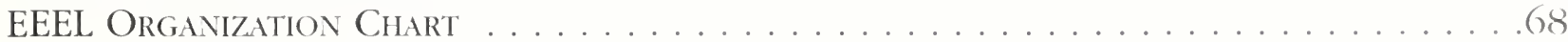




\section{Statement}

The Laboratory improves U.S. economic competitiveness, government operations, and health and safety by providing essential supporting generic technology and fundamental research to industry, government, and educational institutions. Key deliverables are measurement capability (for absolute accuracy and reproducibility) and reference data. These are realized through development of measurement methods, support theory, measurement reference standards (including the national primary standards for electricity), and calibration and other measurement services to assure measurement traceability. The deliverables are provided for electronic and electrical materials, components, equipment, and systems, operating over the range from dc to light. These deliverables support research and development, manufacturing, marketplace exchange, and operation of electronic and electrical products. 


\section{Foreword a Profile of EEEL}

Customers

Through its technical laboratory research programs, the Electronics and Electrical Engineering Laboratory (EEEL) supports the U.S. electronics industry, its suppliers and its customers by providing measurement technology needed to maintain and improve their competitive position. To realize the range and diversity of our customers, the term "electronics industry" must be understood in the broadest sense.

The capability provided by EEEL programs supports entities ranging from giant electric utilities and large aerospace and communication companies with thousands of workers to specialized instrument manufacturers employing fewer than ten individuals - all engaged in a broad spectrum of technologies. EEEL also provides support to the Federal government as needed to improve efficiency in technical operations and cooperates with academia in the development and utilization of measurement methods and scientific data.

Measurement Tecbnology

The measurement technology provided by the Laboratory is essential for industrial research and development, for improvements in the design and manufacturing of quality products, for proof of performance, for marketplace transactions including the acceptance of U.S. products into international markets, and for product applications. In countries throughout the world, all measurements must ultimately be referred back to national reference standards to provide consistency and accuracy. EEEL is the linchpin of this process for electrical measurements in the United States.
Functions

The Laboratory's two major functions are to maintain the national reference standards for electricity for the nation, and to disseminate these standards through appropriate calibration services. calibrated artifacts, and measurement methods to private industry and other clientele. Further. EEEL/NIST must realize national reference standards in terms of their internationally agreedupon definitions to provide equity in international trade. All of these processes require highly trained staff and a dedicated laboratory capabiliț:

The activities necessary to provide fullmeasurement capability range from the timely development of new measurement technology to the maintenance and realization of electrical standards. Dissemination of these standards is also critical. Suitable, practical, meaningful

measurement methods must be made available and accessible to users across the country. Only when this occurs are specialists and nonspecialists alike able to correctly use arailable instrumentation and standards to perform measurements at their required accuracies.

EEEL sees the need for constant diligence to assure that we understand our customers' needs and develop effective programs that meet those needs. Because these needs are so numerous, the Laboratory must plan well to effectively use our very limited resources. We rely, in part. for this needs determination on our close interaction with industry. Information is exchanged during staff visits to other laboratories. staff interactions at conferences, visits by others to our Laboratory. through meetings we conduct or attend, through 
professional societies, cooperative research projects, consortia, participation of guest scientists in our Laboratory, and so on. The Laboratory also periodically contracts for impartial impact analyses on our programs to verify that they are properly targeted and responsive to highly important client needs.

\section{Interactions with Industry}

Measurement problems revealed by our customers become a determining factor in our strategic-and project-planning. which, in turn, improves our ability to respond to measurement challenges in time to meet industry's needs. A more immediate benefit to industry is the opportunity to bring their staff into direct contact with those who are developing the metrology tools. Such contacts have resulted in immediate implementation of NISTdeveloped methods for conducting measurements which enriches the technology resources of the companies. Another typical outcome is the development of partnerships in which both parties work together to refine a laboratory method for industrial use. EEEL considers these informationexchange interactions so important that they are routinely tracked quantitatively.
Communication Activities

\section{Media}

No. of Publications . . . . . . . . . . . . . . 254

No. of Software Packages Distributed . . . . . .197

Talks

Talks Given by EEEL-Offsite . . . . . . . . . . .291

Significant Consultations . . . . . . . . 2,100

Visits

Staff Visits . . . . . . . . . . . . . . . . . . 503

Technical Visitors . . . . . . . . . . . . 330

Meetings

Short Courses or Workshops Conducted . . . . .20

Attendees . . . . . . . . . . . . . . . . . .703

Number of Other Meetings Conducted . . . . . .65

Attendees . . . . . . . . . . . . . . . . . . 335

Major Contributions to Conferences . . . . . . 60

Participation in Industry-

Based Planning Activities

In addition, EEEL participates in significant ways in the industry's own planning activities. A number of EEEL staff actively participated in the

Semiconductor Industry Association's development of its widely respected Roadmap. The Director of EEEL's Office of Microelectronics Programs is a member of the Roadmap Coordinating Committee. Similarly, EEEL staff has participated in the studies of the Optoelectronics Industry Development Association as OIDA prepared surveys and technology plans. EEEL has also been active in the work of the Electronics Subcommittee of the President's National Science and Technology Council. Our contributions to this subcommittee had a strong effect in stimulating the formation of the National Electronics Manufacturing Initiative (NEMI). This is an incorporated body of original equipment manufacturers and their suppliers who carry on joint development activities and are producing a roadmap, coordinated with other associations' plans, to foster a strong supply chain and competitive manufacturing capability in the United States. 
Joint Activities

\section{Standards Organizations}

Staff Participating. . . . . . . . . . . . . . . 49

Memberships. . . . . . . . . . . . . . . . 153

Professional Societies

Memberships. . . . . . . . . . . . . . . . . . 245

Cooperative Research Projects . . . . . . 206

Consortia .................6

Guest Scientists . . . . . . . . . . . . . 45

The NEMI roadmap covers everything from components and modeling to final assembly. EEEL's Director chairs the NEMI Crosscut Working Group on Test, Inspection, and Measurement and is a member of the overall Technical Committee. Many members of the Electronics and Electrical Engineering Laboratory and other NIST Laboratories serve in NEMI's working groups. It is significant that specific attention is paid to measurement needs in $70 \%$ of the chapters of NEMI's roadmap. This development goes hand-inhand with industry's growing realization that metrology is critical to the growth of new technology. In all of these activities. EEEL learns directly from customers about their needs and develops effective channels to transfer our responses to influence or support their advances.

\section{Calibration Services}

In EEEL, the term "calibration services" covers a broad span of activities: extending from the development of a metrology - to the internalization and realization of that metrology to the offering and provision of services to our customers. In fact, it is really through EEEL's calibration services that much of the practical transfer of metrology standards occurs. As these services improve, the improvements are transferred to customers industry wide, upgrading the metrology on a national level.
Calibration Fees Realized in FY 199- . \$1,908,063 No. of Calibration Customers ..........275 No. of Different Types of

Calibrations Performed .............130

No. of New Services Offered . . . . . . . . . . . . 6 SRM Sales Realized in FY 199- . . . . . \$181.833

No.of Standard Reference Materials Sold .....135

EEEL's calibrations support many millions of dollars worth of secondary calibration business in the Lnited States and billions of dollars of industrial business. EEEL offers nearly 200 unique

calibrations on 32 different types of standards. Over and over, EEEL's services have been shown to improve productivity and profitability, stimulate new product commercialization and new company startups, change industry-wide practices, and influence technical and policy actions - all to the benefit of our wide ranging clientele.

For more technical detail on any of EEEL's projects. please feel free to request the FY 1998 Program Plan or a list of EEEL publications in your area of interest. A list of current EEEL research projects is included in the Appendix. The list includes two crosswalks: one of the crosswalks identifies the Division or Office conducting each project; the other identifies the program under which the work is performed. You will also find EEEL's organization chart included. enabling you to contact staff members directly if you wish. 




Judson C. French, Director of EEEL, with colleague Robert E. Hebner, EEEL's Deputy Director. 


\section{Laboratory Director's Message}

wide scope of projects undertaken in our

The Laboratory is a clear reflection of American manufacturers' increased

awareness of the critical need for metrology to support their determination to rebuild a leading U.S. manufacturing environment, help them to develop advanced products, and substantiate their marketing claims. The ubiquitous electronics industry demonstrates the importance of metrology in the number and detailed refinement of their associations' planning activities. Virtually every sector has developed a roadmap, including the Semiconductor Industry Association (SIA), the Optoelectronics Industry Development Association (OIDA), the National Electronics Manufacturing Initiative (NEMI), and several more. In all of these major roadmaps, improved measurement appears as a formal, significant requirement and the need for attention at the national level, and at NST, is prevalent.

EEEL traditionally works actively with industry associations and federal agencies in the development of planning tools such as roadmaps because we think it is a good means to assure that our programs will be highly responsive. To assist in the development of the measurement infrastructure, we focus on a carefully chosen and diverse set of topics defined by our customers' needs and our responsibilities for primary standards as well as for keeping an eye on the future. Organized in this way, we support our customers in a flexible, efficient, timely manner.

In the recent past, the depth and breadth of our participation in planning strategies increased as the number and nature of industry-sponsored roadmaps changed and the recognition of the critical role of metrology became more widespread. The version of the National Technology Roadmap for Semiconductors issued three years ago listed four Grand Challenges: Productivity Improvement, Complexity Management, Advanced Technology Development, and Technology Development funding.

Metrology was not prominent among the formal challenges, but behind the scenes the Sil had stated:
Metrology' is a key' enabler for expipment design and mannfacture, for materials
production, for generating data for
modeling thronghont semiconductor
manufacturing. and for final test and evaluation. Witbont satisfactory' metrology:
the industry will not be able to follon' the
Roadmap and uill cease to be competitive.

Today, the extraordinary rate at which chip technolog: is progressing has increased the number of "Grand Challenges" identified in this vear's version of the National Technology Roadmap for Semiconductors by two: one of which is entitled Metrology' and Test. With billions of dollars at stake, the cry to shorten the gap between current measurement capability and what manufacturing technology requires is intense.

Industry stakeholders fully understand that to be viable competitors in world markets any technological milestones must be underscored with corresponding advances in testing and measurement capabilities. Without that reassurance. the combined technolog: investment and capital investment required of semiconductor manufacturers and equipment/material suppliers is at risk.

Metrologists have labored quietly in relative obscurity for many years, but that is no longer possible. The spotlight grows brighter as the demand for results 
increases and the work is more widely implemented. Consider the words of Senator Richard H. Bryan during the Senate Commerce, Science, and

Transportation Subcommittee on Manufacturing and Competitiveness Hearing on April 23, 1997. Its focus was the current state of manufacturing in the United States:

...cannot oleremphasize the importance of mannfacturing to the U.S. economy... The semiconductor industry bas benefited greatly from NIST programs that assist with precise measuring techniques, critical to complex mannfacturing.

We appreciate this recognition. I believe that much of our success stems from the culture of this unique institution. Capable enough to have world-wide impact, old enough to have appropriate, firmly-rooted traditions — with a lineage that stems directly from our country's Constitution — NIST has been pleased to receive rewarding expressions of appreciation from the clients it has served in industry, academia, and government for almost a hundred years.

Looking back at FY 1997, I think there is evidence that our work will stand up well to the commitments we have made to our customers' needs. I'll give you just two examples.

A landmark achievement is the revolutionary means developed to measure x-ray energy, a system that greatly extends the sensitivity and resolution of $x$-ray microanalytic techniques. The new system is able to analyze the small defect particles generated in the manufacture of semiconductors - a task that grows more daunting with each reduction in chip size. Broader applications of this system will include developing ultra-high resolution detectors for the astronomy community and mass spectroscopy detectors for massive biomolecules. The latter have the potential to greatly improve high-speed DNA sequencing.
And, given EEEL's leadership in developing world-class dc Josephson-junction measurement technology, it was only natural that American industry asked EEEL to provide the same integrity for ac voltage measurements. In response, a new ac voltage standard has been designed which combines a very high-speed digital pattern generator with a Josephson quantizer and synthesizes ac voltages by summing billions of quantum voltage pulses. Our staff achieved the predicted waveform this year, but at a relatively low voltage. The next challenge is to develop a superconducting circuit with more than 100,000 junctions that will generate voltages greater than 1 Volt. Ultimately, the team plans to design a single system that can be used to make a wide variety of calibrations and ac-dc transfers traceable to the intrinsic accuracy of the Josephson volt.

Other exciting challenges are also being met; you will find information on these and other topics in the section of this document entitled Selected FY 1997 Technical Accomplishments. Finally, I would like to take a moment to express my pleasure at the return of EEEL's Deputy Director to his staff responsibilities. For the past year Dr. Robert E. Hebner has very ably served as the Acting Director of NIST. Prior to that period, he served NIST in several other capacities, including that of Deputy Director.

I welcome Bob's return, and especially appreciate his taking time to contribute to this year's edition of our document. You will find his article immediately following these notes. I would also like to thank you for your interest in EEEL.

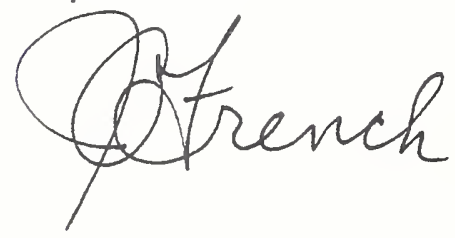

Judson C. French

Director, Electronics and Electrical Engineering Laboratory 


\section{Deputy Director's Message}

\section{Measurements, Science, Standards, and International Trade}

To d a y, extended economic growth and one of the world's strongest economies.

Three essential ingredients for continued economic growth are capital, labor, and technology. In the modern world, all of these are highly mobile. Thus, we have no lock on economic leadership. We must continue to attract capital, develop world class workers, and develop world class technology if we hope to remain a world class economy.

Within these three components of economic growth, technology is increasingly important. Leading economists estimate that technical progress has accounted for as much as one half of economic growth in the Lnited States over the past 50 years. Technology is an area in which the United States has a natural advantage. Since the Second World War. the United States has invested heavily in its research infrastructure. Today we have worldleading universities, government laboratories, and industrial laboratories.

This year the Federal government is investing about $\$ 25$ to $\$ 30$ billion in the research that fuels this emerging technology. The funding is distributed among the National Science Foundation, the Departments of Defense and Energy. NASA, and the Department of Commerce, which includes both NOAA and NIST. This is the Federal funding that provides support to government and university research facilities.
We see clear examples of the growth-inducing power of technology at the industry level. Our research-intensive industries - aerospace. chemicals, communications, computers. pharmaceuticals, scientific instruments, semiconductors, and software - have been growing at about twice the rate of the economy as a whole in the past two decades.

We also see technology's gronth-inducing power at the level of the individual firm. A recent Commerce Department analysis shows that firms using advanced technologies are more productive and profitable, par higher wages, and increase employment more rapidly than firms that do not. Specifically, in the studỵ, employment at plants that used eight or more advanced technologies grew $14.4 \%$ more than plants that used no adranced technologies. and production workers" wages were more than $14 \%$ higher.

At the macroeconomic level, the industry level, and the firm level, technology is the engine of economic growth. It is this economic growth, and the technology that underpins the growth, that provides the challenge for NIST's Electronics and Electrical Engineering Laboratory (EEEL). To appreciate the challenge, it is first necessary to understand how measurements and standards support the economy:

Efficient commerce requires a trusted sistem of money and a trusted sistem to measure quantitt: performance, or both. Without these essential 
supporting elements, an economy cannot progress bevond the barter sistem. For example, when we buy gasoline, we expect the volume of a gallon or liter to be the same at all stations. If we are willing to par a premium price for higher octane, we assume there is a measurement system that assures the higher octane is actually attained. If we are buving a new computer and are considering paving a higher price for a $200-\mathrm{MHz}$ microprocessor than for a $133-\mathrm{MHz}$ microprocessor, we assume there is a measurement system that can distinguish the difference.

In the U.S. Constitution, not only are the monetary and the metrology systems listed in the same line, but the Federal responsibilities for money and measurement also are carried out in similar ways. Banking is a private sector enterprise enabled by the Federal government. Functioning as a central bank, the government supplies currency, assures that the domestic system operates fairly, and fosters international acceptance of U.S. currency. Similarly, metrology is a private sector enterprise with the Federal government exercising a central metrology function. Through NIST, the Federal government expands and strengthens the measurement system as technology advances. It also assures that the domestic sistem operates fairly, and it fosters international acceptance of U.S. measurements.

National and international measurement systems are driven largely by accuracy and it is easy to see why. At a basic level, commerce only requires consistency. If two parties agree on the length of a meter, it does not matter what that length is in absolute terms. They can buy and sell things for example, cloth — and agree on a price per meter of cloth. If the trading circle grows, however, a universally accepted definition of the meter becomes imperative. Once all agree on the definition, a crucial question remains: How accurately can we measure with respect to the definition?
The SI — the international system of units provides the basic definitions for the seven essential measurement units. The meter, for example, is defined through the propagation of light. To find out how long a meter is, one must establish a laboratory containing the apparatus necessary to emit the light and to make the required measurements. Measurements of length are not confined to onemeter increments. You may need one one-billionth of a meter to measure a property of a transistor and thousands of meters to survey your country. Thus, we must develop methods to scale length measurements accurately over these tremendous spans.

The other six base units also must be realized and then scaled, so that one can accurately measure electricity, chemical concentration, temperature, pressure, light, weight, and the thousands of derived quantities required by commerce and regulation. One of these, the ampere, is the responsibility of EEEL. EEEL derives, scales, and disseminates electrical measurements for the United States.

If every public and private laboratory had to realize and scale measurements themselves, the cost would be enormous. NIST can obviate this requirement because most applications do not require the world's most accurate measurement. As a result, if NIST realizes the definitions of the various basic and derived quantities with world-class accuracy, it is unlikely that any other laboratory in the country will need to duplicate that effort. NIST works to exceed all present domestic and commercial needs, sparing laboratories and companies the task of realizing the basic definition themselves. Instead, they can compare with the national measurement institute. If the accuracy requirements are even more modest, companies can compare with a laboratory that compared with the national measurement institute. This is the concept, the power, and the efficiency of traceability. 
Traceability is generally accomplished through a calibration or through a reference material. These serve to transfer measurements. This concept of traceability works well within the United States. The Laboratory provicles the United States with the needed traceability in electrical measurements and performs nearly half of the calibrations performed by NIST.

These activities assure that the measurement capability needed for commerce exists in the United States and can be consistent with other measurements worldwide. Two additional types of activities have evolved to augment the basic capability. The first of these is trust activities. Trust activities include such things as accreditation and conformity assurance. As products become more complex, buyers and sellers may want a trusted third party to assure that the quantity and performance of the goods or services are appropriate. Testing laboratories have served this function for decades. Buvers and sellers around the world have developed a myriad of ways to select and certify the testing laboratories. The procedures depend on both the cultures of the buyers and sellers and the level of trust required. Today, efforts are underway to adopt international agreements in areas like accreditation and conformity assessment that will reduce the effects of cultural differences and standardize, across a wider range of products, the degree of risk that buyers and sellers are willing to assume. NIST provides both accreditation and conformity assessment support to U.S. industry. EEEL staff serve as experts to help in these efforts when electrical measurements are important.

The second augmentation of the basic measurement capability is the market efficiency achieved from voluntary standards. Through standards, buvers and sellers agree on a common set of attributes, tests, and measurements that satisfy their needs. These standards make it easier for commerce and can stimulate innovation, particularly if they are performance based rather than prescriptive. There is clearly a need for international standards. For example, internationally accepted standards make possible a globally interconnected telephone șistem. We also recognize that, since stanclards meet the needs of buvers and sellers, there are valid reasons for local, national, or regional differences. For example, differing weather conditions would lead one to expect different standards for buildings in Canada and Jamaica. EEEL staff work with their industry counterparts to develop effective standards.

So there is a key link between commerce and the measurements and standards support provided by EEEL. This key linkage is the heart of the challenge given to EEEL by technology's influence on economic growth. EEEL provides measurement support in areas easily identified with advancing technology and economic growth, including semiconductors, telecommunications, optoelectronics, magnetic storage, and electronic instrumentation. One cannot support the products made with tomorrow's emerging technology with today's measurements and standards. EEEL's measurement science must be leading edge to respond to the important industrial developments of the next decades.

The Electronics and Electrical Engineering Laboratory's Technical Accomplishments highlights advances in EEEL's portfolio of measurements, standards, and research. The work is challenging. exciting, fun, fast paced, and essential to the nation's economy.

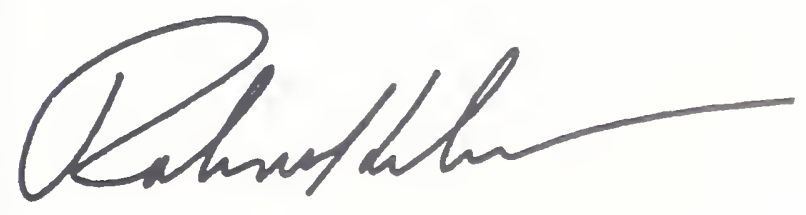

R.E. Hebner

Deputy Director, Electronics and Electrical Engineering Laboratory 

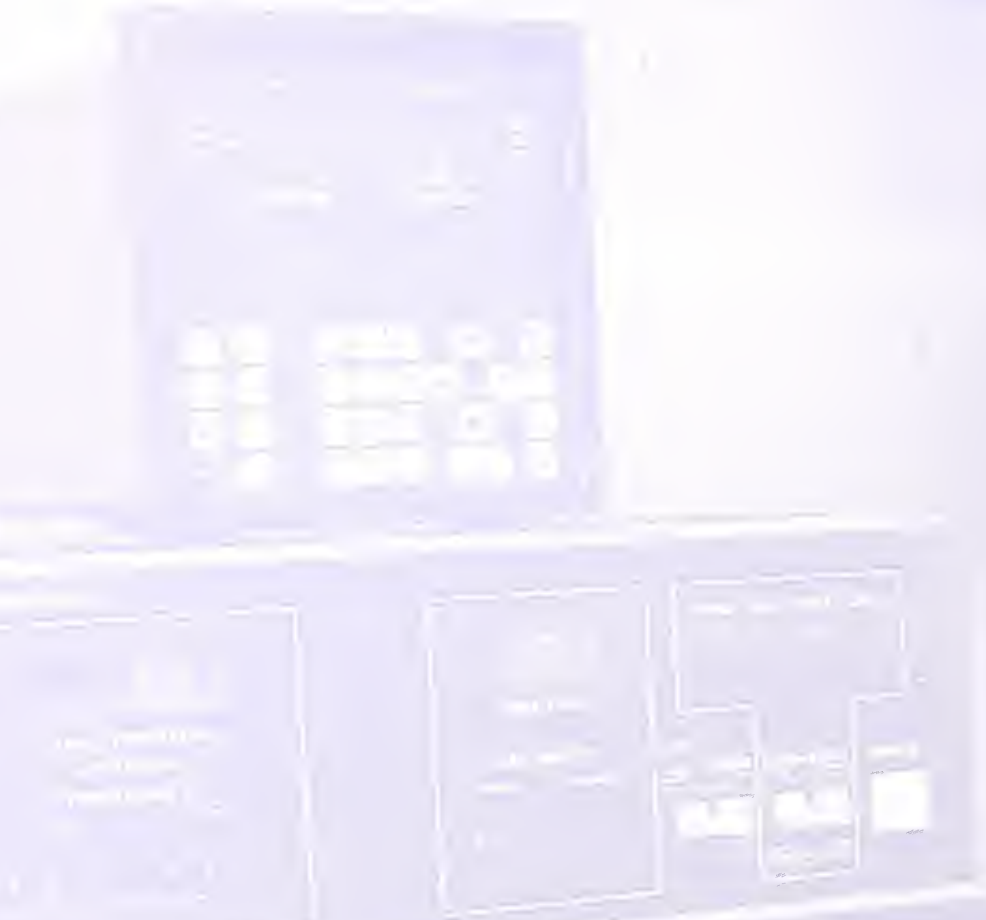

$-1-1-2-1=$ 


\subsection{Technique to Characterize}

Long-Terir ReliabIIITy of Gate Oxides

Will Save Over av Order of Magnitude

in Testing Time

With the introduction of new materials and process changes in the semiconductor industry, the reliability of gate oxides has become a critical showstopper in the drive to shrink feature sizes and achieve tighter control of electrical parameters. Both production schedules and technology changes have conspired to make it impossible to implement the mandatory long-term reliability stress tests during chip production. So, up to now, manufacturers were forced to rely on estimates of device reliability from highly accelerated test results that had not been correlated to device reliability. NIST researcher John Suehle has developed a new technique that enables the extraction of the long-term reliability parameters from the very fast stress tests that manufacturers normally use for production monitoring. The net result is that Suehle's method is saving manufacturers over an order of magnitude in testing time.

The new technique to extract long-term reliability parameters from very fast gate oxide stress tests is at least an order of magnitude faster than conventional time-dependent dielectric breakdown (TDDB) tests. Conventional TDDB tests can take up to several months to obtain statistically significant failure distributions that are used to obtain model parameters for extrapolating product life. The Suehle technique uses voltage versus time curves generated during fast constant-current stress tests. An integration of the curves is performed using a cumulative damage generation model. This not only gives the same TDDB acceleration parameters as those obtained from long-term TDDB life tests, but also provides more statistics on the parameters in a much shorter time.

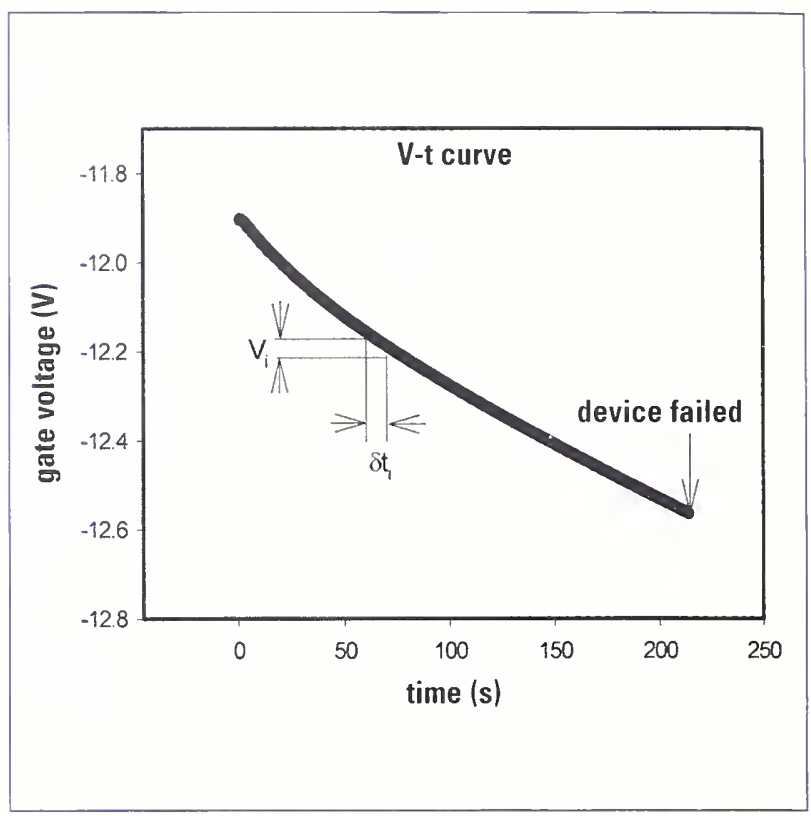

Plot phowing a typical voltage versus time curve obtained during a highly accelerated dielectric breakdown test.

"We have a near seamless team approach with NIST and collaborate on electronic design, optics design, and systems. It's given a tiny company like ours the capability to do what the larger companies do."

BARRY JOHNSON

PRESIDENT

OPTICAL E.T.C.

\subsection{IMPROVED INDUSTRY-DRIVEN SRMS}

Now Avarlable to Users

NIST has developed and certified seven new Standard Reference Materials (SRMs) for resistivity and sheet resistance of silicon wafers. The new SRMs cover the resistivity range $0.01 \Omega \mathrm{cm}$ to $200 \Omega \mathrm{cm}(0.15$ to $3000 \Omega)$ and offer significant improvements over previous SRMs with the same nominal resistivity values. These artifacts are used to calibrate, or to verify the accuracy of, four-point 
probes and eddy-current instruments. The instruments are used throughout the semiconductor industry for applications ranging from verifying the resistivity specifications of starting wafers to monitoring the sheet resistance of ion implants in order to determine the accuracy of an implanted dose. The new artifacts are also expected to be used to calibrate the resistivity/sheet resistance of other types of materials, such as conducting plastics used in the housings of various electronic systems, and conducting optical coatings, such as tin-oxide. The new SRMs were developed at

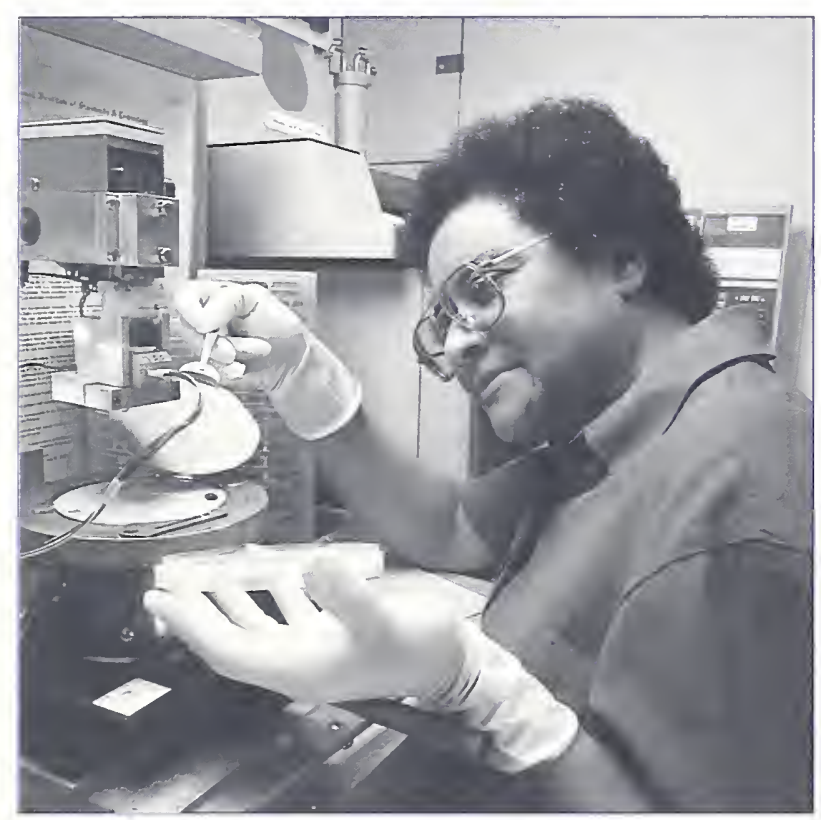

D. R. Ricks - Mounting a silicon wafer on the resistivity instrument stage prior to taking measurements for SRM certification.

industry request, and reflect the general recognition of the need to improve process control measurements that will, in turn, support improved manufacturing.

The improved measurement uncertainty, which depends on resistivity level, is $0.12 \%$ to $0.3 \%$, with a $95 \%$ confidence level. The reduction in uncertainty principally results from the use of an extended application of four-point probe measurements, called "dual-configuration" measurements. The dual-configuration procedure was originally developed and reported for the measurement of the uniformity of ion-implanted lavers. Its adoption for the certification of bulkwafer resistivity followed extensive testing at NIST for this application. The tests indicated that this procedure offered improved measurement precision for short-term measurement sepuences as well as improved consistency between individual four-point probes that might be used for certification. Additional certification procedure improvements, such as use of more tightly controlled measurement-current levels, the use of a two-level measurement-control procedure for monitoring measurement quality, and the formal evaluation of uncertainty components also contributed to the reduction of certification uncertainty.

"NIST ... [is] to be congratulated for your fine work on the new 4-inch sheet resistance [resistivity'] SRM."

ALSTIN BLEW

LEHIGHTON ELECTRONICS

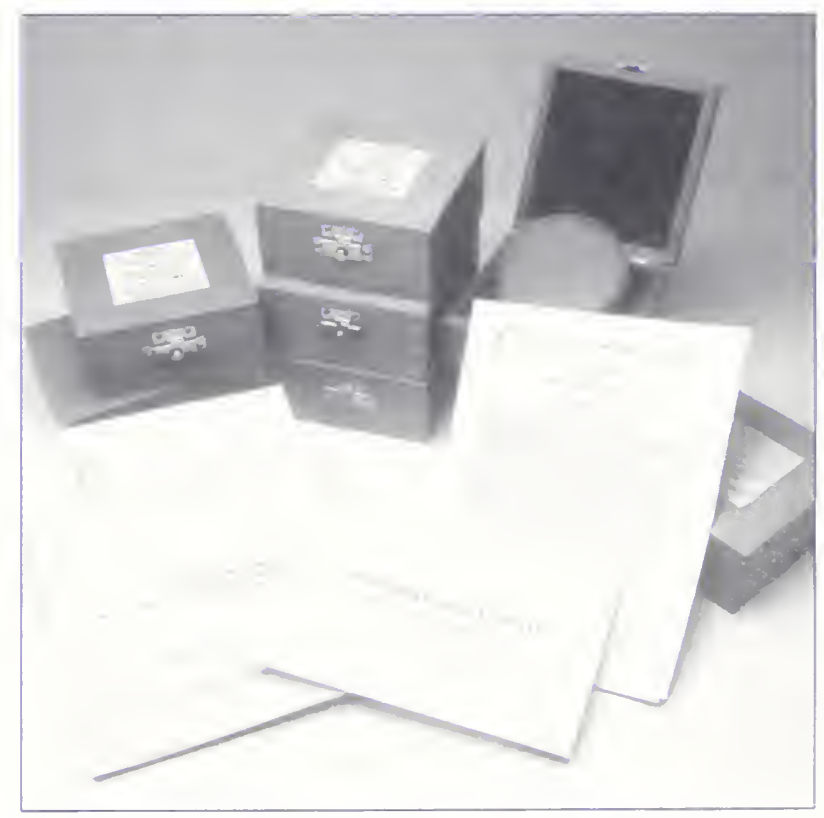

Set of resistivity SRMs, certificate, and documentation. 
All told, the new reference materials offer a better uniformity of thickness and resistivity to reduce errors incurred when instruments are being calibrated with a different sampling area than the one used for certification. The new SRMs also offer a noticeably reduced uncertainty of the certified measurement values, which reduces error propagation in the instrument calibration process. Another improvement is that the certified measurements cover a larger region of the wafer to better document small nonuniformities that may exist. Finally, the artifacts have a larger physical diameter, $100 \mathrm{~mm}$, for better compatibility with instruments tied to automatic wafer handlers.

\subsection{NeW TEChNIQUE IMPROVES}

\section{Performance of Silicon RF Chitps}

NIST and a CRADA partner, a wireless RF communications company, have collaborated with the Navy SPAWAR Systems Center and George Washington Lniversity to develop a new technology, which enables the fabrication of passive microwave components in CMOS ICs. Articles appearing in the EETimes (November 25, 1996) and the IEEE

Transactions Microwave Techniques (vol. 45, no. 5, Mav 1997) described the implementation of $50 \Omega$ coplanar waveguides in CMOS. The work is recognized as a critical step toward industry's drive to integrate wireless communications systems with digital complementary metal-oxide semiconductor (CMOS) integrated circuits.

Lp to now, silicon, the semiconductor substrate material used in CMOS, has not been used for applications above a few gigahertz because it is lossy at microwave frequencies. The collaborators' technical innovation in this project is the use of MEMS silicon micromachining technology to electrically isolate the microwave elements from the silicon substrate. Using this process improved attenuation characteristics by orders-of-magnitude: $4 \mathrm{~dB} / \mathrm{cm}$ with micromachining as compared to $38 \mathrm{~dB} / \mathrm{cm}$ without micromachining. In addition, the waveguides were optimized to provide a $50 \Omega$ characteristic impedance that was verified over the $1 \mathrm{GHz}$ to $40 \mathrm{GHz}$ frequency band. These results extend the frequency range of CMOS and are the first application of CMOS technology in the frequency domain above $10 \mathrm{GHz}$.

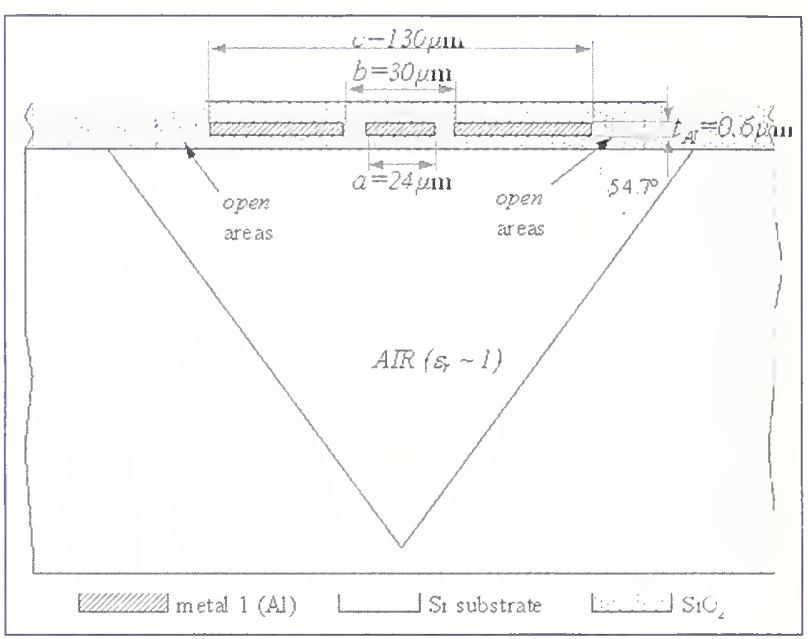

Coplanar transmission line cross section.



Microwave power sensor photograph 
"I wish to take this opportunity to thank [Curt A. Richter] you for your assistance with our research on ultrathin dielectric films. Your characterization of the ultrathin Jet Vapor Deposition (JVD) silicon nitride samples ... has belped us understand the physical and optical properties of the films. As you knou', these nitride films ... shou' great technological promise as a gate dielectric material in future CMOS technologies. The unique capabilities and expertise of your project at NIST bave assisted us in our understanding of these novel and challenging materials. We bope we can continue our collaborations uth NIST, and in particular we look fomard to working with you in the future."

PROFESSOR T.P. MA

DEPARTMENT OF ELECTRICAL ENGINEERING Departient of A PPLIED Physics

YALE UNILERSITY

NIST was the only U.S. institution that recognized the significance of developing a methodology and infrastructure for fabricating MEMS devices through CMOS foundries. This long-term effort was first sponsored by the Navy, specifically to develop CMOS compatible microheating elements for thermal flat-panel displays, and smart microwave power sensor technology with built-in calibration functions. The work also led to the establishment, through the MOSIS service, of formal support of CMOS MEMS technology. NIST scientists Michael Gaitan and Janet Marshall were awarded the Department of Commerce Bronze Medal for the work, which was cited as "providing procedures and software tools to make commercial foundry processes available to designers of micromachines."

The MEMS effort has also cross-fertilized other internal NIST research programs. CMOS MEMS technology forms the basis for a joint-laboratory effort in CMOS MEMS-based microhotplate gals sensors, and for new applications of CMOS MEMS test structures and process monitors for the L.s. semiconductor industry. The latter work is directly related to the goals of the NTRS Roadmap.

Recognized as a rapidly growing segment of the semiconductor industry, MEMS technology's worldwide market forecast exceeds $\$ 10$ billion. NIST continues to develop new metrology programs to support this inclustry:

\subsection{Single-Crystal CD Reference}

\section{Materials for NeXt Generation}

\section{LITHOGRAPHY}

A new measurement artifact that will support the future manufacture of faster, more powerful microchips has been developed by researchers at NIST and Sandia National Laboratories. The artifact is made entirely of a single-crestal silicon film. The reference material's geometric regularity atomically smooths sidewalls along crystallographic planes that are ideal for a comparative measurement of the small, patterned critical dimensions (CDs) that

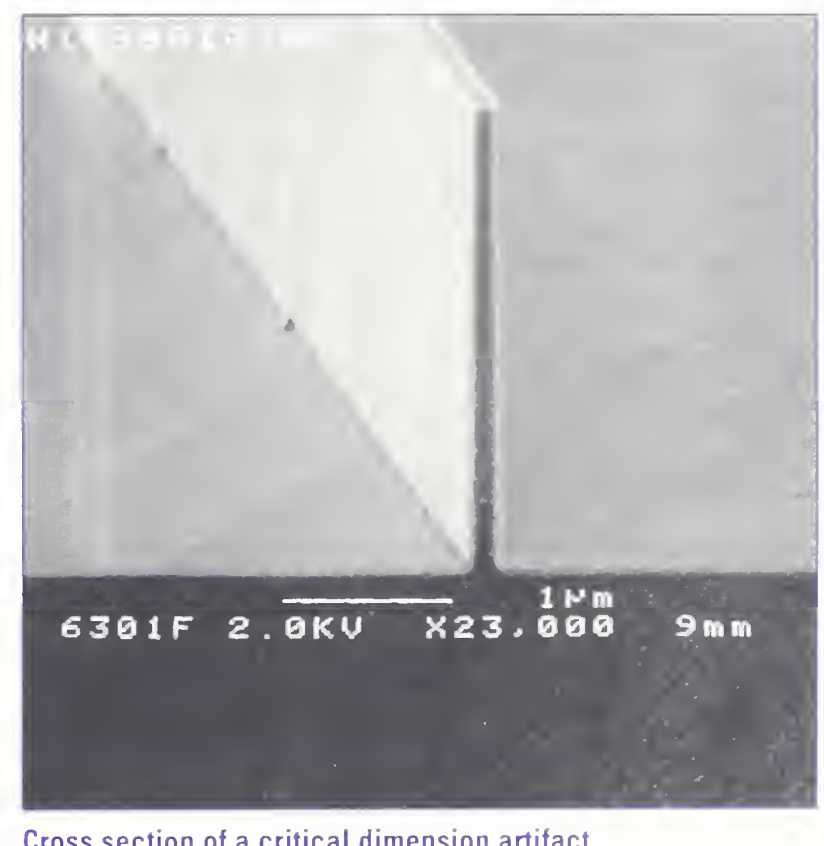

Cross section of a critical dimension artifact. 
make up integrated circuits. Current $\mathrm{CD}$ reference materials are created by the photo patterning and plasma etching of microcrystalline films and, thus, cannot be perfectly uniform. Further, these materials are calibrated using visible-light optical microscopy which restricts their application to samples wider than $0.5 \mu \mathrm{m}$. Additionally, if these samples are measured using different metrology tools, the results disagree due to the phenomenon known as methods divergence. NIST is producing this artifact to provide U.S. chipmakers with the means to calibrate any combination of microchip measuring tools, and enables them to assess features on the order of 100 nanometers. This goal is aligned to the requirements specified in the Semiconductor Industry Association's National Technology Roadmap for Semiconductors.

A number of NIST's electrically characterized samples were distributed to a consortium of 18 private-sector semiconductor manufacturers and metrology instrument companies for evaluation. Comparative measurements were made concurrently with the following conventional metrology methods: electrical techniques, scanning-electron microscopy, and atomic-force microscopy. Initial results were presented by the NIST-led consortium members at a meeting during SEMICON West 1997. In general, they reported good correlation (less than $20 \mathrm{~nm}$ ) between the electrical technique and atomic-force microscopy. Consortium members also provided their assessments of the commercial utility of the prototype reference samples, and suggested design and fabrication enhancements. The proposed improvements could eventually lead to the development of a traceable-to-NIST Standard Reference Material. The intellectual property rights to the artifact materials are jointly owned by NIST and Sandia National Laboratories (U.S. Patent Pending).
"We would like to express our appreciation of your [Curt A. Richter] work in measuring the electrical interface roughness and mobility of our MOSFET samples ... Your data has given us a solid baseline to which we can compare as our present process migrates forward and our future processes develop. We look forward to further collaboration."

WARREN R. ANDERSON BARBARA A. MINER

DIGITAL EQUIPMENT CORPORATION

\subsection{Methodology For VAitidation}

of Compact Microellectronic Package

Thermal Model Proves Viable

As design-cycle times become shorter, computer simulations for system design must be faster and more accurate. Packaged chips are generating more power, which is dissipated as heat, and they are being packed more densely on system circuit boards. The chips will operate at dangerously high temperatures if the thermal design of the system is not adequate. This is particularly true for portable systems, such as laptop and palmtop computers, portable phones, and pagers. Because these systems cannot use fans, natural convection cooling is often the only option. Thus, it is especially important to develop industry-accepted methods and procedures for validating the accuracy and performance of compact models used in the computer-aided design. The methods must be reproducible and relatively easy to implement, but also provide a good representation of the actual use conditions that the packages will undergo. Finally, acceptance of the models must be industry wide before users will have confidence in them. 


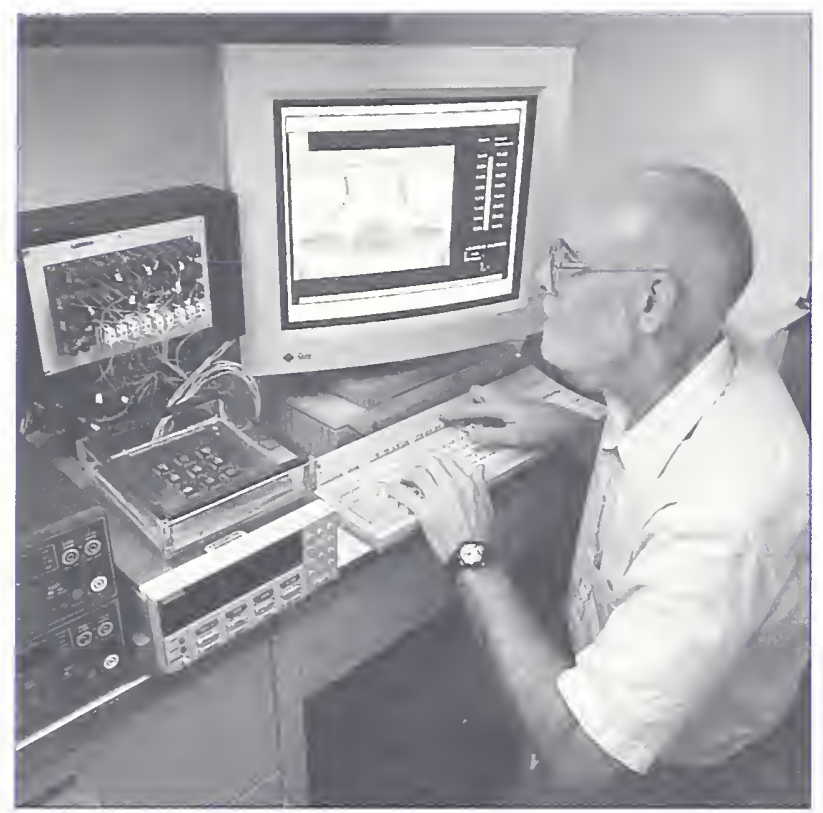

D. L. Blackburn - Validation of compact, microelectronic package thermal models. The computer screen shows the simulated temperature and air flow pattern within a laptoplike enclosure (left center) obtained using validated thermal models for the microelectronic packages on the circuit board enclosure.

A methodology has been developed for the validation of compact thermal models of electronic packages, which uses data and simulations obtained from a simple but realistic system containing the package. The test system used in the NIST study is the enclosure specified by the Electronics Industries Association JEDEC Subcommittee JC15.1 for thermal measurements in a natural convection environment. The simulations for a detailed model and several different compact models for an 88-pin plastic quad flat-package in the enclosure are in good agreement with experimental measurements of junction temperature. The researchers, members of David Blackburn's group, also established that the system must be well characterized, including accurate knowledge of circuit board thermal conductivity and accurate simulation of radiation heat transfer, to serve for validation purposes. For the package used in this study, system-level considerations could outweigh package-level considerations for predicting junction temperature. Providing the system is accurately modeled, the JEDEC enclosure is a viable experimental validation tool for compact models. In addition, members working on this project determined that board-level parameters. such as effective board thermal conductivity; total thermal loading, and spatial distribution of board power also have a significant effect on device junction temperature.

To demonstrate the usefulness of this validation process, the validated compact models were used to simulate the thermal behavior of a complex, highly interactive system, specifically, a three by three array of packages in a narrow-aspect ratio enclosure to mimic a laptop computer. Both the simulated and measured results were in rery good agreement, demonstrating that models previously validated in a relatively simple but well-controlled and defined environment can be used to simulate the thermal performance of complex, real-world systems. In short, this methodology indicates that the development of a viable validation procedure requires a well-characterized test bed, the recommended enclosure in this instance: a procedure that includes simulations with a compact model in the enclosure: and measurements of the temperature of the chip. The test bed must be easily. reproducible, and the measurements relatively easy and fast to perform. Validation procedures, such as this will be used in the development of libraries of compact models for commercial thermal simulators.

"I have spoken with Dr: Joseph Pellegrino of the Materials Technology Group who is currently' conducting compound III-I' semiconductor research at VIST. As a result of his research, Dr: Pellegrino advised us of the importance of HRXRD in the elaluation of thin epitaxial layers. He identified VIST's potential role in a standardization program long before those of us in industry realized 
the requirement ... I would like to explore opportunities for my'self and my' colleagues to participate in a comprebensive standardization program. Obviously, each individual area of the technology from majority carrier devices to optoelectronics and from starting materials to final $R F$ testing u'ill have specialized standardization and characterization requirements. Dr: Pellegrino's compound semiconductor expertise, and his close collaboration with industry professionals as well as academic researchers, uniquely qualifies him to provide vision, focus, and direction to NIST's efforts in support of our industry. I look forward ... to discussing opportunities for ensuring continued U.S. leadership in the high-frequency telecommunications industry."

DOLG MARTEL

DIRECTOR OF QUALITY

QUANTLM EPITAXIAL DESIGNS, INC.

\subsection{Fintte Element Model of SCM}

Enables More ACCurate

Two-Dimensional Dopant Profiling

\section{IN MinUTeS}

A theoretical model of the Scanning Capacitance Microscope (SCM), developed in the Materials Technology Group of the Semiconductor Electronics Division, has been used to extract more accurate two-dimensional (2D) dopant profiles from SCM images. The model was used to calculate a large database of theoretical SCM capacitancevoltage $(\mathrm{C}-\mathrm{V})$ curves for the unique SCM tip curvature and other model parameters. While the individual $\mathrm{C}-\mathrm{V}$ curves are very time-consuming to calculate, when packaged into a database coupled with an accurate interpolation routine, dopant profiles can be extracted from SCM images in a matter of seconds. Further, the finite-element method (FEM) more realistically depicts the inherently three-dimensional (3D) geometry and fields of the SCM than early one-dimensional (1D) models.

Two-dimensional dopant profiling of silicon over the dopant concentration range of $10^{17} \mathrm{~cm}^{-3}$ to $10^{20} \mathrm{~cm}^{-3}$, with $20 \mathrm{~nm}$ spatial resolution, and with $10 \%$ accuracy has been identified in the National Technology Roadmap for Semiconductors as a critical measurement need for the development of next-generation integrated circuits. Small dopant changes in a device's active region can lead to large changes in device performance. Techniques that can accurately measure the critical 2D dopant profiles are urgently needed for the calibration of technology computer-aided design (TCAD) simulators. Truly predictive TCAD simulators will enable a new paradigm where next-generation devices can be designed via computer without extensive experimental process development.

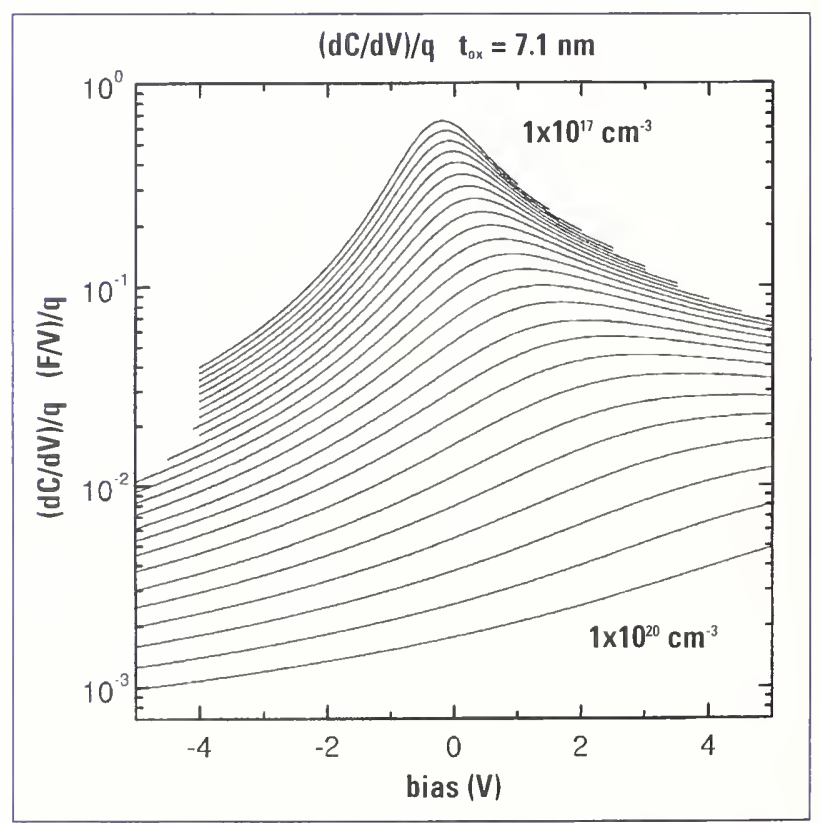

Typical page from the database of capacitance-voltage curves calculated with the 3D FEM of the SCM. 
SCM holds great promise as the technique that can produce the required quantitative 2D dopant profiles. Although this technique has progressed from a research topic to use in the analytical laboratories of many integrated circuit makers, the ability to extract accurate and quantitative dopant information from the technique has been limited. Use of the FEM model improves the accuracy of the method. Prior to this, the models used to interpret SCM data used a spherical probe that ignored the shaft; and the analytic, classical, 1D metal-oxidesemiconductor model that ignored edge effects. Because both the SCM probe tip and the dopant profile are curved in two dimensions, SCM models based on 1D solutions are suspect.

Since the beginning of the SCM effort at NIST, Jay Marchiando has been working to develop the FEM codes to model the geometry and field around the probe and in the oxide and semiconductor more realistically, i.e., in three dimensions. His model has produced solutions that differ from the 1Drelated models by as much as $200 \%$. Preliminary comparison with measurements indicate that the full 3D solution is a much better predictor of the experimentally measured SCM signal than the various analytical 1D-related models.
Marchiando's database will be incorporated into the FASTC2D program that is being developed by Joseph Kopanski and Brian Rennex to quickly interpret SCM data. The FASTC2D approach includes an easy-to-use graphical user interface and extracts dopant profiles from SCM images in a few minutes on a personal computer. To validate and further develop the FASTC2D approach, preliminary versions of the software are being made available as part of $\mathrm{CRAD}_{A} \mathrm{~S}$ with a consortium of industrial collaborators. Our industrial partners will provide state-of-the-art devices of interest for dopant profiling. Feedback from the partners will be incorporated into an enhanced version of the program for publication. The Consortium will result in improved SCM metrology techniques and the development of validated data interpretation models and software. 


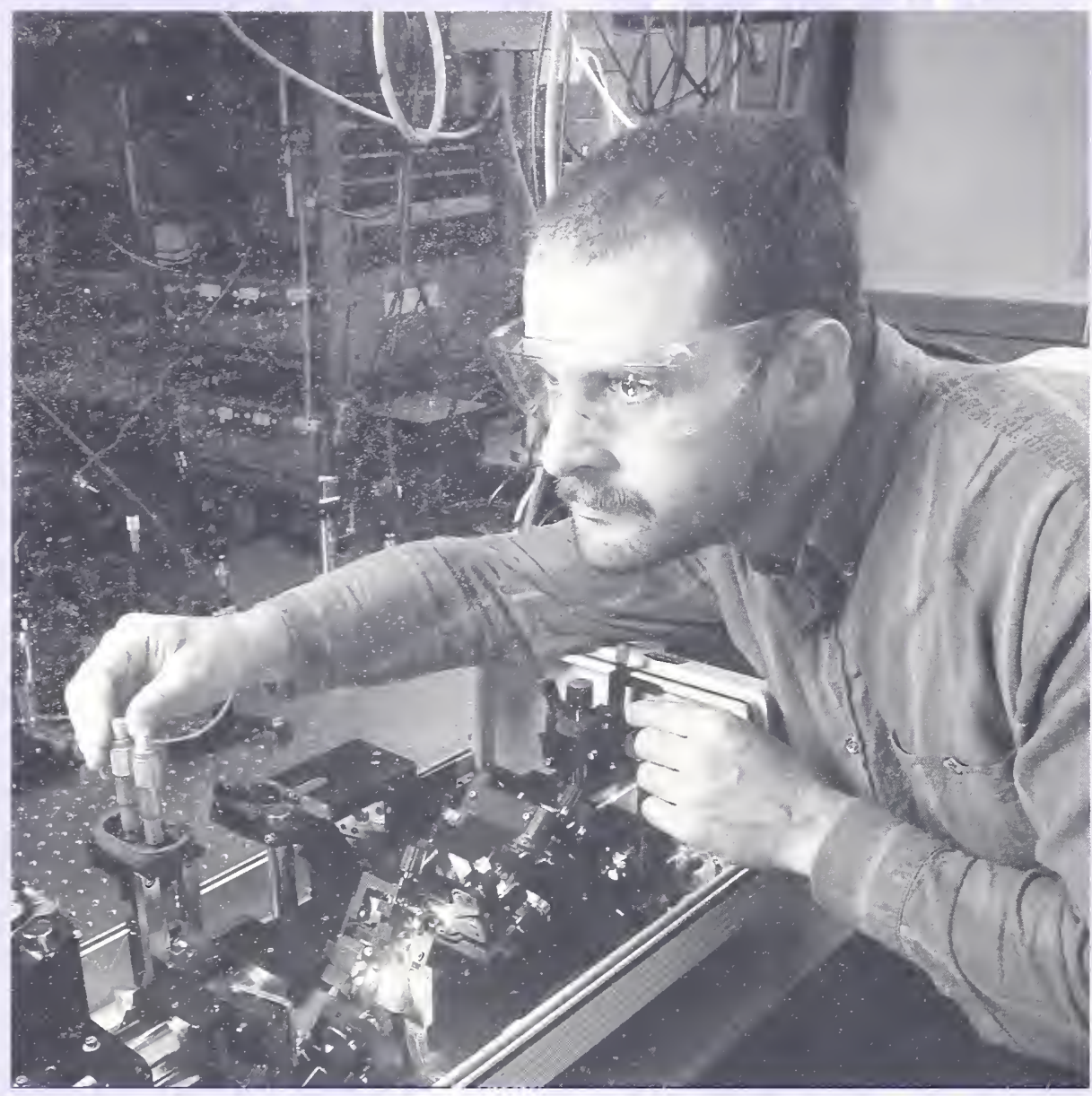

T. J. Silva -

Measurement of

second-harmonic

magneto-optic Kerr

effect (SHMOKE) in thin films. 
Ultra-Fast Magnetic Measurements

Provide Unprecedented Temporal,

Spatial and Dynamic Resolution

As the disk-drive industry continues to push the annual areal density growth rate in excess of $60 \%$, some worry whether recording heads are capable of operating at the extreme data rates predicted for the next decade. Present data rates exceed $200 \mathrm{MHz}$. Current predictions indicate that data rates will exceed $1 \mathrm{GHz}$ within the next decade.

Electromagnetic Technology Division researcher Thomas Silva, in collaboration with Charles Rogers and Thomas Cranford at the University of Colorado (CU) in Boulder, has measured magnetic rotation times in thin-film Permalloy (Ni-Fe) using both optical and inductive techniques with unprecedented temporal, spatial, and dynamic resolution. Using optical sampling techniques with a femtosecond titanium-sapphire laser; the members of the group observed $1 \mathrm{~ns}, 90$ degree rotation times in $50 \mathrm{~nm}$ Permalloy, when driven with $400 \mathrm{~N} / \mathrm{m}(0.5 \mathrm{nt})$ pulsed magnetic fields.

"We are greatly' appreciative of [Dr: Silva's group's] willingness to share their expertise with us ... . We hope that in the future, NIST will continue to support such excellent research programs ... . We look forward to future interactions with NIST."

DR. VIITEN TALGHADER

SEAGATE TECHNOLOGY
Inductive measurements using samples with larger anisotropy and larger field pulses have detected rotation times of 200 ps, five times faster than any previously measured rotation speeds. The magnetic field pulses are provided by both microstrip and coplanar waveguides, which are driven with large voltage-step-function generators. The magnetic samples are placed in intimate contact with the waveguides, exposing the samples to the magnetic components of the electromagnetic waves propagating in the wareguides.

Ultrafast optical pulses from the titanium-sapphire laser are synchronized with the magnetic field pulses with a controlled amount of delas: The magnetic state of the sample is inferred by measuring its second harmonic generation efficiency, which is proportional to the magnetization via the second-harmonic magnetooptic Kerr effect (SHMOKE). By precisely timing the arrival of the optical pulse with respect to the magnetic pulse, a stroboscopic "snap-shot" of the magnetic state of the sample is obtained. The delay is scanned in order to generate a waveform of the magnetization response as a function of time. The temporal resolution of the technique is ultimately limited to the temporal width of the laser pulse ( $\sim 50$ femtoseconds); however, the electronic jitter of the magnetic pulse generation system currently limits the resolution to 50 picoseconds. 


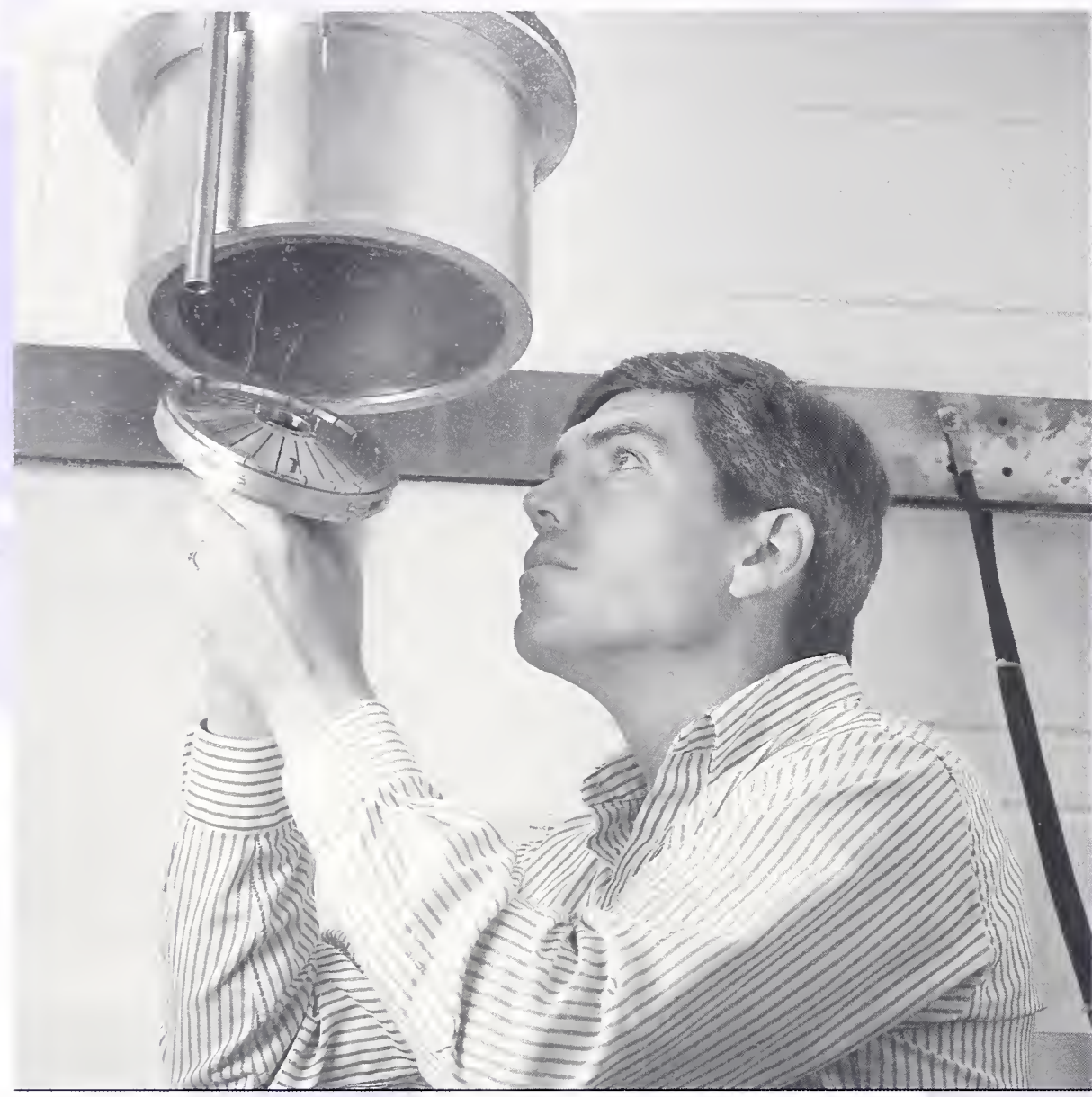

S. L. Bray - Mounting an aluminum-composite ring in superconducting magnet for cryogenic fatigue testing. 


\section{chapter 3 Superconductors}

Unique Measurements Simulate Fatigue

Degradation of Future Aluminum-

Stabilized Superconducting Magnets

NIST scientists Steve Bray and Jack Ekin used a unique measurement system they developed at NIST to simulate the effect of mechanical forces on the electrical performance of a prototype aluminumcomposite stabilizer for the world's largest magnets. The stabilizer was designed for application in large Superconducting Magnietic Energy Storage (SMES) systems, which will be used for power conditioning by electric utilities.

Stabilizer material is needed in high-field superconducting magnets because localized thermal perturbations within the magnet's windings can raise the temperature of the superconductor beyond a critical point, specifically, the point where it loses superconductivity. A normal metal, usually copper, is added in parallel with the superconductor to provide stability. Stability is achieved during the perturbation by allowing the magnet's operating current to locally bypass the superconductor. Without the stabilizer, the perturbation would propagate through the magnet, interrupt its operation, and possibly destroy it. Highpurity aluminum has several advantages over copper as a stabilizer, including higher electrical conductivity at cryogenic temperatures, lower density, reduced cost, lower sensitivity to magnetic fields, and radiation transparency for particle-accelerator applications. A major disadvantage is its low mechanical strength, which can cause conductor fabrication problems and necessitate structural reinforcenent of the magnet. Also, the electrical conductivity of the aluminum, which is closely tied to its effectiveness as a stabilizer, degrades with mechanical fatigue. Moreorer, cyclic magnetic forces during SMES operation subject the stabilizer to fatigue and degrade its conductivity. In sum, to minimize cost and optimize performance, it is necessary to determine the minimum quantity of stabilizer required, allowing for fatigue degradation.

Typical fatigue-test methods using straight tensile specimens are not applicable to the SMES stabilizer. which is a composite of high-purity aluminum for stability and high-strength aluminum alloy for structural reinforcement. Tensile specimens are prone to buckling and delamination in a standard tensile test. NIST"s unique measurement ststem avoids these problems by using a ring-shaped specimen and a force translating apparatus that allows application of hoop stress to the ring, precisely simulating the geometry and stress in the SMES magnet. The simulation tests showed that work hardening of the high-purity aluminum over several thousand fatigue cycles increases its strength and dramatically reduces subsequent electrical degradation. This kẹ result. which avoided a $40 \%$ overestimate of the required high-purity aluminum for the SMES design, will have general impact on the design of future aluminumstabilized superconducting magnets including CERYs Large Hadron Collider and the L.S. Nary's superconducting mine-sweep project.

"The NIST measurements are an important contribution to superconducting magnet technology, particularly in light of the potential cost savings afforded by reducing the amount of HPA [bigh purity aluminum]. Cost is of primary concern to any commercial sy'stem."

DR MiChaEL Nilxes

SENIOR PRINCIPAL ENGINEER

BWX TECINOLOGIES

NAVAL NeCLEAR FEEL DIITSION 


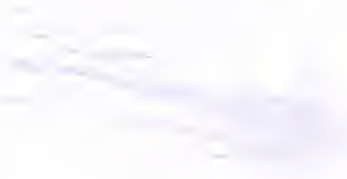

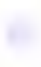

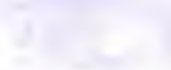

\section{1. cores $x^{2}$}

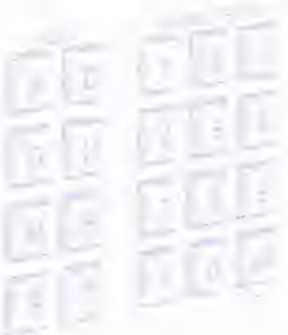

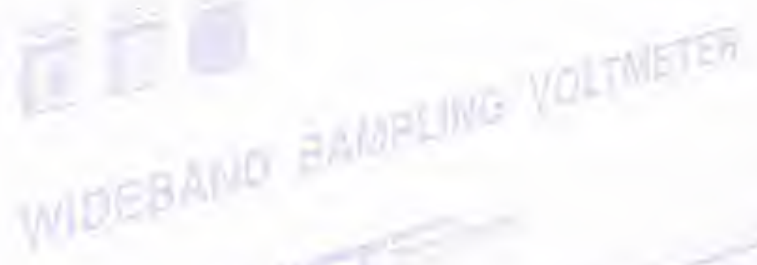

$$
\begin{aligned}
& y=
\end{aligned}
$$




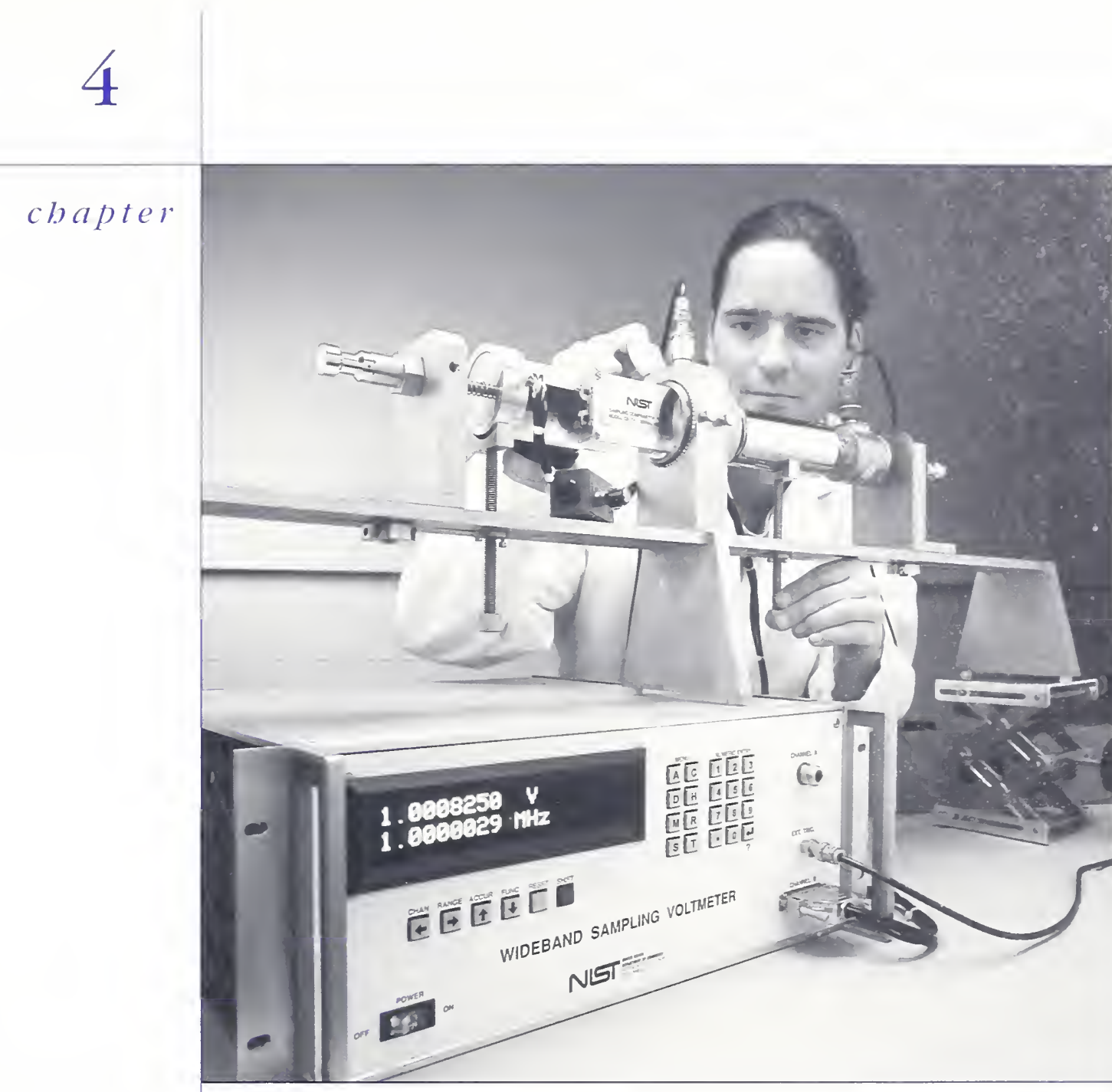

B. C. Waltrip -

Measurement of

voltmeter gain flatness. Adjusting a test jig used to compare the wideband sampling voltmeter with a calibrated thermal voltage converter.

\section{Low Frequency}

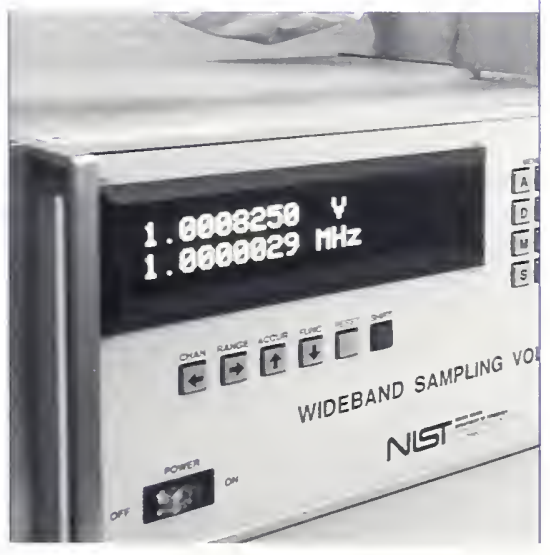




\subsection{Wide-Band SAMPling Voltmeter}

Provides High Accuracy Along with

Wide Bandwidth and Fast Response

Accurate ac root-mean-square (rms) voltage measurements are used for widely different applications ranging from production-line testing of electrical and electronic devices and systems to reading the output signals of precision sensors and transducers. The most accurate ac rms voltage standards are thermal voltage converter (TVC) devices in which the average power produced by the applied ac voltage is equated with the power produced by an equivalent dc voltage. However, TVCs have a number of limitations such as limited (typically 2:1) dynamic range, low input impedance, and time constants that limit their lowfrequency performance and lengthen the time needed for high frequency measurements. For these reasons, wide-band voltmeters have been the preferred measuring instrument for most ac voltage applications where accuracy is not as demanding, but fast response time and wide frequency and dynamic ranges are needed. Now, neither set of limitations must be accepted. A new sampling voltmeter, developed by Electricity Division researchers T. Michael Souders, Owen Laug, Bryan Waltrip, John Deyst, and Robert Palm has both the wide frequency range of commercial instruments, and accuracy approaching TVCs.

The voltmeter is based on a novel sampling method that preserves the wave-shape in the sampled data so that other parameters are readily computed in addition to the rms value. These values include the average value, peak-to-peak value, and total harmonic distortion. Recent flatness (gain versus frequency) measurements of a breadboard version of the instrument have shown that its flatness, which was measured using a NIST-calibrated TVC, is within $25 \mathrm{ppm}$ up to $100 \mathrm{kHz}, 150 \mathrm{ppm}$ up to $1 \mathrm{MHz}$, and $1000 \mathrm{ppm}$ to beyond $50 \mathrm{MHz}$.
In order to achieve this level of performance, the staff had to successfully develop and integrate a circuit to measure the signal frequency accurately on-the-fly, an adaptive time-base that produced sample commands at exact integer multiples of the measured frequency, and a sampling device with high accuracy over the entire $200 \mathrm{MHz}$ bandwidth of interest. Further refinements in the internal timebase circuitry, along with the installation of a timebase autocal circuit that was recently completed, are expected to result in even lower errors at frequencies below $1 \mathrm{MHz}$. In addition to high accuracy, the instrument features a measurement rate of at least one reading per second, and will have the same ergonomic feel as commercial voltmeters. A paper describing the operating principles, architecture, and major error sources of the voltmeter was presented at the 1996 Instrumentation and Measurement Technology Conference held in Brussels, Belgium.

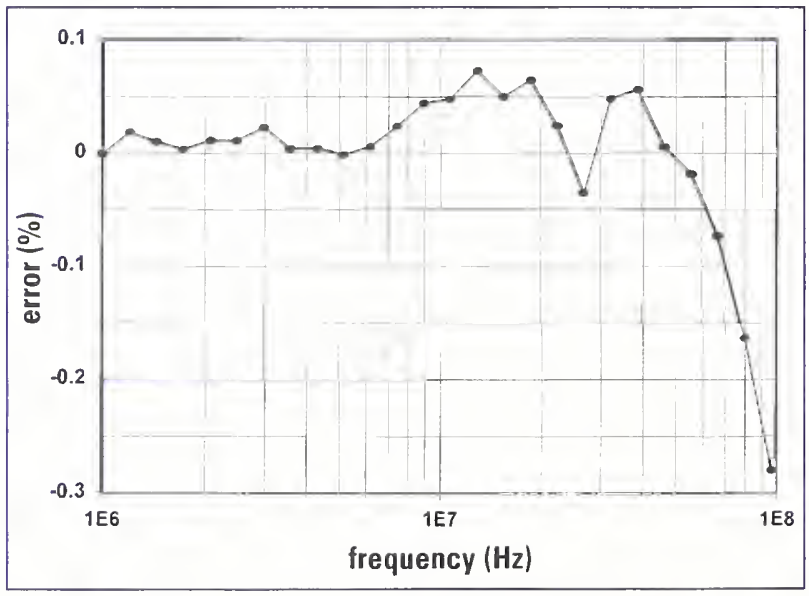

Measured gain flatness versus frequency. The illustration shows the voltmeter gain error versus frequency relative to the gain at $1 \mathrm{MHz}$. The measurement was made with a NISTcalibrated TVC, using the setup shown on the previous page.

\subsection{Special Test Developed for New}

Commercial Fused-Silica Capacitance

STANDARD

Because the best modern capacitance meters have stability better than 0.1 part-per-million (ppm), 
reference capacitance standards at the 1-ppm level of uncertainty or better are needed to support these products. Prior to the development of new, commercial dielectric capacitor standards, the best uncertainty routinely offered by NIST (for gasdielectric capacitance standards) was $4 \mathrm{ppm}$ at $1000 \mathrm{~Hz}$. Since this level of uncertainty is not adequate to support the new capacitance meters, the Electricity Division has provided a new, special test that can.

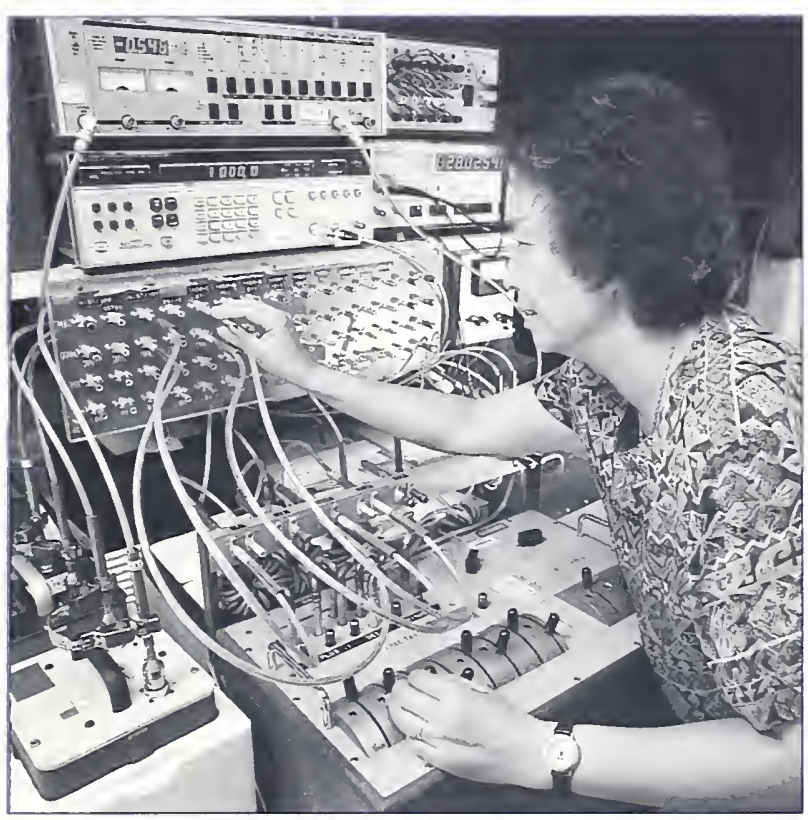

Y. M. Chang - Balancing the Type-2 bridge. Adjustment of the internal capacitance and conductance standards are necessary to obtain a null balance, which determines the value of the capacitor under test.

The first step toward improving the uncertainties of the NIST capacitance calibration services was taken by Y. May Chang and Summerfield Tillett, who created a valuable database history on the reference bank of NIST-built, fused-silica capacitors used in the Division's Impedance Calibration Laboratory. Chang and Tillett made careful periodic calibrations of the reference bank in terms of the NIST Calculable Capacitor (the NIST realization of the SI-defined Farad). Instead of using the most recent measured value as a reference, the use of the recent chronological set of measurements allows the statistical prediction of the present value of the reference bank with high confidence. L sing this statistical process, they determined that the NIST reference standard capacitors are all drifting at less than $0.025 \mathrm{ppm}$ per year, with an arerage rate of less than $0.003 \mathrm{ppm}$ per year.

This statistical process control makes possible a week's measurement time using the NIST Type-2 Capacitance Bridge to compare the NIST-built fused-silica transfer standard to the reference bank with a 0.05 ppm Type A standard uncertainty at $1000 \mathrm{~Hz}$. However; the total assigned measurement uncertainty (coverage factor, $k=2$ ) for customers fused-silica capacitors is $2.4 \mathrm{ppm}$ when the frequency dependence of the reference bank is included. This is because the unit of capacitance is obtained from the Calculable Capacitor at a frequency of $1592 \mathrm{~Hz}$, but industrial calibrations are at $1000 \mathrm{~Hz}$. The frequency dependence of the fused-silica capacitors is conservatively estimated to be about $1.12 \mathrm{ppm}$. The remaining technical challenge is to reduce this uncertainty by developing multifrequency bridges and standards.

With a U.S. company claiming that their instruments are "The World's Most Stable Capacitance Standards" in commercial production, the Electricity Division is now handling state-of-the-art calibration requests for these new standards. Thus far, there have been nine such tests on $1^{-}$ capacitors provided to eight customers since the new service was first offered. Seven of the tests were completed during the past year with a typical turnaround time of only three weeks. 



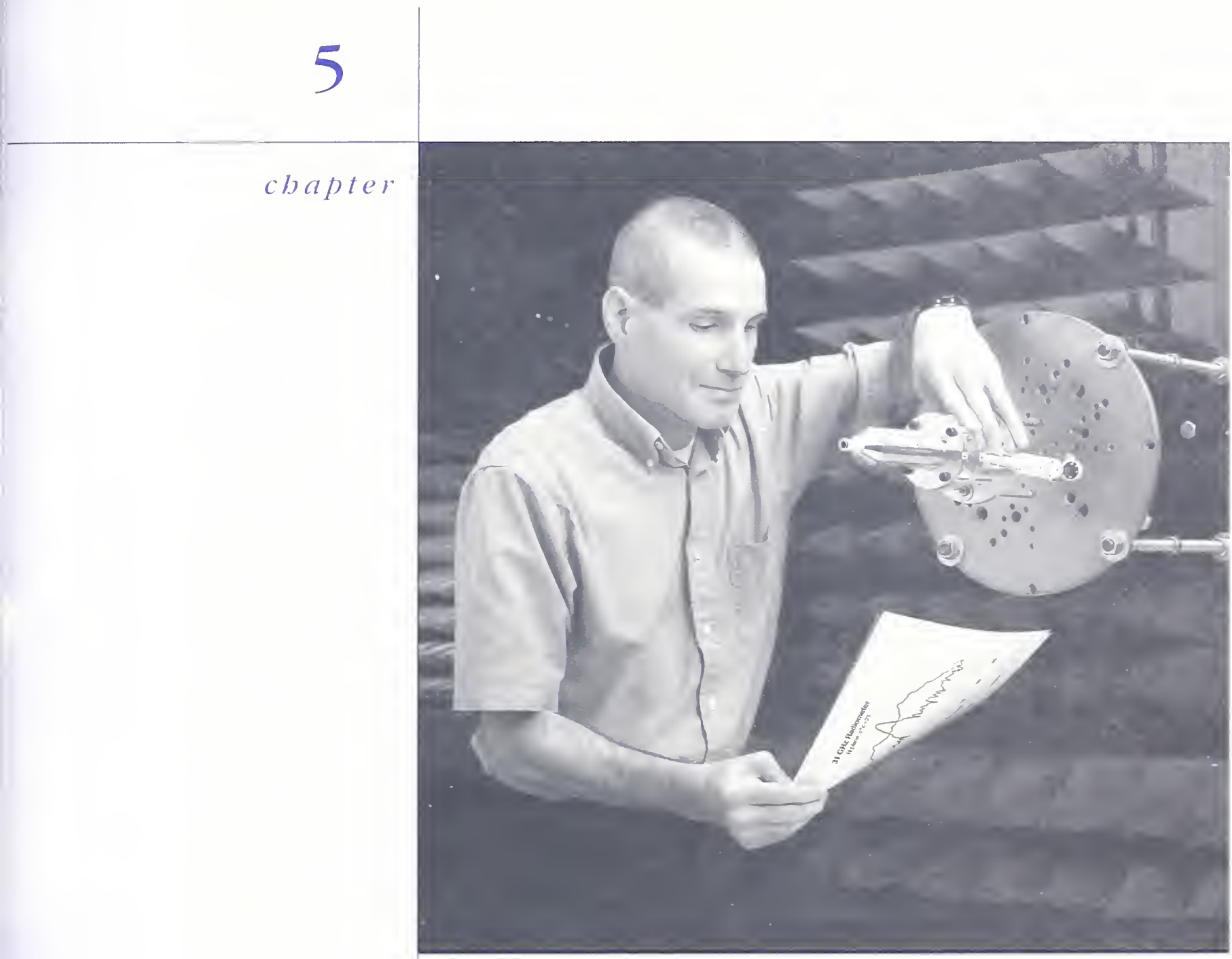

M. H. Francis - Bronze Medal recipient for new algorithm.

\section{Microwaves}

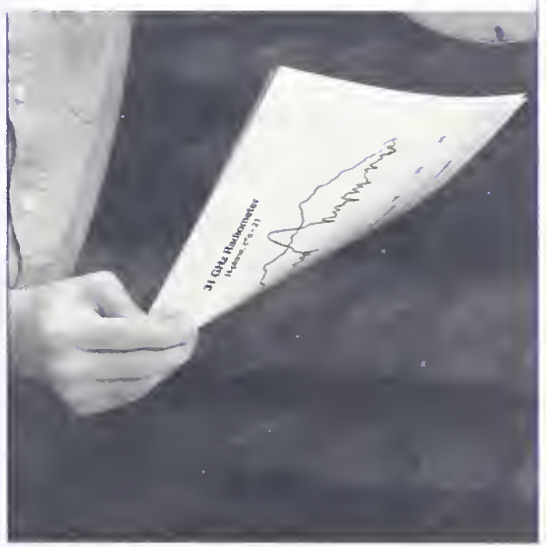


5.1 AtTractive, New Measurement

SERVICE FOR VECTOR NETWORK ANALYZER

(VNA) VERIFICATION

An attractive, new NIST measurement service has been established for microwave scattering parameters by researchers John Juroshek and Dennis LeGolvan. With this service, the customer performs measurements on one of the various verification kits and returns the data to NIST for analysis. NIST then issues a formal report that compares the customer's measurements to those made by NIST. The report notes the differences in the measurements as compared to NIST's uncertainties to enable customers to assess the accuracy of their measurements. The verification kits are available in three different coaxialconnector sizes.

These kits consist of sets of standard coaxial verification devices that have been characterized through extensive measurements at NIST. The characterizations were used to establish a database. In addition, software was developed for processing customer data and for incorporating graphics into the customer reports. The verification process involved creating a simulated service, using two of the kits, with other laboratories within the NIST Electromagnetic Fields Division. The development of this service is an experiment; part of the concept of re-engineering measurement services to stay abreast and ahead of customers' needs. Lower in cost and broader in scope than previous offerings, the service allows the customers to assess the total ability of their laboratory to perform the measurements and to assess the accuracy of their measurements relative to NIST.
5.2 Algorithim for Probe-Position

ERror CORRECTION EXPANDS USE OF

Current Planar Scanning Ranges from

MAXIMUM Frequency of $30 \mathrm{GHz}$ To

FREQUENCIES FROM $500 \mathrm{GHz}$ TO $1000 \mathrm{GHz}$

To determine antenna patterns using standard nearfield scanning, very accurate positioning of the scanning probe at points on a planar spatial lattice is required. As the corresponding wavelengths decrease at higher frequencies, the accuracy requirements exceed the positioning capabilities of modern mechanical positioning systems. This not only introduces errors into the raw data acquired in the near-field, it results in errors in the computed far-field patterns. Although, the probe's actual positions can be measured to greater accuracy than an automated positioning system can position the probe, prior attempts to develop a mathematically rigorous, three-dimensional, computationally efficient position-error correction have fallen short on all three criteria.

Now, three NIST scientists, Michael Francis and Ronald Wittmann from the Electronics and Electrical Engineering Laboratory and Bradley Alpert from the Information Technology Laboratory, have attacked the full three-dimensional positionerror correction problem, and succeeded. Their algorithm is an outstanding success in several ways. The algorithm can simultaneously correct for errors in all three spatial dimensions; its computational efficiency far exceeds that of previous one-dimensional algorithms; and it is free of restrictive assumptions - the underlying theory has been clearly explained and includes a rigorous proof of convergence. The team's results can also be adapted to cylindrical and spherical near-field measurements. The software for the algorithm has been developed and the code has been fully validated. The work was tested using both 
simulations and planar near-field measurements, which were performed on a $1 \mathrm{mby} 1.2 \mathrm{~m}$ phased array at $32 \mathrm{GHz}$, and on a $1.2 \mathrm{~m}$ dish antenna at $4 \mathrm{GHz}$. Alpert, Francis, and Wittmann were awarded the Department of Commerce Bronze Medal for their achievement.

Near-field scanning, which was pioneered at NIST, is the predominant, worldwide-test method used in many modern communications and radar systems. both commercial and military. Many test range facilities have been established in the Lnited States. The implementation of NIST's probe-position error correction techniques will expand the use of these very costly, near-field scanning facilities to include higher frequencies. Standard planar near-field measurements require probe-position accuracies on the order of $1 / 50$ of a wavelength — difficult to achieve at frequencies above $30 \mathrm{GHz}$. This algorithm makes it possible to use current planar scanning ranges at frequencies from $500 \mathrm{GHz}$ to $1000 \mathrm{GHz}$. It also makes possible the development of less-costly portable near-field scanners. Portable scanners are needed for both the calibration of pattern and for the diagnosis of element failures in new array antennas that must be tested in situ.

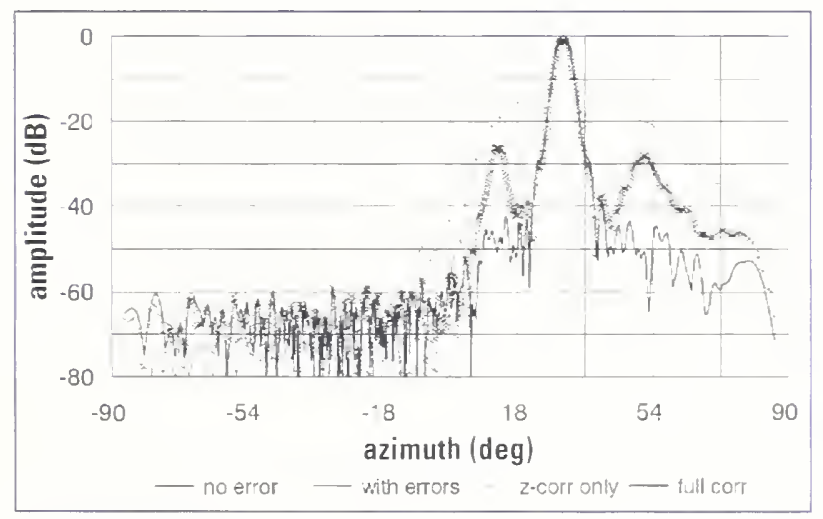

Steered beam, $31 \mathrm{GHz}$ radiometer.

\subsection{International Collaboration}

Brings ReseARChers to BetTer

Understanding of MUlticonidctor

Transmission LINES

The behavior of multiconductor transmission lines, which are essential components in computer busses and microelectronics packaging, now limit the performance of many high-performance microware and digital circuits. Researchers in Europe have long focused on this problem. NIST scientist Dỵlan Williams recognized the importance of the work and embarked on an extensive collaboration with scientists at the l'Institut d'Electronique et de Microélectronique du Jord. the Department of Information Technolog: at the University of Ghent, and the Ferdinand-BraunInstitut für Höchstfrequenztechnik.

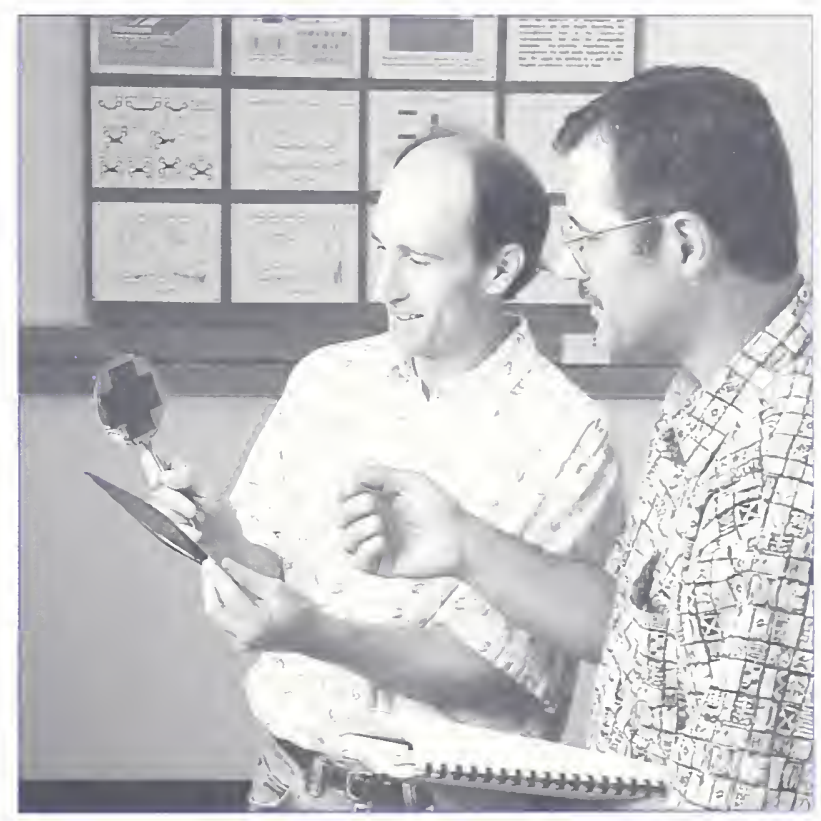

(Left to right) D. F. Williams, R. M. Judish. Examining multiconductor transmission lines fabricated on a silicon substrate.

Lnderstanding the line's beharior proved to be rer difficult. The success of their work has fundamentally revised our understanding of the phỵsics of eren the most common quasi-TEM 
multiconductor transmission lines, and provided accurate characterization methods. Jointly, the researchers developed and validated new methods for the characterization of coupling phenomena in lossy, multiconductor transmission lines. Their crowning achievement occurred when, for the first time, they successfully measured large modal cross-powers and other parameters that describe the phrsics and electrical behavior of these lines. At the conclusion of the effort, the group also developed estimates of the uncertainties of the measurements.

\subsection{WR-28 NOISE-TEMPERATURE}

Measurement Service Developed to

$\overline{\text { SuPPORT EMERGING TECHNOLOGIES FOR }}$

MititaRy AND CoMmerCial Applications

Thermal noise is a limiting factor in the performance of all types of electronic devices and equipment. James Randa, John Rice, Robert Billinger, and L. Andrew Terrell recently completed the extensive experimental, developmental and theoretical work necessary to initiate a new noisetemperature measurement, which provides NIST calibrations of WR-28 waveguide thermal noise sources - and covers the frequency band from 26.5 GHz to $40 \mathrm{GHz}$. Noise-temperature measurements and standards, in this and other microwave frequency bands, are necessary to support emerging technologies destined for new military and commercial applications. Through the use of NIST's measurement services, industrial and government laboratories across the nation are able to support and maintain local noise sources and perform quality measurements linked to national and international standards.

Descriptions of the measurement system, the experiments performed to validate it, and the measurement procedures used for performing calibrations are documented in NIST Technical Note 1395, Noise-Temperature Measurement Sy'stem for the WR-28 Band, by J. Randa and L. A. Terrell. Because the physical theory and the measurement procedures are similar, the technical note actually documents three thermal noise measurement systems. The other two systems are already in place and have been providing measurement services for WR-62 and WR-42 waveguide thermal noise sources, covering the bands $12.4 \mathrm{GHz}$ to $18 \mathrm{GHz}$ and $18 \mathrm{GHz}$ to $26.5 \mathrm{GHz}$, respectively. The WR-28 system offers continuous frequency coverage of the entire band - with typical expanded uncertainties between $1.0 \%$ and $1.5 \%$ for the measured noise temperature.

Originally of interest primarily for military applications, the WR-28 band is now also seeing commercial development for local multipoint distribution systems (LMDS), specifically, interactive television. Industrial customers have already submitted several noise sources for the new measurement service, and the first calibrations have been successfully completed.

\subsection{DeVELOPMENT OF}

\section{INFRARED/MICROWAVE HOLOGRAPHY}

Antenna Measurement Technique

Researchers at NIST and the University of Colorado at Colorado Springs (UCCS) have jointly developed theory and methods whereby holographic techniques are used for antenna amplitude and phase measurements. The method requires only the detection of signal amplitude, and is based on employing a known reference field. The reference may be either radiated or hard-wired, thus, signal detection can be accomplished using any amplitude measurement device. A particularly interesting application, which has been under development by 


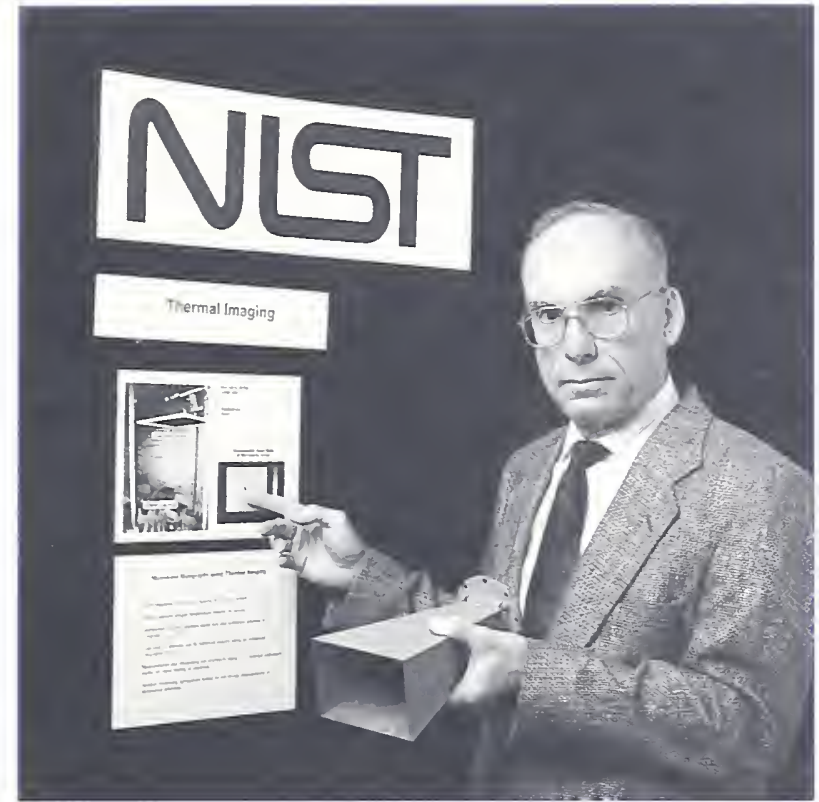

C. F. Stubenrauch - Explaining holographic technique.

the collaborators at LCCS, is the use of an infrared camera to measure the temperature field arising when a resistive screen is irradiated by microwave energy. Such a detection scheme allows the measurement of the amplitude of the microwave field without employing conventional microwave receivers. As part of this effort, NIST performed tests and analyses on a $1.2 \mathrm{~m}$ reflector antenna, using a hard-wired reference and microware receiver, and a 6 by 6 element microstrip array antenna, using infrared detection.

Recently, Carl Stubenrauch successfully processed infrared data, which he acquired at Rome Laboratories (RL), in conjunction with John Norgard of LCCS and Michael Seifert of RL. The researchers successfully obtained far-field patterns for a 6 by 6 element array, using the holographic technique. Good results have been obtained for the main beam and first sidelobe. This very important development will permit the use of amplitude-only receivers and create the potential for significant sarings for planar near-field measurement facilities. At higher frequencies (above $30 \mathrm{GHz}$ ), accurate phase measurements are more difficult than accurate amplitude measurements. Thus, the method also has the potential for extending the useful frequency range for near-field antenna measurements. The extension to infrared detection shows promise for rapid characterization of antennas as well, benefiting the entire satellite communications industry

\subsection{Development of Microwave}

Characterization Ability Meets

National Metrology Need

Richard Gever and Chriss Jones of Division 813 s Electromagnetic Properties of Materials Project have developed measurement techniques and successfully completed microware measurements of the demagnetized. scalar complex permeability and tensor complex permeability of ceramic ferrites when applied static tuning biases are applied. Significant differences in the real permeability and magnetic loss factors of the tensor components are evident as a function of saturation. magnetization and applied static tuning magnetic

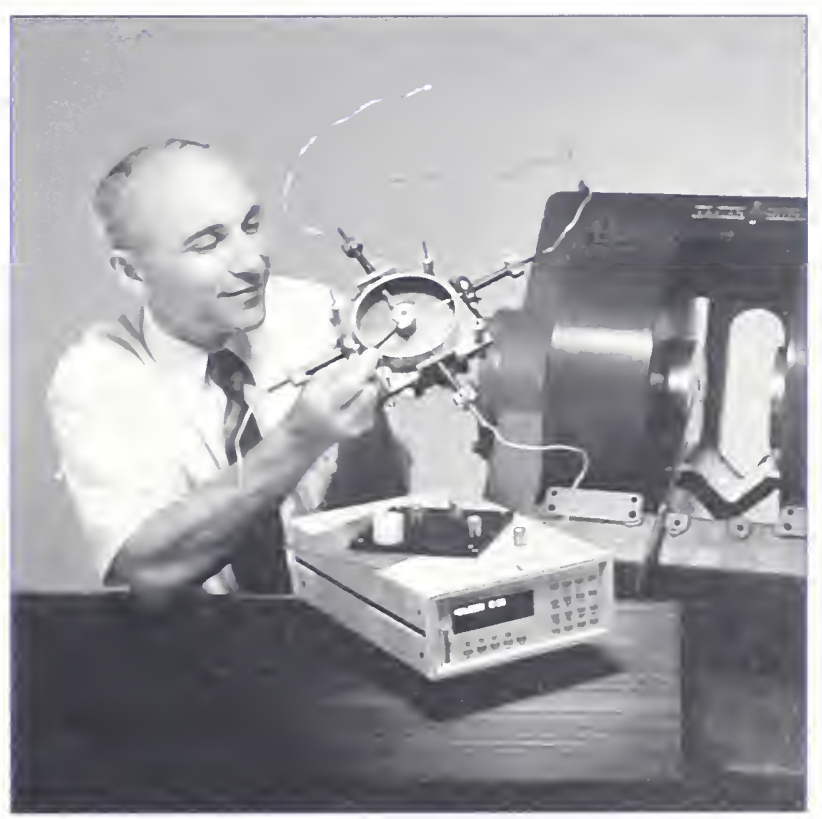

R. G. Geyer-Describing use of low-loss dielectric ring resonators. 
field. To achieve their goal, Gever and Jones constructed low-loss dielectric ring resonators that allow accurate permeability measurements to be performed over a broad range in frequency using a single ferrite rod sample.

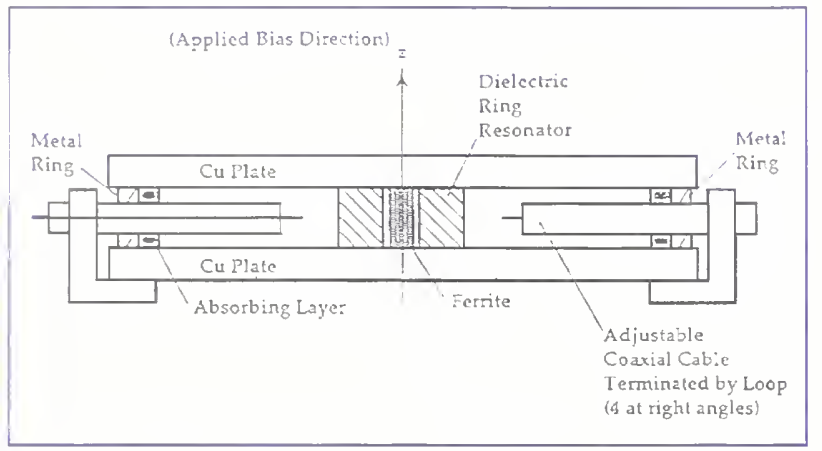

Resonant system for measurement of permeability tensor components of a single ferrite sample.

The significance of this work stems from the fact that the optimal designs of critical microwave components that employ biased ferrites, such as circulators, isolators, attenuators, limiters, YIGtuned oscillators, and phase shifters require accurate knowledge of the microwave properties as a function of the bias field levels of these materials. The new NIST measurement capability meets a critical measurement need because very few facilities for performing such measurements exist in the Lnited States, and ferrite manufacturers generally do not supply such data.

"As a producer of microwave magnetic materials, my company is in a position to report the need for improved measurements of the microwave properties of ferrite and garnet materials. For decades, companies such as Trans-Tech published catalog parameters of these materials to satisfy a predominantly military market. Microwave measurements were therefore standardized near $9.4 \mathrm{GHz}$, a very popular frequency for military radars. In addition, some material parameters were, and still are, made at $\mathrm{KHz}$ or lower frequencies. ... Seldom if ever have microwave measurements been made on the final configuration to be delivered to the customer. This course was, and has been, prompted by expediency and the need for standardized measurements in a volumemanufacturing environment.

Today's market for microwave materials ... has shifted toward primarily commercial applications. ... Microwave component manufacturers are market-driven to achieve the lowest possible signal losses for the lowest possible cost. The design engineer prudently seeks the best materials for low loss, but is forced to rely on data measured neither at his use frequency nor under the conditions of static magnetic field that must be designed into the product. ... We would be pleased to participate with NIST in the preparation of samples and development of measurement techniques for commercial applications."

JOHN DERISO

APPLICATIONS ENGINEER

TRANS-TECH, INC.

\subsection{High-Temperature Capability for}

Characterizing eM Properties of

\section{Materials}

For the past two years, staff on the NIST Electromagnetic Properties of Materials Project, including James Baker-Jarvis, John Grosvenor, and Bill Riddle have been developing an RF measurement capability in order to perform dielectric and magnetic characterization of bulk materials at temperatures both below- and aboveambient temperature. The first phase focussed on a survey of much of the past work performed in hightemperature measurements and the various 


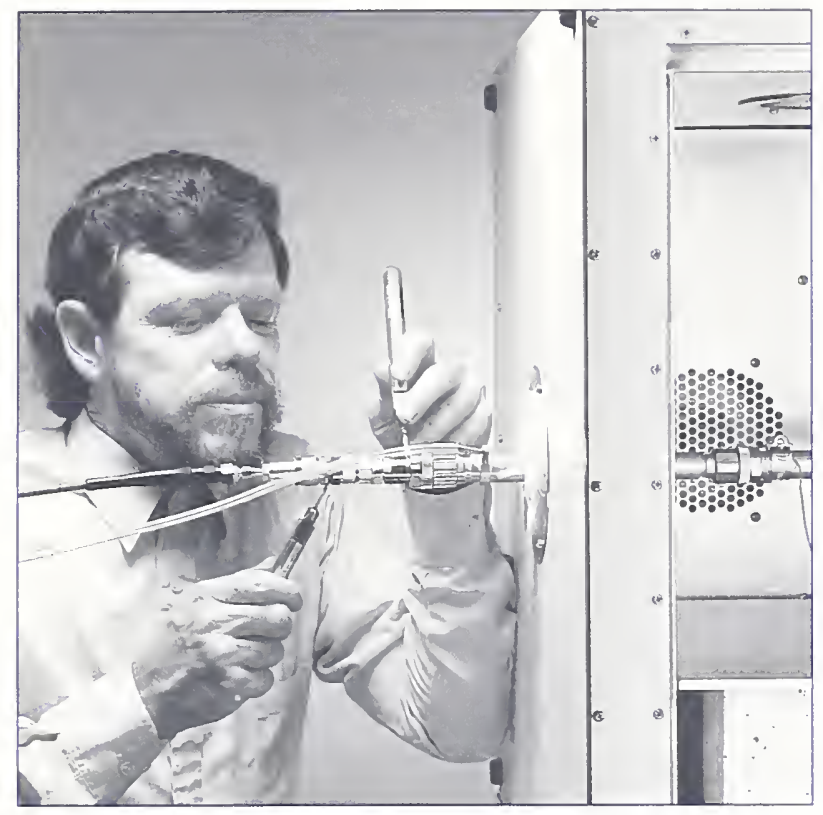

J. H. Grosvenor, Jr. - Preparing for high-temperature material measurements using new environmental chamber.

techniques involved. These findings were published in NISTIR 5045, Dielectric and Magnetic Measurements from $-50^{\circ} \mathrm{C}$ to $200^{\circ} \mathrm{C}$ and in the Frequency Band $50 \mathrm{MHz}$ to $2 \mathrm{GHz}$. Following the study, three basic techniques were selected for implementation at NIST: the broadband $(0.05 \mathrm{GHz}$ to $8 \mathrm{GHz}), 14-\mathrm{mm}$ diameter coaxial air line method; the coaxial re-entrant cavity method at $500 \mathrm{GHz}$ and $1000 \mathrm{MHz}$; and the split-post resonator method at $2 \mathrm{GHz}$.

The newly developed measurement system includes an environmental chamber that can operate over a broad temperature range, from $-100^{\circ} \mathrm{C}$ to $350^{\circ} \mathrm{C}$. The chamber can be remotely programmed and controlled using a personal computer. To ensure that any toxic fumes generated during sample heating are safely exhausted out of the laboratory, the chamber is mounted beneath a laboratory exhaust hood. The success of this project has not only renewed NIST's ability to accurately characterize bulk materials, such as polymers, ceramics, and ferrites; it also significantly advances this capability over a wider temperature range. Staff are now far better equipped to provide data on the temperature coefficient of dielectric permittivity and magnetic permeability, and more satisfied with their enhanced ability to meet industry s needs.

"I unould like to commend NIST for the superior technical expertise that bas been delivered to $3 M$... it is well knou'n that NIST is a world leader in Microndu'e and RF material characterization techniques. ... Your group has also done a tremendous job in transferring this technology' ..."

BRADLEY L. GIVT

$3 M$ CORPORATE RESEARCI LABORATORIES

\subsection{NIST Develops Method to Permit}

\section{Direct Measurement of Thin-Film}

\section{Properties}

A determination of the electromagnetic properties of thin-films used in modern. high-speed.

integrated circuits typically required the fabrication of special thin film samples that were then placed in a test fixture. However. Dỵlan Williams and Michael Janezic of the Electromagnetic Properties of Materials Project have devised measurement methods that eliminate at least two of these steps. Their objective was to find a means to measure the thin-film properties directly on commercial derices fabricated on wafer, and, ultimately, in a production environment. Their approach has been validated.

They have shown that it is possible to determine the electromagnetic properties of thin films using easyto-perform in-situ transmission-line measurements. The research developed by Williams and Janezic has evolved into a collaborative effort between NIST, a world-wide American chemical corporation, and three major players in the semiconductor industry. 


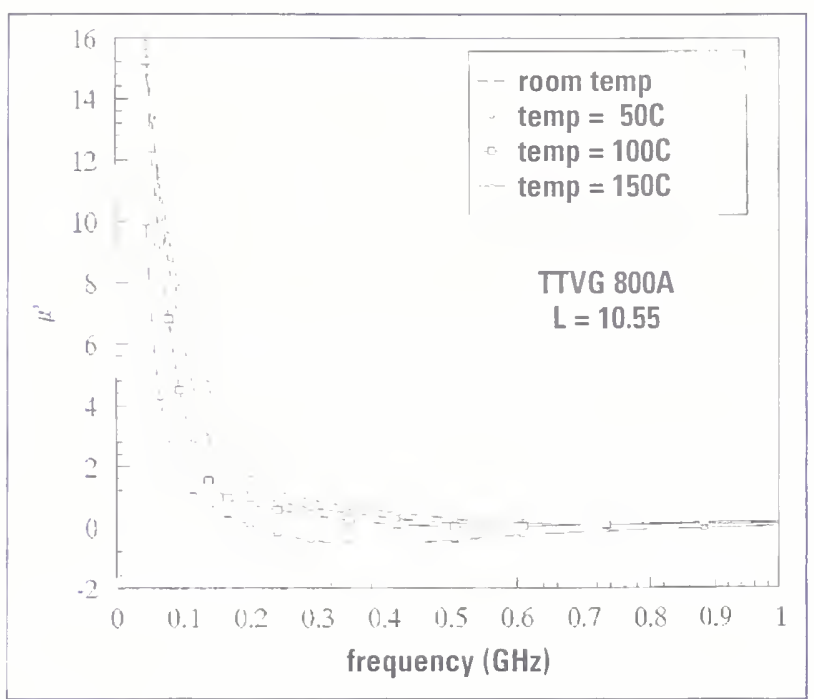

Measured relative magnetic permeability, $\mu^{\prime}$ versus frequency at room temperature and elevated temperatures to $150^{\circ} \mathrm{C}$ for a sample of calcium-vanadium garnet ferrite.

The project stems from successful, breakthrough measurement methods originating in NIST's MMIC Program. The new methods permit the characteristic impedance of small printed transmission lines to be measured directly and accurately. This quantity, when combined with conventional propagation constant measurements, can be used to separately determine the capacitance, conductance, inductance, and resistance per unit length of the transmission line. These parameters, which are closely related to the electromagnetic properties of the materials of which the line is constructed, allow the dielectric constants of thin films used in the construction of the line to be determined over broad frequency ranges. Prototype structures used in this work were designed in a collaboration between Williams and researchers at l'Institut d'Electronique et de Microélectronique du Nord in France.

The prototypes were then tested with inexpensive in-situ on-wafer-probing measurement methods. The team identified serious problems that were related to contact-pad parasitics. In collaboration with a major American instrument manufacturer, NIST designed, fabricated, and tested new prototypes that resolved these problems. Using the new samples, they were able to extract the desired material parameters from the transmission line measurements.

In a study with another participant in the collaboration, a similar test vehicle was developed. Williams and Janezic demonstrated and compared methods on thick dielectric substrates, evaluated the standard test vehicle fabricated by the industry participant, and designed and fabricated a NIST test structure at a foundry. The team found that neither the Company's standard designs nor the initial NIST designs were suitable for dielectric characterization. Having identified the critical problems, they renewed the effort to design, build, and fabricate viable new test structures. In one case, they progressed to the electrical-testing stage and demonstrated complete resolution. Their cumulative success indicates it will be possible to accurately characterize thin films in the near future. This is critical for thin films play a crucial role in modern microelectronics. 


\subsection{Important Polarization Behavior}

\section{Revealed in Surface-Emitting Laser}

\section{RESEARCH}

Continuing research on precision measurement systems for vertical-cavity surface-emitting lasers (VCSELS) has yielded an important new understanding of how polarization effects relate to performance. VCSELs are a relatively new class of semiconductor lasers that are becoming important in optical data communication systems and may well find other applications.

While involved in a project to characterize VCSELs, NIST scientists Gregory Obarski and Richard Jones discovered that when a VCSEL beam composed of a single transverse higher-order mode passed through a polarizing optical component, such as an optical isolator, its noise and beam profile

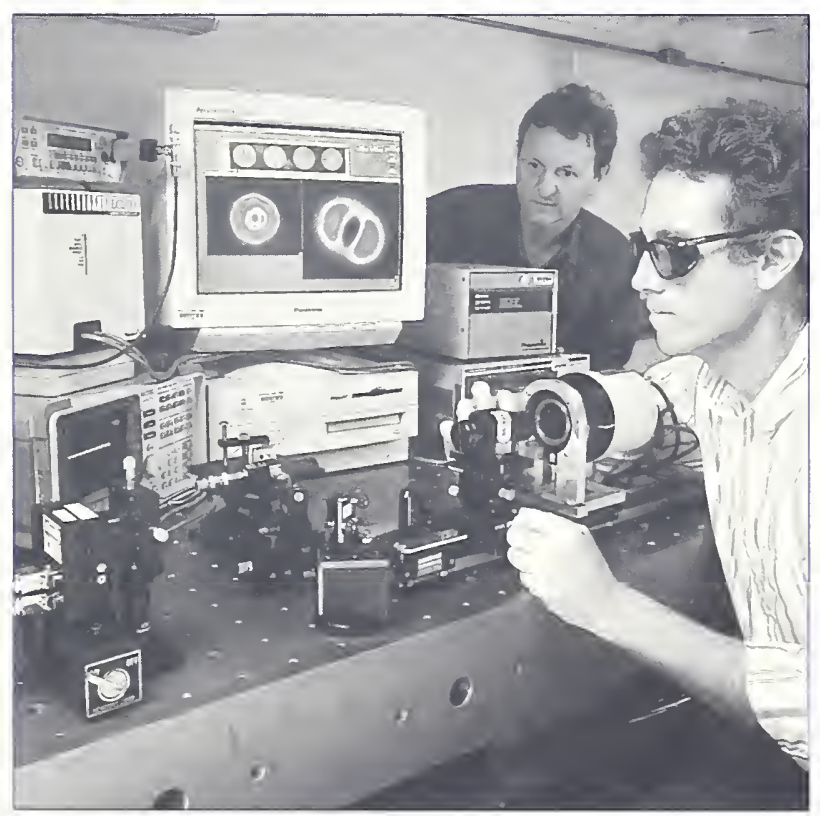

(Front to back) R. D. Jones, G. E. Obarski - Jones shown finetuning the RIN measurement apparatus. characteristics could be altered dramatically. In some cases, they found that the relative intensity noise (RIN) of a single transverse higher-order mode that had passed through a polarizer could be as much as 10,000 times greater than that measured without the polarizer. They also found that the noise associated with a polarized beam can be much more dependent on operating conditions, such as laser drive current, than the unpolarized beam. Laser noise, generally described as RIN, is an important factor in establishing the error rates of data communications systems.

Using a specially designed system for simultaneous measurement of laser RIN, beam profile, and polarization states, Obarski and Jones investigated the operating conditions under which these effects become significant. They found that the single transverse mode was composed of degenerate polarization states, which governed the beam properties. These results were shown to depend on the spatial overlap of the degenerate polarization states, with strong evidence that the RIN of orthogonal components can be anti-correlated.

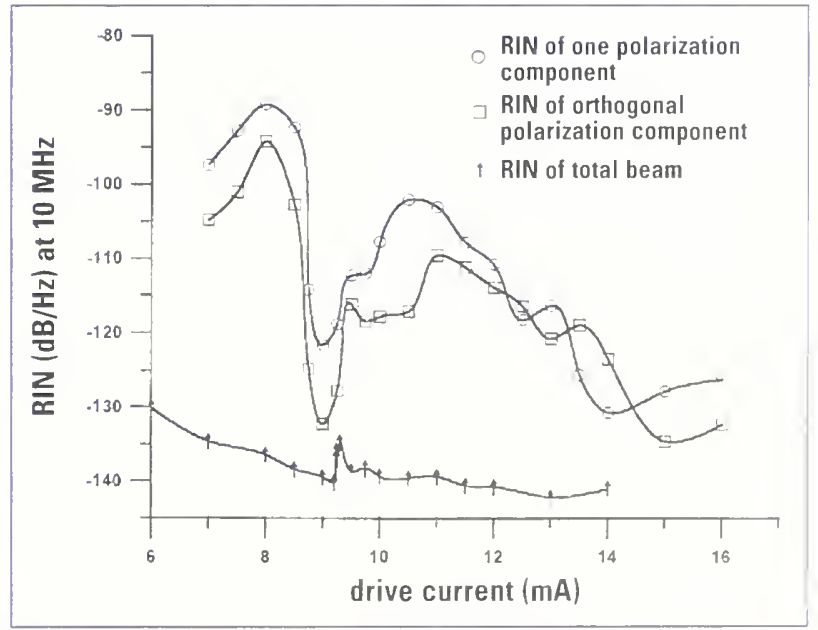

RIN of a polarized beam component is as much as $40 \mathrm{~dB} / \mathrm{Hz}$ greater than that of the total beam. 
Thus, when the orthogonal components are combined, the RIN decreases, sometimes dramatically.

Additional beam profile and RIN measurements in which the beam was passed through a SoleilBabinet variable retarder, demonstrated that the observed lasing in a high-order mode could occur in tangential, radial, or even elliptical polarization states, depending on the drive current. The beam properties and RIN are highly dependent on the phase difference between the orthogonally polarized components. All of these effects may have contributed to discrepancies in RIN measurements reported in the literature.

\subsection{Multimode Fiber Measurements}

Support Gigabit local Area Networks

John Schlager and Douglas Franzen have completed a project with members of the Telecommunications Industry Association (TIA) and an IEEE Gigabit Ethernet standards group to characterize the bandwidth of multimode optical fiber for high speed data networks.

Most of these networks use multimode fiber, rather than single-mode fiber, for transmission. In a multimode fiber, the transmission bandwidth depends on the spatial and angular excitation of the fiber core. Ideally, these fibers should be measured and specified with launching conditions that predict a worst case bandwidth, so systems will not degrade when practical sources are used. Prevailing industry practices need to be improved to achieve this goal.

To establish the facts, NIST worked with industry representatives to conduct an extensive interlaboratory comparison of bandwidth measurements. Using a number of launching conditions, measurements were performed on several 300-m lengths of a 15 fiber cable. NIST contributed measurements and compiled the vast amount of submitted data. Measurements using well-controlled laboratory launching conditions were compared to results obtained with practical system sources. Findings were presented at the June 1997 TIA meeting and at subsequent meetings of a Gigabit Ethernet standards group.

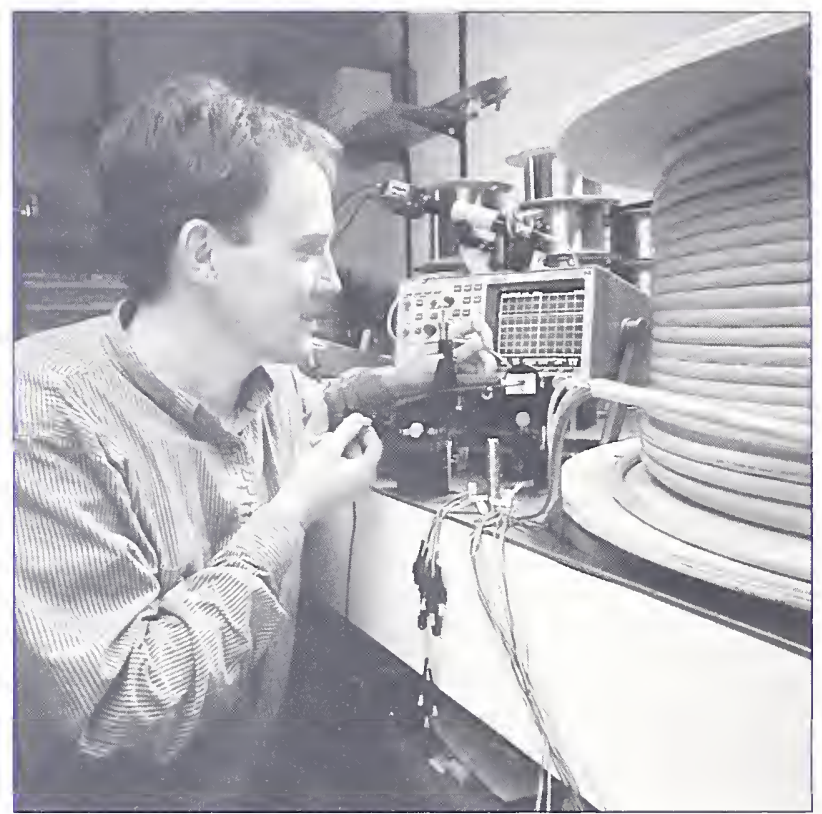

J. B. Schlager - Making bandwidth measurements on an optical fiber cable containing 15 multimode fibers. This project is part of an industry-wide round robin comparison with members of the Telecommunications Industry Association (TIA).

Data from the round robin were used to recommend maximum link lengths for $62.5 \mu \mathrm{m}$ and $50 \mu \mathrm{m}$ diameter core fibers for operation at the planned Gigabit Ethernet data rate of $1.25 \mathrm{Gbit} / \mathrm{s}$. Data from the study will also be used in recommending further work toward an optimum launch specification for this application.

During the course of this work, NIST developed a novel, frequency-domain, phase-shift method for measuring differential mode delay (DMD) in multimode fiber. DMD measurements give insight into the modal dependence of fiber bandwidth, and the NIST measurements on the round robin fibers 
helped to explain some of the observed behavior. The NIST technique allows DMDs to be obtained in real time with very high temporal resolution. The time resolution was sufficient to measure the 300-m lengths used in the round robin study.

\subsection{New System for Polarization-}

\section{Dependent Loss Measurements}

Optical components often have different transmission coefficients for different polarizations of light. In advanced optical communication systems and optical fiber sensor arrays — systems which contain many components and in which the polarization may vary with time - this polarization-dependent loss (PDL) can lead to unexpected and unacceptable signal degradation. There are now several commercial instruments that

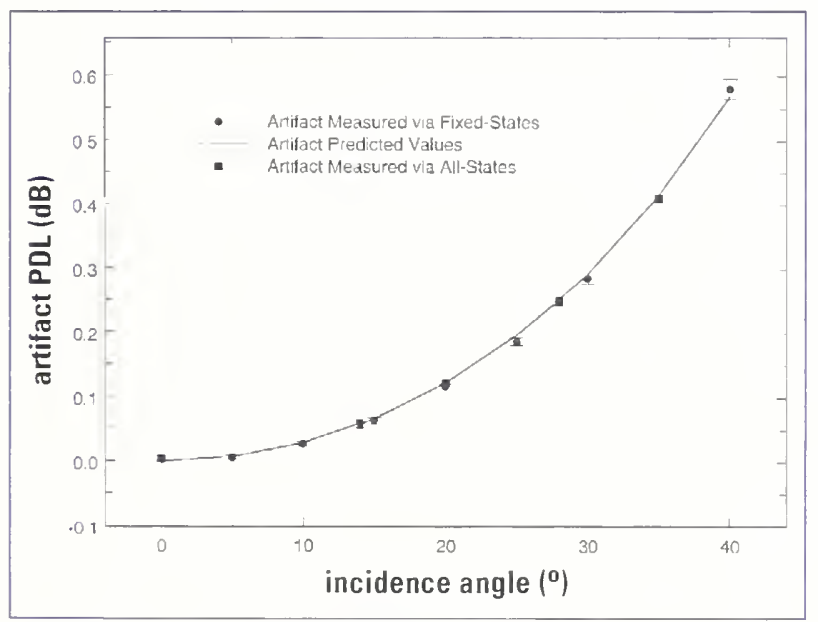

Experimental and theoretical PDL of a glass cube artifact. Open-beam artifact data from both the fixed-states and allstates systems with theoretical PDL values derived from a plane wave-model.

measure PDL and some report resolutions as low as $\pm 0.001 \mathrm{~dB}$, but there is currently no independent method of determining the uncertainty of the measurements they provide. Note: $0.001 \mathrm{~dB}$ corresponds to a transmittance difference of $0.02 \%$.

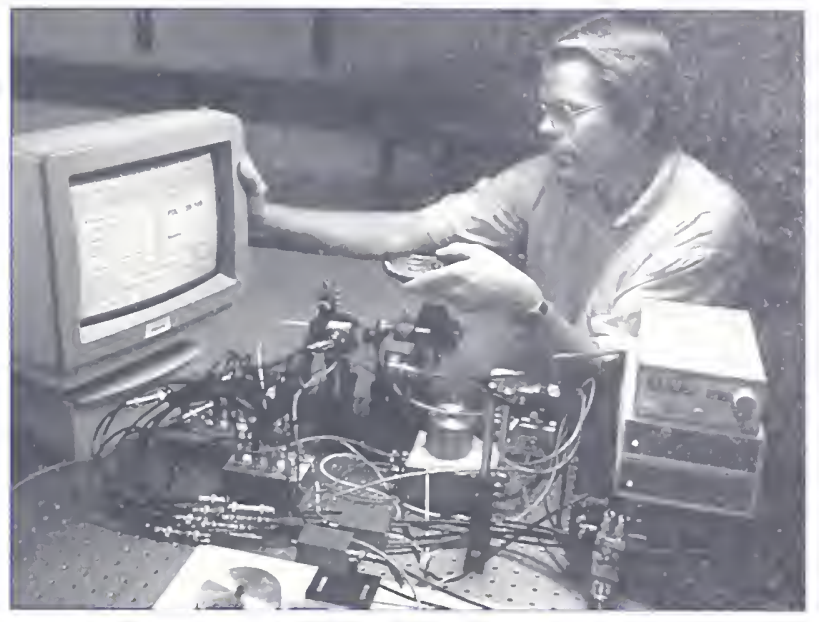

R. M. Craig - Variable retardance, fixed states system for measuring polarization-dependent loss. Measurement parameters are entered through a visual interface with a handheld remote.

The Optoelectronics Division has recently developed an automated, high-resolution. polarization-dependent loss and gain measurement system to aid in the study of a variety of measurement methods upon which commercial instruments are based. The new ststem is a fixedpolarization-states measurement șstem in which four well-defined polarization states are generated: the PDL of a component can be derived from its transmittance of these states. Voltage-controlled, liquid-crystal, variable retarders are used to switch polarization states rapidly, aroiding drift and permitting the use of synchronous detection to monitor the transmittance as the polarization is switched.

To determine the uncertainty of measurements provided by the new system. NIST scientist Rex Craig compared measurements with theoretical predictions of the PDL of well defined components. and with measurements obtained with a commercial instrument based on an allpolarization-states method (a system that scans continuously through all possible polarization states). Using a rotatable glass cube to produce a variety of PDL values, he obtained a resolution of better than $0.001 \mathrm{~dB}$ and agreement with 
theoretically calculated values to within $2 \%$. Good agreement with the lower-resolution commercial measurement sistem was also obtained. Using an angled optical fiber connector, agreement with the commercial instrument was within $\pm 0.003 \mathrm{~dB}$, with the uncertainty apparently dominated by PDL in other fiber connectors in the system. These ongoing studies suggest that the new system may be capable of measurements of PDL with an expanded uncertainty of $\pm 0.002 \mathrm{~dB}$, provided fiber connectors are not used. Fiber connectors appear to increase the uncertainty by approximately $\pm 0.00+\mathrm{dB}$. This work may lead to the development of a Standard Reference Material for PDL.

\subsection{Tools to Support Semiconductor}

Modeling, Manufacturing, AND

\section{CharaCterization}

Staff of the Semiconductor Materials and Devices Project in the Optoelectronics Division have developed and demonstrated a number of tools to

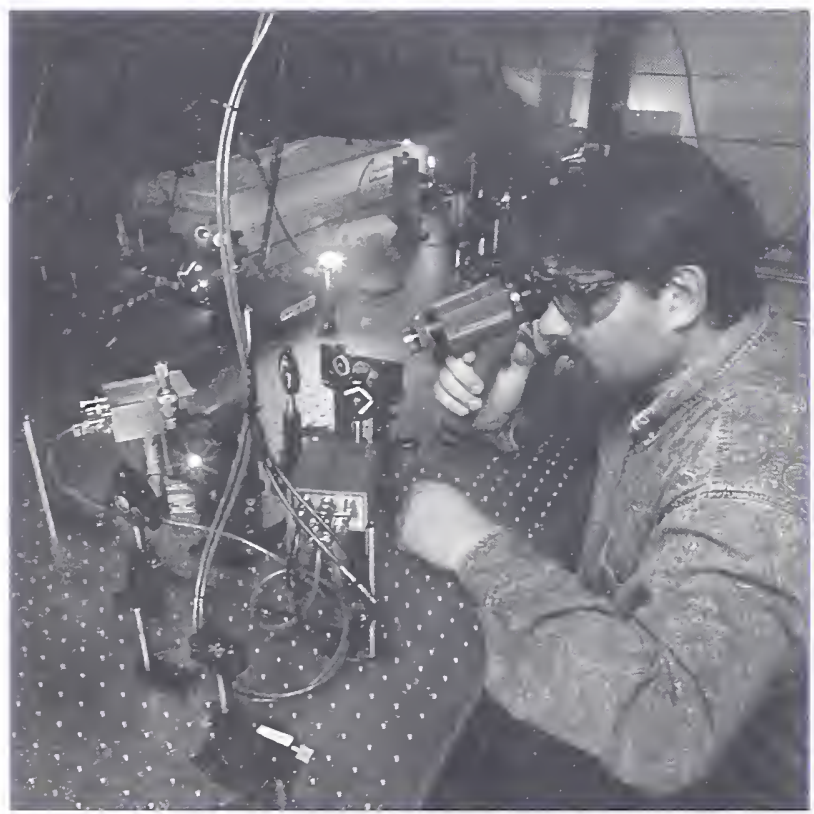

M. J. Munroe - Alignment of the optical homodyne detection system. Characterization of the optical and material properties of devices used in ultrafast communications and spectroscopy depends on ultra-short and ultra-sensitive pulse measurements by the system. aid the design, fabrication, and characterization of semiconductor lasers and photodetectors. The work is focussed in part on the vertical cavity surface-emitting laser (VCSEL) as a vehicle to refine and prove design and manufacturing metrology concepts. The Optoelectronics Industry Development Association (OIDA) has identified the VCSEL as a strategic component in international competitiveness in optoelectronics.

The growth of compound semiconductor layers for VCSELS requires a thickness-accuracy of better than $1 \%$ in layers that are typically $70 \mathrm{~nm}$ or less thick. Devices often consist of hundreds of layers grown over periods of hours. Various in situ diagnostic methods, including optical reflectance spectroscopy (ORS) and atomic absorption (AA) measurements, are used to monitor and control the growth of the devices. The OIDA believes that in situ measurements are a key to efficient manufacturing.

A problem commonly encountered when using in situ measurement techniques that probe the substrate surface is a systematic variation of signal

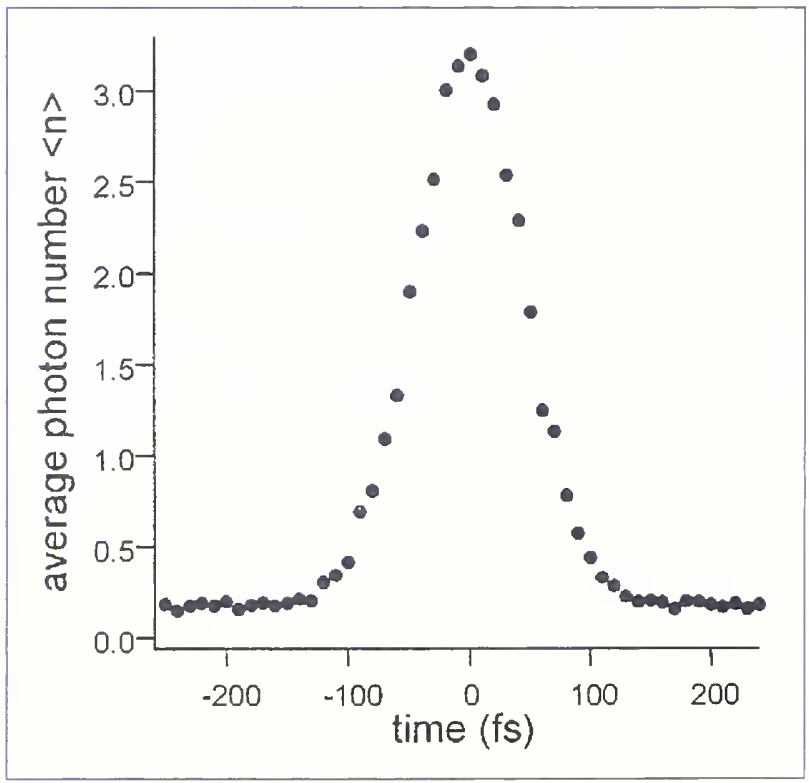

100 fs pulse measured by optical homodyne detection. Pulse of $10^{-18} \mathrm{~J}$ energy measured using local oscillator signal of 100 $\mathrm{fJ}$ energy and $70 \mathrm{fs}$ duration. Each data point is an average of 10,000 samples over $0.5 \mathrm{~s}$. 
resulting from the wobble of the rotating substrate. Through data acquisition stnchronized to the substrate rotation, NIST researchers have reduced the variation of the signals from ORS and AA-inreflection by factors of three to thirty. Improvements in these techniques are leading to the real-time control of epitaxial growth.

In situ measurements must be calibrated against post-growth, ex situ measurements. Staff researchers have demonstrated the ability to detect $1 \%$ variations in laver thickness using $x-1$ ray diffractometry and optical reflectance spectroscopy. In sitn and ex sitn measurements must be combined with effective modeling, based on accurate materials data, to manufacture devices with high performance and yield. Division staff have refined refractive index modeling procedures for the AlGaAs material system. To demonstrate their value, these models have been used with in sitn RHEED diagnostics, to design and fabricate the highest speed resonant-cavity-enhanced (RCE) Schottky photodetectors yet reported $(35 \mathrm{GHz})$.
To achieve high-gain bandwidth performance. control of laver thickness to within $0.2 \%$ of design was required and demonstrated.

As VCSEL-based data communications move to higher bit rates, design and measurement tools must focus more on the dynamic behavior of the lasers. To meet this challenge, the staff developed an ultra-short optical pulse characterization sistem, using optical homodyne detection, with a 60--fs resolution and detection noise equivalent to less than 0.2 photons over a five microsecond integration time. Using this ș̣stem with specially designed cavities that will pass ultra-short pulses with minimum dispersion, carrier-scattering processes which limit the performance of highspeed VCSELs can be studied. 


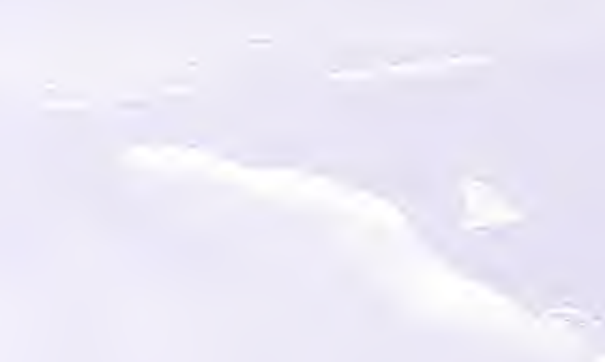




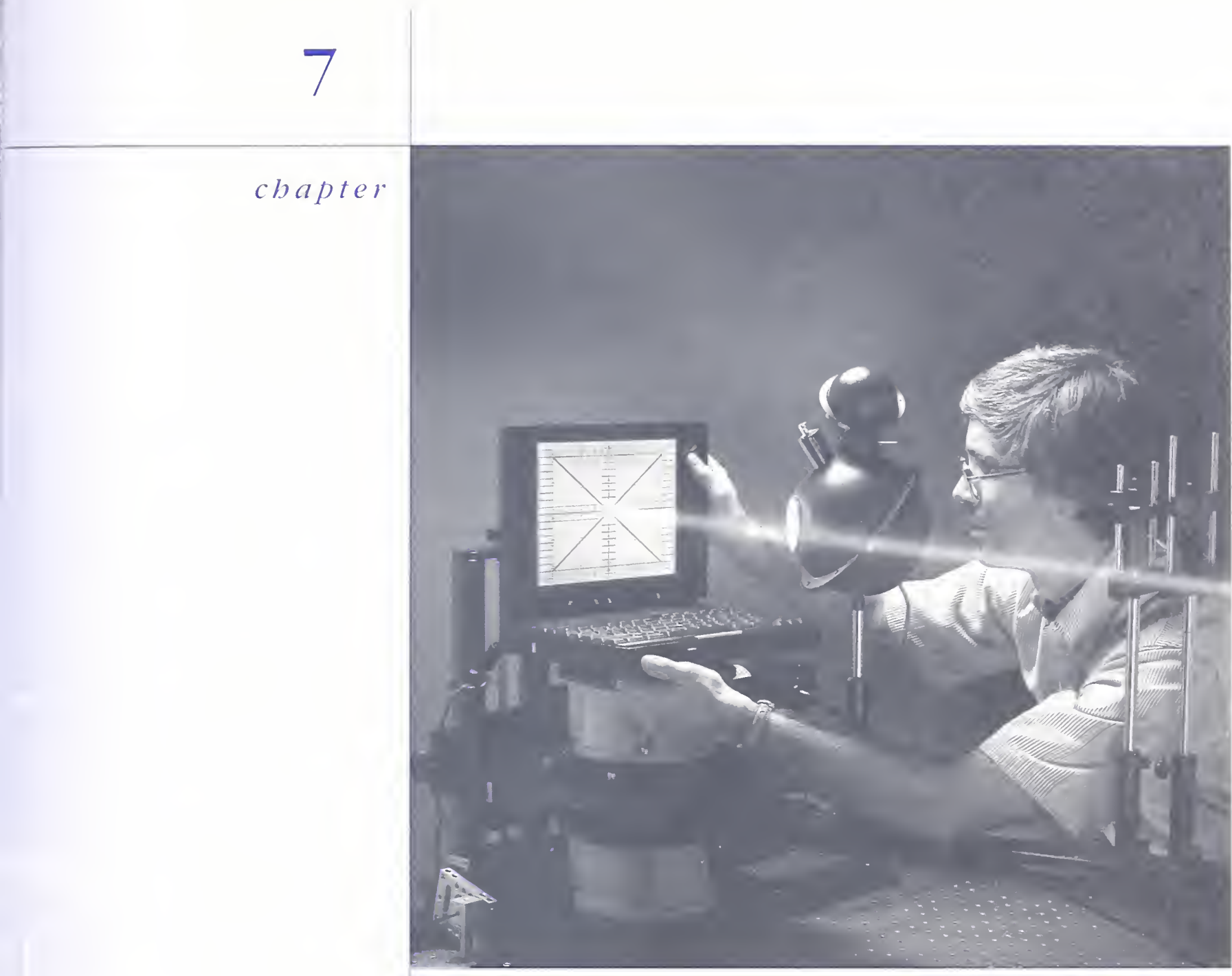

G. R. Jones aligns apparatus in preparation for display reflection measurements.

\section{Video}

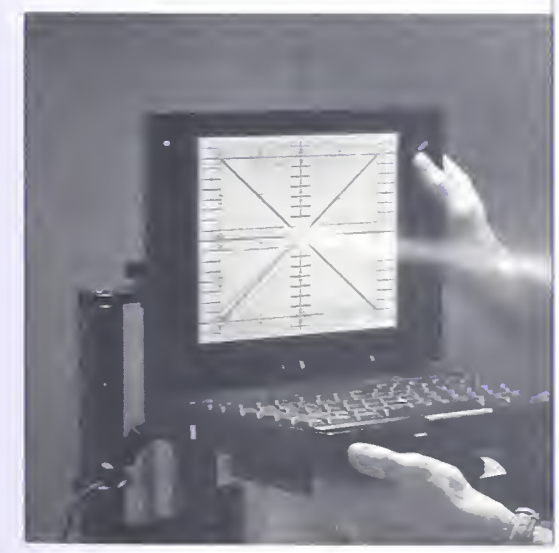




\subsection{Characterization of Fiat Panel}

DisPlays SUPPORTS STANDARD

\section{DeVELOPMENT}

Any manufacturer of a competitive product containing an electronic display wants the display to look as good as possible. However, it is not an easy task to translate "hard" scientific measurements into how the human eve perceives a displayed image. We can quickly determine quality in a side-by-side comparison of a display and, now, because of recent EEEL research, measurements have been developed that best represent the eye's perception of display quality.

Because of the explosive and innovative growth of the flat panel display industry, good display metrology needs to be put in place as fast as possible to provide a common basis for original equipment manufacturers to accurately judge the quality of a large variety of competitive displays. Display-quality issues have to be faced early in the design and manufacturing process. To develop and promulgate to industry a meaningful set of tests, Edward Kelley of NIST is leading a Video Electronics Standards Association (VESA) working group to develop a VESA Flat Panel Display Measurements Standard.

VESA is an industry consortium with over 300 member companies, whose mission is to promote and develop timely, relevant and open standards for the video electronics industry, ensuring interoperability and encouraging innovation and market growth. The Association's aggressive approach to standards development is aimed at decreasing the normal standards development time from many years to one or two years. Building on earlier work by Kelley, the Flat Panel Display Measurements Working Group created a 230-page draft document in only 15 months.
"The document you are writing is one of the best I have seen on picture quality. The structure, quality, pictures, explanations, etc., make it one of the best for international use."

MAX LINDFORS

TUV, FINLAND

Currently undergoing industry review, the document's presentation is uniquely designed to enable the user to rapidly grasp the fundamentals of good display metrology. Its approach includes basic tutorials on photometry and colorimetry, discussions of how to avoid difficult measurement problems, and reproducible measurement procedures to characterize display performance.

The proposed standard covers pixelated direct-view (emissive or transmissive) color displays and represents a significant improvement over previous documents. It describes good metrology for unambiguously characterizing flat panel displays so that all users will get the same results on the same display. In addition, the document provides the user with a standardized procedure for readying a display for test, and 58 measurement procedures, each of which includes a description and purpose of the test, setup procedures, detailed measurement procedures, a discussion of analysis of the data, and a reporting requirement.

The tests run the gamut from luminance and color measurements, detail, resolution, artifacts, pattern measurements, temporal response, uniformity, and electrical performance. Based on the intended use of the display, the user can select the measurements required to determine the important characteristics of the displays under consideration. The 15 tutorial sections included in the document focus on difficult metrological issues, such as avoiding glare in large area measurements, spatial invariance and 
integration times, polarization effects diagnostics, detector linearity measurements, and array detector measurement errors. The 25 technical discussions present the reader with the basies of photometry, colorimetry, and other relevant subjects.

\subsection{NIST Digital Video Compression}

\section{System Test PatTerns in Use by INDUSTRY}

The current move to digital television (DTV) is generating tremendous interest across the board. Video equipment producers, broadcasters, content providers, and users are anxious to get on the bandwagon. To support these parties as well as others, an infrastructure is needed that will support both the creation and distribution of digital video, and reimbursement for its use.

Digital video`s high-data-rate requirements typically demand that the video be mathematically compressed to reduce its storage and transmission requirements. This compression can degrade the quality of the images. However, there is no widely accepted objective method for assessing the quality of compressed digital video. The traditional test patterns that are used for analog video are generally static images that do not reveal the performance of modern digital video systems.

To date, attempts by industry-based voluntary standards organizations have been unsuccessful in developing "universal" test patterns that will work with the many available compression methods being used. The users of compression technology do seem to be moving toward the adoption of MPEG-2, an international standard developed by the Motion Picture Experts Group. Much work remains, though, as the problem is twofold: to develop test patterns that create in the compression process reproducible impairments (errors) similar to the type encountered with typical video seculences, and to develop a metric that cuantifies the impairments.

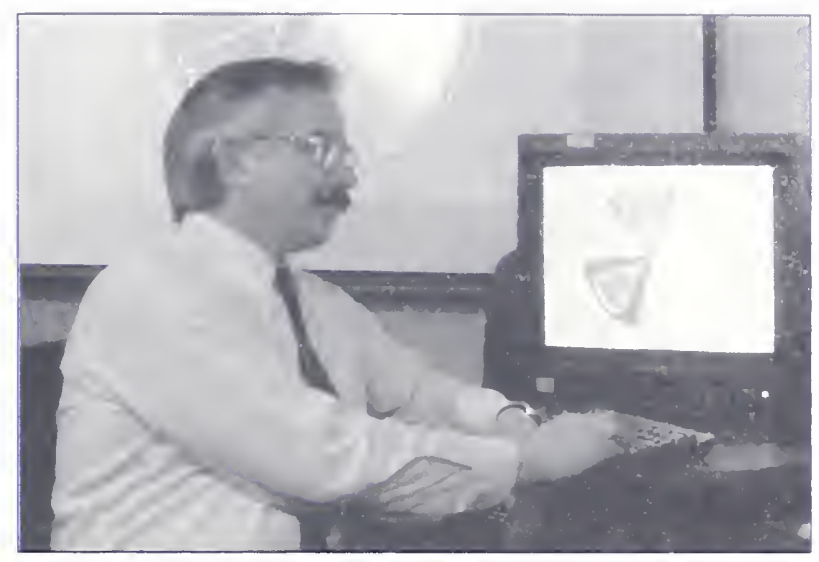

C. P. Fenimore working with NIST spinning color wheel test pattern.

EEEL researcher Charles Fenimore is working on the development of a suite of synthetic (i.e.. computer generated) test patterns to "stress" MPEG-2 video encoders in a reproducible manner. Recently developed test patterns inclucle a spinning color-wheel test pattern. which exploits the known difficulty MPEG-2 encoders have with compressing rotational motion. Specifically, blocks of constant luminance and color are spuriously generated by the encoding process at low bit rates. These blockimage impairments tend to disappear as the bit rate is increased. The perceptibility of these blocks has been shown to depend on the local contrast of the image.

Industry researchers are eager to get hold of any available test patterns so a collection of test clips has been made available to L.S. industry.

"The NIST test patterns offer a unique opportunity to test the effectiveness of the Just Noticeable Difference algoritbm under controlled conditions."

PALL BREWLR

BELL ATLAWTIC RED 


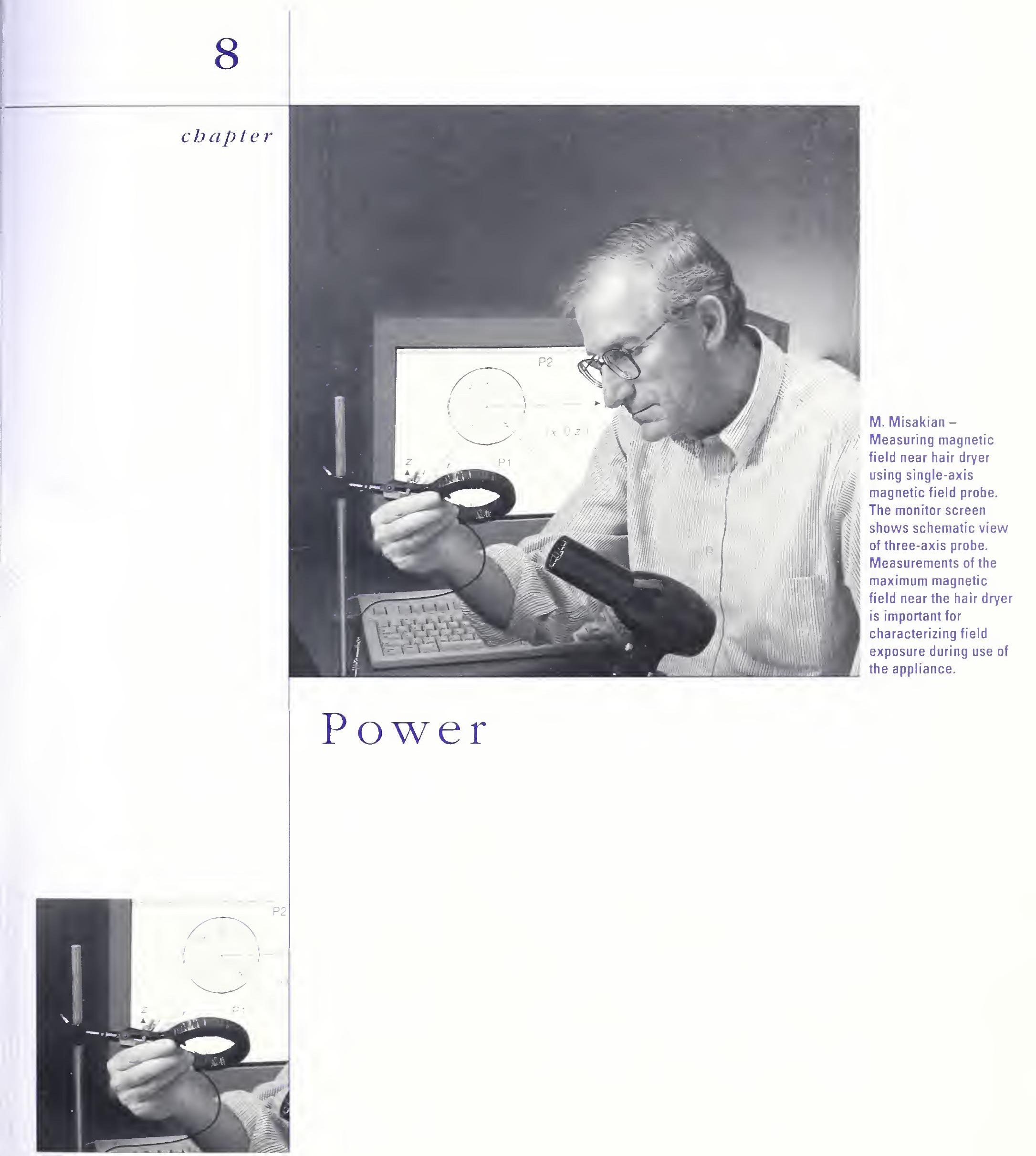


\subsection{Research Focused on Calculations}

of Magnetic-Field Measurement-Error

\section{Distributions Close to Electrical}

\section{Applances}

The concern in the mid-1970s regarding health effects from exposure to electric fields in the vicinity of power lines shifted in the 1980s to health-effect concerns from exposure to powerfrequency magnetic fields in homes, work places, and transportation systems. The magnetic fields in these environments can be highly non-uniform, particularly near electrical equipment containing motors, transformers, and heating elements, such as shavers and hair dryers. To accurately measure human exposure to these fields, a probe of sufficiently small cross-sectional area must be used in order to avoid averaging effects (errors) by the probe. The probe must also be precisely positioned in the field because of the rapidly changing magnitude close to the field source.

Martin Misakian and Charles Fenimore have performed calculations to determine the probability distributions for the measurement errors that could occur when magnetic field meters with single-axis and three-axis coil probes are used to measure the magnetic flux density produced by a small loop of alternating current, i.e., a magnetic dipole. The magnetic dipole field was chosen as the relevant field because to a good approximation, its geometry simulates the field geometry of many electrical appliances. In each case, the distributions are found to be asymmetric and explain why two identical three-axis magnetic field meters used to make measurements at the same point in space near an electrical appliance can yield values that differ by more than 30\%. However, using these computations, estimates of uncertainty can now be assigned to measurements performed in such highly non-uniform fields. The results of the calculations also allow selections to be made of probe size, which are consistent with total permitted measurement uncertainties.

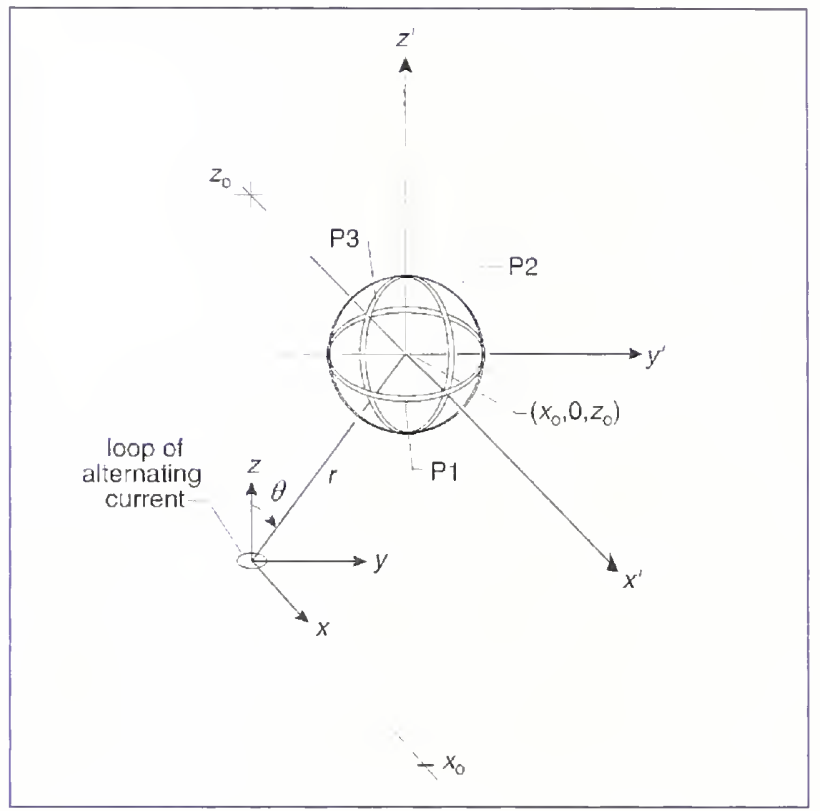

Schematic view of three-axis magnetic field probe with its center at location $x=x_{0}, y=y_{0}$, and $z=z_{0}$. A small current loop, representing the electrical appliance, produces a dipole magnetic field. Calculations for the error distributions are expedited by transforming the origin of the xyz-coordinates to the center of the probe. [IEEE Transactions on Instrumentation and Measurements, 45:244-249 (1996)]

\subsection{New Calibration Service Provides}

Customers With FASTER,

MORE-ECONOMICAL WatTHOUR METER

\section{Calibrations}

A quality-review effort by the Electricity Division identified our customers' need for faster turnaround times and a desire for a reduction in the cost of watthour meter calibrations. To meet this need, researcher Thomas Nelson developed a measurement system based on a commercial calibrator, and improved internal calibration processes. Nelson's effort permitted NIST to offer a faster turn-around and reduced cost service. Turnaround time is now less than two weeks, approximately one fourth of the turn-around time 
for standard watthour meter calibrations, and the cost is reduced by more than a factor of three.

The new service, which minimizes custom setups, restricts the calibration of watthour meters to the three most commonly requested calibration points, and uses automated data collection and analysis software. One integrated current and voltage source is used to cover all the test points offered. This practice eliminates the need to stop the test when additional amplifiers or other equipment must be manually wired into the circuit. The three test conditions are: voltage of 120 volts, current of 5 amperes, frequency of 60 hertz, and power factors of unity, $0.5 \mathrm{lag}$, and 0.5 lead. The tests are performed over two days, with a minimum of 20 data points at each test point. Despite the reduced test time, quoted uncertainties are equivalent to the standard high-precision routine calibrations.

Although the new system is based upon an automated commercial calibrator, the instrument alone is not assumed to provide sufficient accuracy. Rather, it is used to simultaneously power two carefully characterized NIST watthour reference standards as well as the watthour meters under test. The known characteristics of the reference standards are used to calculate the values of the watthour meters. Flexibility is another characteristic of the new service. For instance, as customer demand expands, the service can easily be extended to additional test conditions by characterizing the reference watthour meters to meet those new requirements.

\subsection{IEEE Publishes Guide for}

Measurement of Quasi-Static Magnetic

AND Electric Fields

Concerns about the health hazards of extremely low frequency electric and magnetic fields have led to a realization of the limitations of present measurement practice. Scientific investigation of possible biological effects due to electromagnetic fields requires that the fields be reproducible and accurately reflect known electromagnetic environments. A recent publication of the Institute of Electrical and Electronics Engineers (IEEE), IEEE Guide for the Measurement of QuasiStatic Magnetic and Electric Fields, (IEEE Std 644-1996) is the culmination of work begun at NIST two years ago. The project, which describes measurement techniques developed for electric and magnetic fields at power frequencies, was led by NIST researcher Martin Misakian, a recognized researcher in the area of low frequency electric and magnetic field measurements. Misakian chaired a working group of IEEE Standards Coordinating Committee 28 and prepared the first draft and subsequent revisions of the Guide in collaboration with Working Group members. The measurement techniques discussed in the Guide should be helpful in investigations of health effects related to exposure to fields from electrical equipment.

The purpose of the Guide is to help groups and individuals who are interested in developing magnetic and/or electric field measurement protocols. As such, the Guide describes different magnetic and electric field measurement methods that can be used to accomplish specific measurement goals. A single measurement approach is not given because the measurement strategies and instrumentation requirements will differ depending on the measurement environment of interest and the goals of a measurement program. For example, the measurement protocols and instrumentation for characterizing electric and magnetic fields from power lines will differ significantly from those for characterizing fields from electrical appliances, such as hair dryers and shavers. 
A companion document for the Guide, IEEE Std 1308-1994, Recommended Practice for Instrumentation: Specifications for Magnetic Flux Density and Electric Field Strength Meters - $10 \mathrm{~Hz}$ to $3 \mathrm{kHz}$ was also developed under Misakian's guidance. The Recommended Practice describes the types of available instrumentation used for measuring quasi-static magnetic and electric fields, their principles of operation, definitions of terminology, calibration procedures, and sources of measurement uncertainty.
IEEE Std-1308 and IEEE Std-1460 were combined under NIST guidance to form the first draft of a new International Electrotechnical Commission (IEC) standard, Low Frequency Magnetic and Electric Fields with Particular Regard to Exposure of Human Beings - Instrument Requirements and Guidance for Measurement Procedures. This document is currently under review by National Committees to the IEC. 


\subsection{EMC MEASUREMENT UNCERTAINTY}

Analysis and Antenna Calibration

\section{IMPROVEMENTS}

Researchers at NIST have developed a generic uncertainty model for radiated emissions measurements that will help test laboratories and industry manufacturers to elevate and reduce measurement uncertainties of radiated emissions. Created by David Hill, Motohisa Kanda, Kenneth Cavcey, and Stephen Kawalko, the model's applications range from antenna calibrations to compliance testing of electronic products for radiated emissions.

The model includes the following sources of uncertainty:

- setup of equipment under test

- measurement procedure

- facility

- antenna

- receiver

New measurement techniques and advanced computational models were used in the antenna analysis. The net result is that now it is possible to reduce uncertainty in antenna calibrations performed on open area test sites and in anechoic chambers.

These improvements in the understanding of uncertainty components of antenna measurements will enable improvements in facilities, measurement systems, and measurement techniques, nationwide. Smaller measurement uncertainty makes it easier for American manufacturers to demonstrate compliance with national and European standards for product emissions. This work is presented in NIST Technical Note 1389, Measurement Uncertainty of Radiated Emissions, by David IIill and Motohisa Kanda.

\subsection{NisT's New Model Enables}

Absorber-Lined Chamber Evaluation

Using Time-Domain Technique

The burgeoning wireless and consumer electronics revolutions have fueled an unprecedented construction boom in absorber-lined chambers. In response, a team of NIST scientists, including Robert Johnk, Arthur Ondrejka, and John Ladbury developed several time-domain measurement systems that evaluate the performance of state-ofthe-art absorber systems in the frequency range of $20 \mathrm{MHz}$ to $4000 \mathrm{MHz}$. The sistems include an accurate time-domain technique for evaluating planar and wedge shaped absorbers for both normal and oblique incidences. Their scattering measurement technique enables industry to perform low-cost factory floor or in situ (in a chamber facility) broadband characterizations of material performance.

The solution to the problem was to find a means to determine the scattering and depolarization characteristics of absorbers under test. In addition, the team performed an assessment of measurement uncertainties for the oblique incidence and depolarization measurements of RF absorbers, using both statistical and deterministic numerical methods. The team has also successfully applied this method to the broadband characterization of several industrial facilities. 
Specific efforts for industry included developing techniques to enable the performance of evaluations of hỵbrid absorber systems using readily available vector network analyzers. Other outcomes directly stemming from work with individual companies included the development of a differential measurement technique that intercompares open-area test site (OATS) results with absorber-lined chamber results. The method resulting from the latter study is a potentially powerful chamber diagnostic and analysis tool. Early in the past year, industry engaged the team to perform a precision time-domain calibration of a free-space directional coupler. The coupler is the key element of a newly developed absorber measurement that is being used in an aggressive chamber evaluation program. 


\section{chapter 10 Electronic Data Exchange}

\section{FACTORY INFORMATION NEEDS IDENTIFIED}

for Crucial, Next-Generation

\section{Manufacturing Productivity}

With the cost of new semiconductor fabrication lines climbing to well over $\$ 1$ billion and product life-cycles being measured in weeks, manufacturers are under tremendous pressure to be first to market with niche products offered at mass-volume prices. While manufacturers look to all aspects of their business to meet this challenge, one of the kers to overall productivity improvement is the ability to use data to identify and react quickly to change. It is no longer sufficient to automate and monitor isolated processes. Information from throughout the manufacturing enterprise must be synthesized and be available to whoever needs it, along with analytic tools, to support decisionmaking.

Working with the National Electronics Manufacturing Initiative (NEMI), NIST researcher Barbara Goldstein co-chaired an industry's Factory Information Systems (FIS) working group that published a Roadmap of Industry's Factory' Information Systems Needs through 2004. Factory information sțstems form the nervous system of a manufacturing facility, taking in data and information from automatic sensors, machines, and people and making this information and data arailable to those machines and people who need it to make decisions. Factory information sistems do not process material; they process the information needed to process material efficiently: The Roadmap identified the following pressures driving new technology development:
- complex end-products require flexible, highcapital factories with interchangeable best-ofbreed software;

- competitive pressures force shortened conceptto-market and order fulfillment cycle times:

- low-cost end-products require increased factory utilization and efficient manufacturing processes:

- changing customer expectations and erosion of loyalty demand custom products at massproduction prices;

- and globalization of design, manufacturing, and marketing has created distributed supply chains. facilities and partnerships.

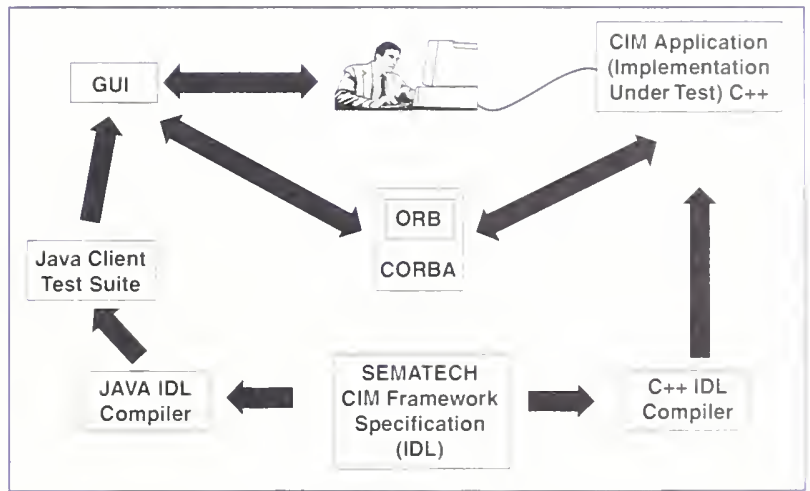

SEMATECH CIM Framework testing environment.

To address the needs noted in the Roadmap. the NEMI FIS working group has initiated a "Plug and Play Factory" project to help manufacturers create a software infrastructure that allows the seamless integration of multi-vendor applications. To further assist industry to achieve this goal, NIST is helping SEMATECH, a consortium of semiconductor manufacturers, develop and verify the Computer Integrated Manufacturing (CIM) Framework. The CIM Framework has reached a sufficient level of maturity to be incorporated into commercial implementations. Now; those companies basing 
products on the framework need tools to verify that their products conform to the specification. To assist the early implementors, NIST researchers Kevin Brady and John Messina have developed a prototype testing environment which will allow rendors to remotely test their applications for compliance to the SEMATECH Framework. The testing environment is based on open standards and distributed object technology, and is easily extensible to testing other information technology standards. This project is also extending the CIM Framework test environment to provide conformance testing of emerging assembly standards.

"Automation is a must in 300-mm semiconductor factories ..."

GEORGE LEE

DIRECTOR

300-HII INITIATIVE

SEMICONDUCTOR EQUIPMENT AND MATERIALS

INTERNATIONAL TRADE GROUP

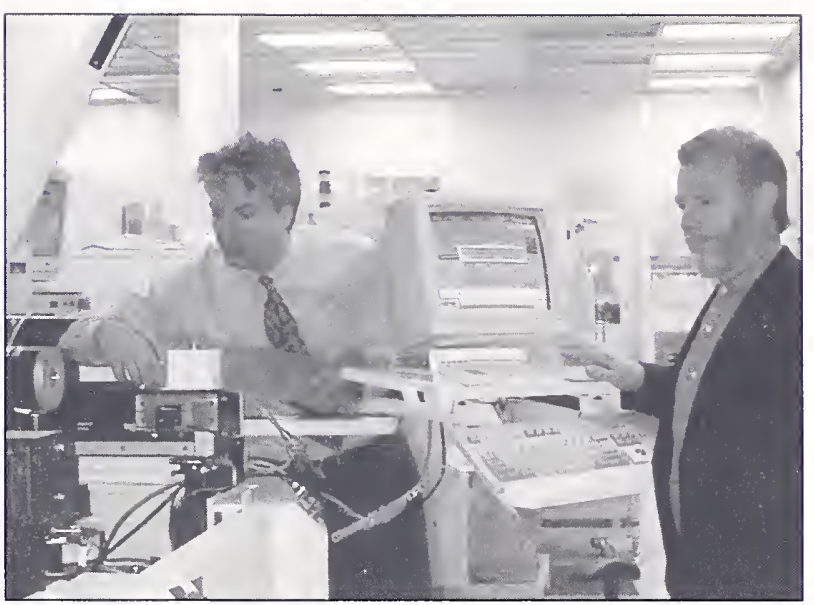

(Left to right) A. D. Dugenske, C. H. Parks - As part of a new cooperative project on Internet Commerce for Manufacturing, C. H. Parks, EEEL, checks incoming data while A. D. Dugenske, Manager of Research Services, Georgia Institute of Technology, monitors the production of circuit boards. The ICM project is establishing a testbed to demonstrate open systems and standards for the exchange of technical and business information used in the manufacture of electronic circuit assemblies. 


\section{chapter 11 National Electrical Standards}

\subsection{The Kilogram: A New Definition?}

The last artifact remaining among the SI base units is the Kilogram. The platinum-iridium cylindrical mass housed at the International Bureau of Weights and Measures has proven to be an excellent unit for more than 100 years. Unanswered questions remain however. Does its mass change through wear or absorption? Will an atomic definition be superior?

Researchers Richard Steiner, Edwin Williams, and David Newell are attempting to find answers to these questions while accurately measuring several fundamental constants, such as the mass of the electron. The two-part experiment is called the SI Watt determination. In the first part, the electric force on a current-carrying coil in a magnetic field is balanced against the gravitational pull on a kilogram. In the second part, the coil is moved within the field to generate a voltage; this determines the magnetic-field-geometry factor. The combination measures a mechanical watt, which depends on the kilogram, in comparison to an electrical watt, which is related to pure quantum standards. Key for nearly all high-accuracy measurements is testing for errors, that is, changing as many parameters as possible while checking that the result is the same. This is difficult for this experiment because there are so many influential factors, and because both parts of the experiment take an hour to complete and a full measurement set takes from 8 to 36 hours with no interruption.
"The domain of mass measurement, bating been very' quiet for much of the past one bundred years, has now awakened to the challenges presented by neu' phy'sics, and u'e can expect some exciting developments to take place over the next decade."

TERRY J. QIINW

DIRECTOR, BLREAL IVTER NatIO.NA. DFS POIDS FT MESL RES (BIPM)

The Division's investment in new automated instrumentation for taking and analyzing data has both dramatically increased the production of data, and eased the testing procedures. The instrumentation consists of seven networked computers, each using a graphical programming language to control different aspects of the experiment. For example, one of the computers controls a Josephson array voltage standard that

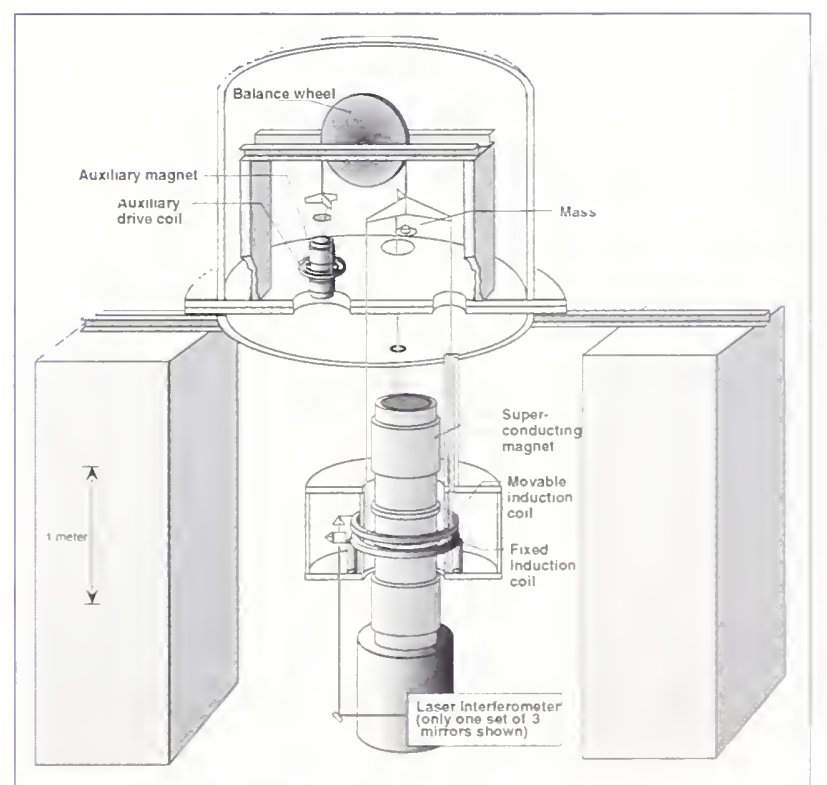

The NIST watt balance: monitoring the kilogram. A schematic showing the basic elements of the experiment and the future vacuum enclosure. 
has been installed at the NIST non-magnetic facility, providing a close tie to one of the quantum standards. This year, researchers have recorded nearly 5000 hours of data, looking for some 35 systematic uncertaintry components. There is now about a 95\% success rate (previously about 30\%) for the overnight runs, and the complex analysis takes 2 minutes instead of 2 hours.

The researchers are now monitoring a mass standard at the one part in $10^{-}$level and have evidence that the sistem could be capable of a few parts in 10 . Further, a new vacuum chamber, soon to be delivered, will help reach the goal of monitoring a mass to better than 1 part in $10^{8}$. At this level, changing the definition of the Kilogram becomes a serious consideration.

\subsection{Major Step Taken Toward}

AChieving aC Voltage Measurements

Using Pulse-Driven Array of

JOSEPHSON JUNCTIONS

With the widespread implementation of Josephson standards for dc measurements, there is increasing pressure from the metrology community to achieve the same advantages for ac voltage measurements. A joint patent held by a major aeronautical manufacturer and NIST has recently paved the way for a new ac voltage standard. It combines a very high-speed digital-pattern generator with a Josephson quantizer, and synthesizes ac voltages by summing billions of quantum voltage pulses. The pulse pattern is computed using a delta sigma algorithm that is already commonly used in the electronics community. A knowledge of the digital pattern, the clock frequency, and the number of Josephson junctions in the quantizer is sufficient to precisely calculate the output voltage waveform. Quantization noise suppression and sub part-permillion accuracy are achieved by maintaining a very

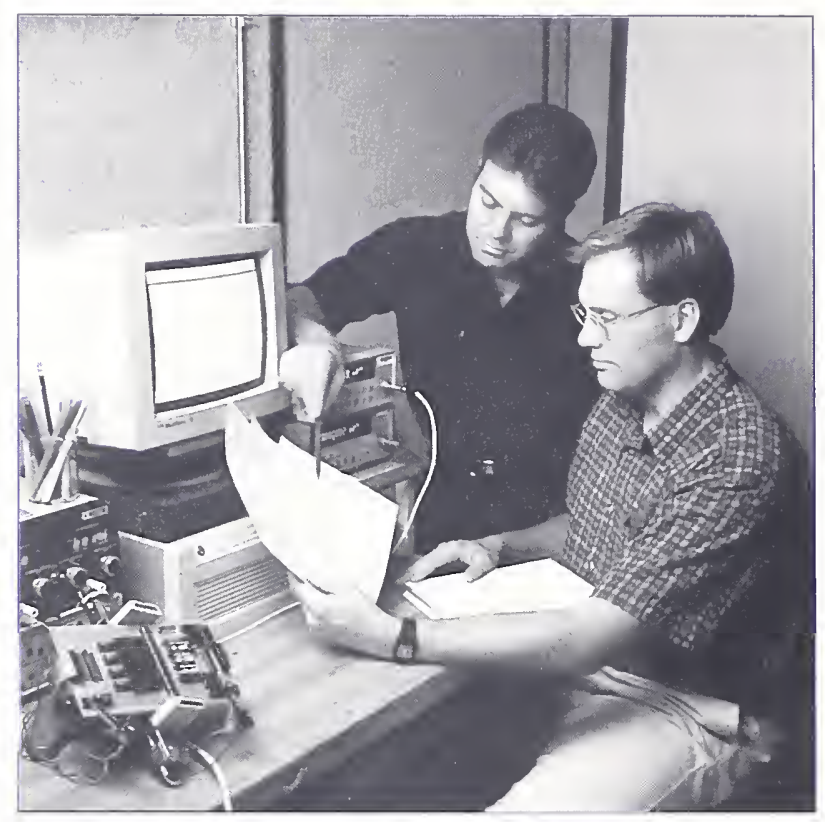

(Front to back) S. P. Benz, C. J. Burroughs - Studying the margins of the pulse-driven ac Josephson voltage standard.

large ratio between the clock frequency $(12 \mathrm{GHz})$ and the signal output frequency (0 to $1 \mathrm{MHz}$ ).

Electromagnetic Technology Division researchers Samuel Benz and Charles Burroughs demonstrated the feasibility of this idea. Their experiment required the design and construction of a microwave circuit to uniformly distribute the $12 \mathrm{GBit} / \mathrm{s}$ digital signal to 4000 Josephson junctions on a 1 by $1 \mathrm{~cm}$ superconductive integrated-circuit chip. The predicted waveform was achieved, but at a relatively low voltage. The next challenge is to develop a circuit with more than 100,000 junctions that will generate voltages greater than $1 \mathrm{~V}$. Their ultimate goal is to design and develop a single system that can generate both dc and ac voltages at any voltage from $0 \mathrm{~V}$ to $1 \mathrm{~V}$, and any frequency from $0 \mathrm{MHz}$ to $1 \mathrm{MHz}$, with a better uncertainty than the present state-of-the-art. The reward for this objective would be significant: a single system could be used to make a wide variety of calibrations and ac-dc transfers, all of which would be traceable to the intrinsic accuracy of the Josephson volt. 


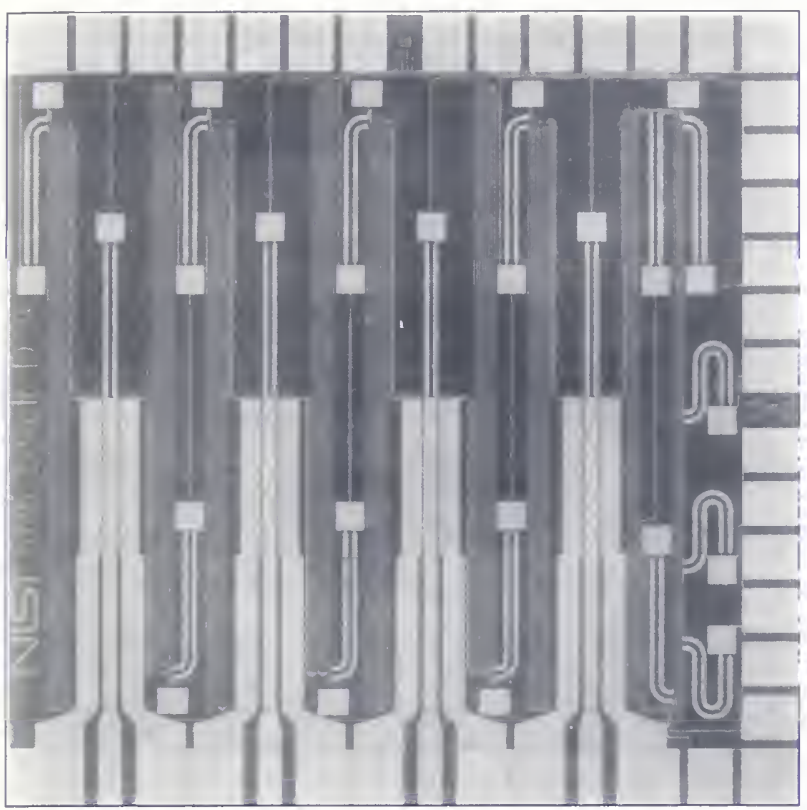

Stable 1-Volt programmable voltage standard. This $1 \mathrm{~cm}$ by $1 \mathrm{~cm}$ chip is a fully functional $1 \mathrm{~V}$ programmable standard. It contains 32,768 Nb-PdAu-Nb Josephson junctions. Each junction is $2 \mu \mathrm{m}$ in diameter. The chip is biased with a continuous $16 \mathrm{GHz}$ microwave frequency.

\subsection{Revolutionary Advance in X-Ray}

Energy Measurement

$\mathrm{X}$-ray spectroscopy is a very important microanalysis tool, particularly for high-tech industries such as the semiconductor industry. Working with NIST researcher John Martinis as their mentor, members of the Electromagnetic Technology Division have developed a new x-ray detector that provides a revolutionary advance in $\mathrm{x}$-ray energy measurement that greatly extends the usefulness of x-ray micro-analytical techniques. Up to now, conventional $x$-ray spectrometry has been performed using one of two types of spectrometers: energy-dispersive spectrometers (EDS), which use charge collection in a semiconductor crystal to measure x-ray energy, and wavelength-dispersive spectrometers (WDS), which measure incident $\mathrm{x}$-ray energy using Bragg diffraction. The more widely used EDS provides an easy to use system with an energy resolution of roughly $130 \mathrm{eV}$, while WDS attains a much better energy resolution of $2 \mathrm{eV}$ to $20 \mathrm{eV}$, but is a difficult technique to use.
The staff has developed a new detector system that offers the best of both techniques: a WDS-like energy resolution of 8 el (at $6 \mathrm{kel}$ ) with a detector area. speed, and ease of use which approaches that of EDS sistems.

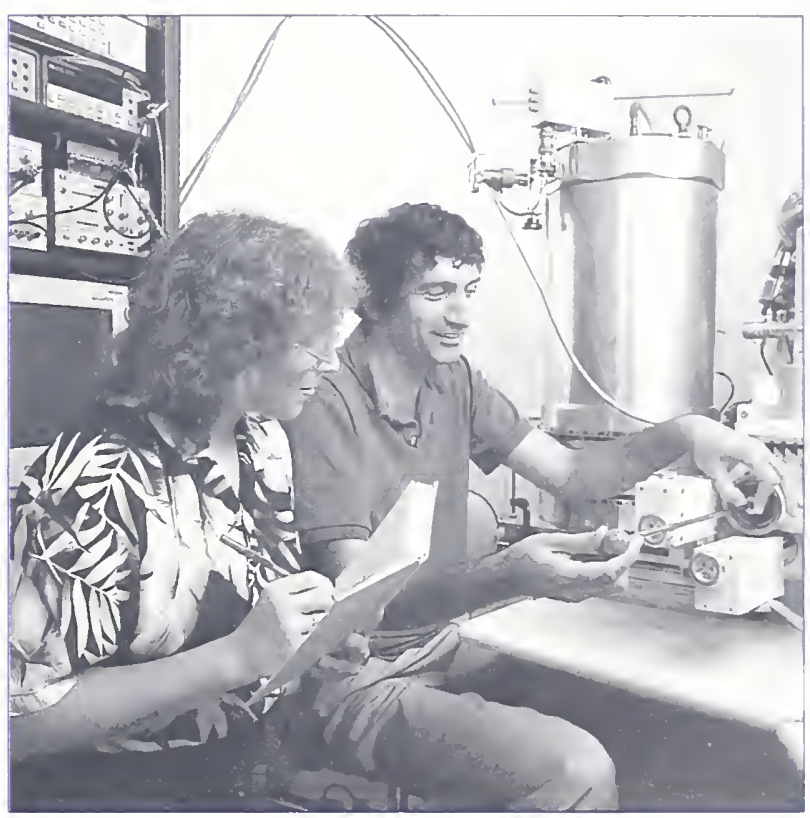

(Front to back) L. L. Dulcie, J. M. Martinis - Loading samples into a scanning electron microscope to test the performance of their microcalorimeter in $\mathrm{x}$-ray microanalysis.

The microcalorimeter spectrometer consists of a normal-metal x-ray absorber coupled to a superconducting transition-edge sensor (TES). When an $x$-ray is absorbed, the temperature rise of the absorber is measured by the TES, providing a measurement of the absorbed $x$-ray energ: The detector is cooled to its operating temperature of $100 \mathrm{mK}$ by a compact adiabatic demagnetization refrigerator (ADR). The NIST-designed ADR is compatible with the scanning electron microscopes commonly used for $\mathrm{x}$-ray microanalysis. Cooling to $4 \mathrm{~K}$ is provided by conventional liquid cryogens. while the cooling to $100 \mathrm{mK}$ is performed by purely electrical means, making this a convenient lowvibration means of achieving these low operating temperatures. 
One of the most compelling applications of this new detector is the analysis of small defect particles generated in the manufacture of semiconductors. As semiconductor geometries have continued to shrink, it has become increasingly difficult to measure the chemical composition of small defect particles. In order to cause x-rars to only be generated in the volume of the defect being studied, it is necessary to use extremely low electron-beam voltages $(\sim 2 \mathrm{keV})$. It is then very difficult to analyze the spectra using a low-resolution detector; such as a conventional EDS detector. This difficulty is further compounded by overlapping x-ray lines. Overlapping x-ray lines are commonly found because many important semiconductor materials, such as WSiz and TiN, have x-ray spectra in which the lines of the two elements fall within 10's of eV of each other. This condition makes analysis very difficult using conventional technology. The group's preliminary experiments reinforce the applicability of the detector to this important problem.

From a broader perspective, this general class of detector holds great promise for wide application in the future. One expectation is that it will be possible to attain much better energy resolution (1 $\mathrm{eV}$ to $2 \mathrm{eV}$ ), which will enable the measurement of the chemical shift of characteristic x-ray lines. In fact, the technique not only allows the identification of chemical elements, but also the determination of the local chemical bonding state. Such ultra-high resolution detectors are of great interest to x-ray astronomers. By optimizing the detector for lower energy, it will be possible to create very sensitive infrared detectors that will also be important to the astronomy community. Another variation of this basic detector type has been used as a detector for mass spectrometry of massive biomolecules. Used in this way, the detector has the potential to greatly improve applications such as high-speed DNA sequencing.

The Laboratory is currently pursuing manufacturing licenses for the microanalysis version of this detector with several companies. In response to interest from SEMATECH and several member companies, a user facility will be set up to allow outside researchers access to the new technology in the period before it becomes commercially available. 


\section{Programs Matrix-Managed by EEEL}

\section{Electronics and Electrical Engineering \\ T b e Laboratory administers NIST-wide laboratory programs in}

microelectronics and law enforcement as well as the programs sponsored by our own Laboratory. You will find descriptions of matrix-managed programs that are conducted within EEEL in the Accomplishments section of this document. Additionally, to offer a sense of the significance, quality, and impact of the matrix-managed work performed by other cooperating laboratories within NIST, we have provided the following examples:

\section{OMP - National SEmiconductor Metrology Program (NSMP)}

\section{Automated RGA Calibration system}

Staff of the Chemical Science and Technology Laboratory have developed an automated calibration system to study the types of residual gas analyzers (RGAs) used on semiconductor processing tools.

Unattended, this system can calibrate an RGA over its entire operating range with independent control of two different gas species. The results of this work have established bounds of expected performance for "out of the box" commercial instruments, that is, instruments that have not been modified in any way after leaving the manufacturer. Specifically, using the system helped researchers to identify the root causes of unsatisfactory performance, and led to procedures that all users can follow to significantly improve the performance of some of the instruments.
Metbod for Destruction of CFCs

An efficient new method for destroving chlorinated fluorocarbon compounds (CFCs) without producing undesirable byproducts has been devised by the Chemical Science and Technology Laboratory. The process involves burning the CFC in a sodium rapor stream that is produced by heating metallic sodium to about $700^{\circ} \mathrm{C}$. The CFC is carried into the flame by an inert gas such as argon. The process products take the form of solid particles of sodium salts and elemental carbon, and are readily captured by conventional filters. There are no gaseous byproducts of any kind. The argon and any excess sodium are recycled.

To validate the process, researchers chose to demonstrate it on $\mathrm{CF}_{+}$, which is the most difficult chlorinated fluorocarbon compound to destroy. The method's efficiency scored $99.999 \%$. As the technique appears to be easily scalable, its potential applications range from cleansing the exhaust line of a single piece of process apparatus to the destruction of CFCs in tonnage quantities at large plants.

Chip View Doubled by New SEM Stage

A new scanning electron microscope (SEM) stage. jointly developed by NIST"s Manufacturing Engineering Laboratory: E. Fjeld Company, North Billerica, Massachusetts; and SEMATECH, will permit researchers using a very common laboratory SEM to cover nearly all angles when examining their samples. The new stage doubles the viewing range of the typical SEM stage and 
increases the tilt to better than 90 degrees from the horizontal. as compared to a previous capability of 60 degrees.

The improved performance capabilities are expected to increase the usefulness of SEMs as measurement and research tools. For some time, NIST has been working with SEMATECH, a consortium of U.S. chip makers assisting their equipment suppliers, to improve the measurement performance of SEMs and other microscopes used in semiconductor manufacturing.

Index of Refraction Advances for Pbotolitbograpby

Measurement of the index of refraction - the property that determines how a lens focuses light is critical to the development of photolithographic exposure tools for the manufacture of futuregeneration integrated circuits. Lens designers require extremely precise data to design components accurately for new tools.

Staff of the Physics Laboratory have made long strides toward developing a method to obtain the required level of precision. To date, they have achieved an accuracy of 10 parts per million of the index of refraction of fused silica and calcium fluoride at wavelengths near $193 \mathrm{~nm}$. The improvement was made possible by upgrading a precision refractometer, specifically, by improving its temperature control to $0.1^{\circ} \mathrm{C}$.

This work, which was performed in collaboration with MIT Lincoln Laboratory and SEMATECH, seeks to develop the infrastructure required to apply $193 \mathrm{~nm}$ laser emission for making $0.18 \mu \mathrm{m}$ integrated circuit feature sizes. These results keep industry on track to meet the National Technology Roadmap for Semiconductors' (NTRS) target date of 2001 for commercial production of these chips.
Polarized Signatures May Lead To Tinier Chips

Optical scattering is used to measure the microroughness of silicon wafers and to detect surface particles and defects. However, light scattering due to microroughness can obscure or overwhelm scattering caused by particles smaller than $100 \mathrm{~nm}$. Such particles are identified as a problem at 180-nm scale in the NTRS.

Researchers in the Physics Laboratory have discovered how to clearly distinguish the scattering by microroughness from that of other sources. They have found that at specific angles and with certain polarization conditions, light scattered by microroughness can be suppressed, while scattering from particles and surface defects is essentially unaffected. The theory behind this effect has been fully developed.

A provisional patent covering instrumental applications of this discovery has been filed. In addition to its usefulness in process inspection of silicon wafers, the method is expected to be valuable for identifying and characterizing defects in optical components, disk storage materials and film coatings.

\section{OFFICE OF LAW ENFORCEMENT STANDARDS (OLES)}

Domestic Counterterrorism
Program

The Antiterrorism Act, which was signed by President Clinton on September 30, 1996, reflects the international threat posed by terrorists, foreign and domestic. Under this Act, $\$ 10$ million was appropriated for the National Institute of Justice (NIJ) Domestic Counterterrorism Program. The initial focus was to select technologies for funding 
based on the priorities stated by Congress. To determine priorities within these broad categories, NIJ consulted with federal, state and local law enforcement agencies to ascertain their technology development needs.

The key role that OLES undertakes in this Program is articulated in Section 821 (2) "Develop standaurds to ensure the adequacy of products and compatibility with relevant national systems." To date, NIJ and the law enforcement agencies have identified those standards that are high priority requirements for agencies and directly support counterterrorism efforts. OLES will now focus on the next mandated objective: responsibility for expanding existing law enforcement standards and testing programs to include selected counterterrorism technologies and equipment. Approximately \$3 million is being committed to the counterterrorism standards effort.

Forensic Laboratory

Handbook

Designing and building a forensic laboratory is a complicated undertaking. The design issues include those considerations present when designing any building, but more is also required. Special requirements involving environmental health and safety, hazardous materials, management, operational efficiency, adaptability, security of evidence, preservation of evidence in an uncontaminated state, and stringent budgetary concerns must also be considered.

To help laboratory directors move efficiently through this process, OLES designed, planned, and hosted two workshops during FY 1997. The project was undertaken at the request of the American Society of Crime Laboratory Directors (ASCLD) and the NIJ. Its objective was to develop guidelines for planning, designing, constructing and moving crime laboratories.
OLES invited experts in all the relevant fields to participate in the workshops, and submit papers on their topics of expertise. The proceedings will be issued as an .VIJ technical report entitled Forensic Laboratories: Hanalbook for Facility' Planning. Design, Constmation and Hoving. The document is currently moving through the Washington Editorial Review Board (WTRB) process.

\section{NHTSA Publication}

The National Highway Traffic Safety Administration (NHTSA) document Model Ninimm

Performance Specifications for LIDAR Speed Measurement Devices was revised and published in February $199^{-}$as Technical Report DOT HS 808 539. The new specifications reflect the results and experience gained from recent joint testing of light detection and ranging (LIDAR) devices by OLES and the International Association of Chiefs of Police (IACP) Laboratory, which is located at the Lniversity of California's Davis Campus. The revised publication clarifies the intent of certain performance requirements as well as the protocols to be used for both the laboratory and the field testing of this type of device.

\section{NIJ Standards}

Revisions to NI Standard-0204.02. Mobile Antemmas, and NI Standard-0205.02, Fixed and Base Station Antennas, have been completed. These standards establish minimum performance requirements and test methods for antennas used by law enforcement agencies. The objective of the standards is to help law enforcement personnel to select and procure antennas designed to operate in the $25 \mathrm{MHz}$ to $50 \mathrm{MHz}, 150 \mathrm{MHz}$ to $174 \mathrm{MHz}$, $406 \mathrm{MHz}$ to $512 \mathrm{MHz}$ and $806 \mathrm{MHz}$ to $930 \mathrm{MHz}$ police radio bands. In addition to radio frequency performance, these standards also establish requirements and test methods for structural and environmental performance. 


\section{EEEL Awards and Recognition}

Department of Commerce

GOLD MEDAL

Robert E. Hebner

Robert $\mathrm{E}$. Hebner is recognized for leadership of NIST through positions of rapidly increasing responsibility at a time when its programs and activities have been under increasing scrutiny and challenge. He accelerated the pace of accomplishments toward all four of the Institute's priorities through his action-oriented, resultsfocused leadership. Hebner's leadership style and incisive analytical ability have been critical to the overall management, strategic planning, program direction, budget priorities, and day-to-day operations of the Institute. His efforts have led to a vision for the future of NIST that will assure its contribution to technology-based economic growth for the nation.

\section{NIST}

\section{BRONZE MEDAL}

\section{Donnie R. Ricks}

Donnie R. Ricks is cited for meticulously conducting certification measurements for over 1,900 silicon resistivity Standard Reference Materials (SRMs) since 1984. She has consistently met the demanding requirements for extreme care, for example, in establishing the apparatus and monitoring the measurement results to detect any drifts or other indications of instrument malfunction. The importance of her work lies in the fact that resistivity is the most important parameter for specifying silicon starting material and that all U.S. semiconductor companies depend on NIST SRMs as the basis for resistivity measurement.

\section{Norman A. Sanford}

Norman A. Sanford is recognized for his development and application of a method to nondestructively map the uniformity of lithium niobate, resulting in an order-of-magnitude improvement in sensitivity of the measurement of $\mathrm{Li} / \mathrm{Nb}$ ratio over methods commonly used by industry. He developed and applied the nonlinear optical Maker fringe technique to mapping the uniformity of refractive index, composition, thickness, and strain nondestructively across ferroelectric wafers used in the commercial production of integrated optical devices. A U.S. manufacturer credits his system as being "vital in identifying wafer and process variations."

\section{Michael H. Francis \\ Ronald C. Wittmann \\ Bradley $K$. Alpert}

Francis, Wittmann, and Alpert, are cited for their development of a position-error correction algorithm for planar near-field scanning, now the most-used method for advanced antenna systems. Their achievement applies to a wide range of frequencies and includes incorporation of a proof of solution convergence, which gives assurance that the algorithm produces useful results. The team's work resolves issues of compensating for errors in positioning the probe used to survey the antenna, long a challenging aspect of antenna characterization by planar near-field scanning at higher frequencies where position errors become increasingly critical. Francis and Wittmann are members of EEEL's Electromagnetic Fields Division. Alpert is affiliated with NIST's Information Technology Laboratory. 
Edward Uhler Condon Award

Richard L. Kautz

In response to an invitation from Reports on Progress in Physics extended by Terry Quinn, Director of the BIPM and a member of the RPP editorial board, R.L. Kautz wrote a paper entitled Noise, Chaos, and the Josephson Voltage Standarl, Reports on Progress in Physics 59(8), 935-992. August 1966. The paper reviews in exquisite detail a decade of the author's own theoretical and experimental work on the nonlinear dynamics of chaotic systems. It presents for the first time a complete picture of how quasipotentials can be used to evaluate the stability of nonlinear systems. It is the theoretical foundation for the design of Josephson voltage standards and the model that explains their behavior. The analytical technique is quite general and is expected to find broad application in science and engineering. The paper highlights NIST work that has helped to create a revolution in voltage standards, bringing greatly improved accuracy to national and industrial standards laboratories around the world.

\section{American Physical Society (APS)}

\section{APS Fellow}

\section{Marvin E. Cage}

Marvin E. Cage was elected a Fellow of the American Physical Society for excellence in measurement research that led to an accurate experimental SI determination of the quantized Hall resistance and adoption of the quantum Hall effect as the new international standard for resistance. Cage received a Department of Commerce Gold Medal as a member of a NIST team that made essential contributions to the 1990 international adjustment of electrical units. He is a member of the Fundamental Electrical Measurements Group in the Electricity Division.
InTERnATIONAL Union OF RADIO SCIENCE

(URSI) Young SCIENTIST Award

\section{Donald DeGroot}

Donald DeGroot of the Electromagnetic Fields Division received the URSI Young Scientist Award at the XXVth General Assembly in Lille, France. The Young Scientist program recognizes the work of scientists and engineers early in their careers and encourages international cooperation through travel support for the recipients and through Young Scientist events held during the conference.

The award also recognizes the specific research submitted by the recipient. During the conference DeGroot presented an invited talk, Heasurement Errors in Time-Domain Neturork Analyzers using Multiline TRL Calibration. The presentation covered recent developments in the Electromagnetic Fields Division on the application of time-domain instruments to frequency-dependent measurements of microelectronic devices and interconnects. This work has produced a low-cost measurement system with good accuracy to $12 \mathrm{GHz}$ and has identified potential solutions to significantly extend the frequency range of accurate time-domain network analisis.

\section{INSTITUTE OF ELECTRICAL AND ELECTRONICS}

\section{ENGINEERS (IEEE)}

\section{IEEE FELLOWS}

\section{Barry A. Bell}

Barry A. Bell was elected a Fellow of the Institute of Electrical and Electronics Engineers by its Board of Directors. Bell was cited for technical leadership in the development of analog electronic standards based on digital technology. He is a Department of Commerce Silver Medal recipient and the Leader of the Electronic Instrumentation and Metrology Group in the Electricity Division. 
Herbert S. Bennett

Herbert S. Bennett has been elected a Fellow of the Institute of Electrical and Electronics Engineers by its Board of Directors. Bennett was cited for contributions to modeling heary doping and transport physics in semiconductors. He served an appointment as a Commerce Science and Technology Fellow and was named by the Maryland Academy of Sciences as its Outstanding Young Scientist in 1970. Bennett is a Senior Research Scientist in the Semiconductor Electronics Division.

\section{IEEE Power Engineering Society}

1997 Working Group Recognition AwARd

High Voltage Test Techniques (HVTT)

SUBCOMMITTEE:

\section{Gerald J. FitzPatrick}

Robert E. Hebner

Ronald H. McKnight

Martin Misakian

Oskars Petersons

The Institute of Electrical and Electronics Engineers (IEEE) Power Engineering Society (PES) awarded its 1997 Working Group Recognition Award to the High Voltage Test Techniques (HVTT)

Subcommittee for the publication of the revision to IEEE Standard 4, Standard Techniques for High Voltage Testing. Members and former members of the Electricity Division and predecessor organizations contributing to the revision through membership in HVTT since 1979, when the Standard was last revised, include Gerald J.FitzPatrick, NIST Acting Director/Acting Deputy Director Robert E. Hebner, Ronald H. McKnight, Martin Misakian, and Oskars Petersons.

The PES recognizes its working groups with two awards given annually: one for the best technical report and the other for the best standard or guide.
NIST has provided significant technical support to the development of this revision of Standard 4, particularly in the sections covering the measurement of impulse high voltages. A convolution technique developed at NIST has been incorporated into Standard 4 as one of the tests for qualifying high-voltage impulse dividers. This technique checks the temporal response of dividers with a low-voltage step pulse to determine if they are suitable for measuring impulses having microsecond risetimes. The digitized response is mathematically convolved with an analytic waveform of the type to be measured. A comparison of the resultant waveform to the analytic input waveform then shows if the divider introduces significant measurement errors.

The latest revision of Standard 4 is the seventh edition of a document that has existed as a separate standard since 1928. (Historical note: the subject of high-voltage measurements was addressed in the earliest Standardization Report of the American Institute of Electrical Engineers (AIEE) in 1889.) The seventh edition incorporates major changes from the sixth, including new tests such as the convolution test described above. In addition to the PES Working Group Recognition Award, HVTT's development of the new edition was recognized in 1996 by the IEEE Power System Instrumentation and Measurements (PSIM) Committee for "producing the best standard of the previous three years."

Microbeam Analysis Society

MACRES AWARD

David A. Wollman

Gene C. Hilton

Kent D. Irwin

John M. Martinis

EEEL Electromagnetic Technology Division members David A. Wollman, Gene C. Hilton, Kent 
D. Irwin, and John M. Martinis received the Macres Award, conferred by the Microbeam Analysis Society for the Best Instrumentation or Software Paper presented last to the Society. The group's paper, entitled EDS X-ray' Microcalorimeters uith $13 \mathrm{eV}$ Energy Resolution, was presented at the 30th annual conference of the society and heralded a breakthrough in detector technology. The most common EDS (energy dispersive spectroscopy) detectors in use, based on silicon or germanium, are limited in energy resolution to about $100 \mathrm{eV}$ and often fail to resolve closely spaced lines encountered in $x$-ray fluorescence microanalysis. A new detector was the focus of the breakthrough. The detector, which measures the energy of an $X$-ray photon by recording the temperature rise of a metallic absorber cooled to $0.1 \mathrm{~K}$, has sufficient energy resolution to completely resolve the closely spaced characteristic lines of silicon and tungsten, materials of importance in the semiconductor industry that are difficult to distinguish with conventional detectors.

\section{National ACADEmy of Engineering (NAE)}

NAE Frontiers of ENGINEERING

\section{SYMPOSIUM}

\section{Roger B. Marks}

Among those invited to participate in the second Frontiers of Engineering Symposium in Irvine, California was Roger B. Marks of the Electromagnetic Fields Division. The Academy's strategy was to convene "select group of engineers from disparate fields and challenge them to think about developments and problems at the frontiers of areas different from their own." The selection committee, headed by Robert Brown, Dean of Engineering at MIT, was charged with identifying about 100 "outstanding leaders, generally between the ages of 30 and 45 years."
To meet Symposium goals, the organizers selected outstanding talks in the areas of Design Research, Visualization for Design and Display, Innovations in Materials and Processes, and

Microelectromechanical Systems (MEMS). Dr. John Armstrong, retired Vice President of Science and Technology of IBM, attended the meeting and gave an evening address on the role of industrial. academic, and government research in a downsized environment.

\section{National Conference}

OF STANDARDS LABORATORIES

Dr. Allen V. Astin Award

Samuel P. Benz

Clark A. Hamilton

Charles J. Burroughs

Todd Harvey

Lawrence Christian

A paper on Josephson ac voltage standards earned a team of scientists from EEEL's Electromagnetic Technology Division, including Samuel P. Benz, Clark A. Hamilton, Charles J. Burroughs, Todd Harvey, and visiting scientist Lawrence Christian, the Dr. Allen V. Astin Award, which is conferred by the National Conference of Standards Laboratories for the best paper presented at the $199^{-}$Simposium.

Their paper, entitled "Josephson Standards for AC Voltage Metrology," describes a method of synthesizing voltage waveforms by adding together billions of carefully timed quantized voltage pulses. The method is implemented on an integrated circuit chip with over 32,000 active superconductive devices. The chip can be used to synthesize sine wares at frequencies up to $1 \mathrm{MHz}$. Since the amplitude of these sine waves is directly calculable from the Josephson representation of the volt, the new technique represents a promising new approach to ac voltage metrology. 


\section{Appendix}

\section{TABLE 1: EEEL PROGRAMS AND THEIR PROJECTS}

PROGRAMS

OFFICE OF MICROELECTRONICS PROGRAMS
PROJECTS

National Semiconductor Metrology Programs

\begin{tabular}{|c|c|}
\hline SEMICONDLCTORS & Metrology for Nanoelectronics \\
\hline & Optical Characterization Metrology \\
\hline & Scanning-Probe Microscope Metrology \\
\hline & Thin-Film Process Metrology \\
\hline & Silicon-on-Insulator Metrology \\
\hline & Metrology for Simulation and Computer-Aided Design \\
\hline & Metrology for Process and Tool Control \\
\hline & Interconnect Reliability Metrology \\
\hline & Dielectric Reliability Metrology \\
\hline & Micro-Electro-Mechanical Systems (MEMS) \\
\hline & Plasma Chemistry - Plasma Processing \\
\hline
\end{tabular}

\begin{tabular}{l||l}
\multicolumn{1}{l||}{ MAGNETICS } & Magnetic Recording Technology \\
\hline \multirow{2}{*}{ Magnetic Instruments and Materials Characterization } \\
\cline { 2 - 3 } & Nanoprobe Imaging for Magnetic Technology
\end{tabular}

Superconductor Interfaces and Electrical Transport

High Performance Sensors, Converters, and Mixers

Josephson Array Development

Nanoscale Cryoelectronics

High- $\mathrm{T}_{\mathrm{C}}$ Electronics

Superconductor Standards and Technology

LOW FREQLENCY
AC-DC Difference Standards and Measurement Techniques

Waveform Acquisition Devices and Standards

Waveform Synthesis and Impedance Metrology

Measurements for Complex Electronic Systems 


\begin{tabular}{|c|c|}
\hline MICROWAVES & IIigh-Speed Microelectronics Metrology \\
\hline \multirow[b]{7}{*}{ LIGHTWAVES } & Power Standards and Measurements \\
\hline & Impedance, Voltage Standards and Measurements \\
\hline & Network Analysis and Measurements \\
\hline & Noise Standards and Measurements \\
\hline & Antenna Measurement Theory and Application \\
\hline & Metrology for Antenna, Radar Cross Section and Space Systems \\
\hline & Dielectric Materials and Devices \\
\hline & Semiconductor Materials and Devices \\
\hline & Fiber and Discrete Components \\
\hline & Integrated Optics Metrology \\
\hline & Optical Fiber Sensors \\
\hline & Optical Fiber Metrology \\
\hline & High Speed Source and Detector Measurements \\
\hline & Laser Radiometry \\
\hline VIDEO & Video Technology \\
\hline
\end{tabular}

\begin{tabular}{l||l} 
POWER & Dielectrics Research \\
\hline & Metrology for Electric Power Systems
\end{tabular}

\begin{tabular}{l||l} 
NATIONAL ELECTRICAL STANDARDS & Ohm and Farad Realization and Dissemination \\
\hline & Quantum Voltage and Current
\end{tabular}

\begin{tabular}{l||l} 
ELECTROMAGNETIC COMPATIBILITY & Standard EM Fields and Transfer Probe Standards \\
\hline & Emission and Immunity Metrology \\
\cline { 2 - 2 } &
\end{tabular}

Electromagnetic Properties of Materials

\begin{tabular}{l||l} 
ELECTRONIC DATA EXCHANGE & Integrated Infrastructure for Electronics Design \\
\hline & Infrastructure for Integrated Electronics Manufacturing
\end{tabular}


TABLE 2: EEEL ORGANIZATIONS AND THEIR PROJECTS

ORGANIZATIONS:

OFFICES AND DIVISIONS

PROJECTS

SEMICONDLCTOR ELECTRONICS DIVISION

\begin{tabular}{||l|} 
Metrology for Nanoelectronics \\
\hline Optical Characterization Metrology \\
\hline Scanning-Probe Microscope Metrology \\
\hline Thin-Film Process Metrology \\
\hline Metrology for Simulation and Computer-Aided Design \\
\hline Silicon-on-Insulator Metrology \\
\hline Metrology for Process and Tool Control \\
\hline Interconnect Reliability Metrology \\
\hline Dielectric Reliability Metrology \\
\hline
\end{tabular}

Micro-Electro-Mechanical Systems (MEMS)

OFFICE OF MICROELECTRONICS PROGRAMS

National Semiconductor Metrology Programs

ELECTRICITY DIVISION

Plasma Chemistry - Plasma Processing

AC-DC Difference Standards and Measurement Techniques

Waveform Acquisition Devices and Standards

Waveform Synthesis and Impedance Metrology

Measurements for Complex Electronic Systems

Video Technology

Dielectrics Research

Metrology for Electric Power Systems

Ohm and Farad Realization and Dissemination

Quantum Voltage and Current

Integrated Infrastructure for Electronics Design

Infrastructure for Integrated Electronics Manufacturing 
High Speed Microelectronics Metrolog:

Power Standards and Measurements

Impedance, Voltage Standards and Measurements

Network Analysis and Measurements

Noise Standards and Measurements

Antenna Measurement Theory and Application

Metrology for Antenna, Radar Cross Section and Space Srstems

Standard Electromagnetic Fields and Transfer Probe Standards

Emission and Immunity Metrology

Electromagnetic Properties of Materials

FLECTROMAGAETIC TECHNOLOGY DIVTSION

Nanoprobe Imaging for Magnetic Metrology

Magnetic Instruments and Materials Characterization

Magnetic Recording Metrology

Superconductor Interfaces and Electrical Transport

High-Performance Sensors, Converters, and Mixers

Josephson Array Development

Nanoscale CrToelectronics

High- $\mathrm{T}_{\mathrm{C}}$ Electronics

Superconductor Standards and Technology

OPTOELECTRONICS DIVISION

Dielectric Materials and Devices

Semiconductor Materials and Devices

Fiber and Discrete Components

Integrated Optics Metrology

Optical Fiber Sensors

Optical Fiber Metrology

High Speed Source and Detector Measurements

Laser Radiometry

OFFICE OF LAW ENFORCENENT STANDARDS

Enabling Technologies for Criminal Justice Practitioners 


\section{EEEL FY 1997 RESOURCES}

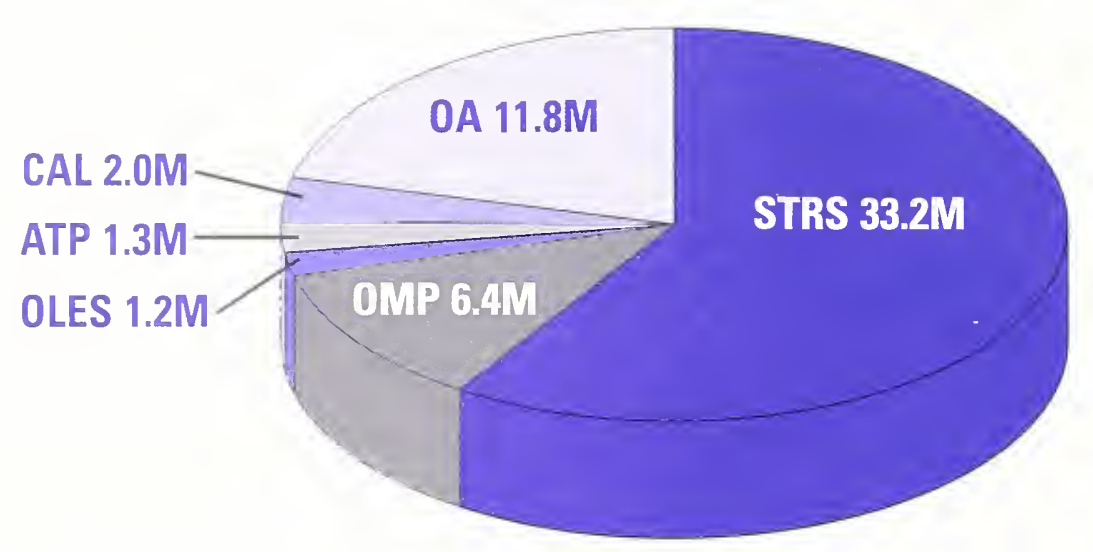

The funds used to operate the Electronics and Electrical Engineering Laboratory (EEEL) are derived from several sources. Scientific and Technical Research and Services (STRS) funds are direct Congressional appropriations. Advanced Technology Program (ATP) funds are provided by the program of the same name at NIST. Calibration funds are received for performing calibration services for industry and government. Other agency funds (OA) may be obtained from a variety of sources, including other Federal agencies, non-Federal government organizations, cooperative research and development agreements (CRADAs), and NIST internal calibration and standard reference material (SRM) development funds. The Office of Microelectronics (OMP) and the Office of Law Enforcement Standards (OLES) funds cited are for support to NIST Laboratories external to EEEL.

\section{EEEL FY 1997 CRADAs}

EEEL participated in 45 cooperative research and development agreements (CRADAs) with industry during FY 1997. CRADA participants included large and small companies across the nation. EEEL actively seeks industrial, academic, and non-profit partners to work collaboratively on projects of mutual benefit. Special efforts are made to tailor cooperative programs to the individual needs of research partners. CRADAs typically cover joint research efforts in which both NIST and the cooperating company provide staff, equipment, facilities, and/or funds, in any number of possible combinations for a project of mutual interest. Under a CRADA, NIST can protect confidential or proprietary information exchanged during the project, keep research results confidential, and provide exclusive rights for intellectual property developed. EEEL welcomes industry to collaborate on projects of mutual interest through the CRADA format. A detailed directory of research areas available for cooperative research, entitled Guide to NIST, can be obtained at no cost using fax number: (301) 926-1630. 


\section{ORGANIZATION}

Advanced Micro Devices

Analogy, Inc.

Astralux, Inc.

Bell Laboratories/Lucent Technologies

Benchmark Technologies, Inc.

BIO-Rad Laboratories, Ine.

Cascade Microtech, Inc.

Crystal Technology, Inc.

Digital Equipment Corporation

Digital Instruments, Inc.

Digital Instruments, Inc.

Digital Semiconductor

EMAG Technologies, Inc.

General Electric Company

Hewlett Packard Company

Honewwell, Inc.

Hughes Aircraft Company

IMRA America, Inc.

International Business Machines Corp.

Keithleỵ Instruments, Inc.

Keithley Instruments, Inc.

KLA Instruments

KLA Instruments

Lancaster Lniversity

Nanometrics Incorporated

Opal Inc.

Optical E.T.C., Inc.

Optical Specialties, Inc.

Photronics, Inc.

Quantum Design

Renishaw PLC

RF Microsystems (NRAD)

Schott Glass Technologies, Inc.

Science Applications International Corp.

SEMATECH

SEMATECH

SEMATECH

Tektronix Federal Systems, Inc.

Texas Instruments

Texstar, Inc.

The Regents of the University of Colorado

TRIV, Inc.

U.S. Air Force Base, Newark AFB

VLSI Standards, Inc.

VLSI Standards, Inc.
PROJECT TITLE

Evaluation of Single-Crystal CD-Reference Materials Consortium

Power Semiconductor Devices in Electronic Circuits

Processing of GaN Derices

Evaluation of Single-Citstal CD-Reference Materials Consortium

Evaluation of Single-Cițstal CD-Reference Materials Consortium

Scanning Capacitance and Electromagnetic Sensor Consortium

MMIC Consortium

Analysis of Lithium Niobate Wafers

Dielectric/Silicon Interface Property Measurements on Digital Transistors

Scanning Capacitance and Electromagnetic Sensor Consortium

Evaluation of Single-Citstal CD-Reference Materials Consortium

Evaluation of Single-Crystal CD-Reference Materials Consortium

High-Frequency Characterization of Low-Loss Materials

Parameter Extraction for High Power IGBTs

MMIC Consortium

Optical Fiber Sensors

MMIC Consortium

Rare-Earth Doped Waveguide DBR Lasers and Polarization Discriminating

Receivers

Thin Film for Magnetic Storage Media

Electrical CD Test Structures

Evaluation of Single-Crystal CD-Reference Materials Consortium

Evaluation of Single-Crystal CD-Reference Materials Consortium

Scanning Capacitance and Electromagnetic Sensor Consortium

Scanning Capacitance and Electromagnetic Sensor Consortium

Evaluation of Single-Crystal CD-Reference Materials Consortium

Evaluation of Single-Crystal CD-Reference Materials Consortium

Integrated Dynamic Thermal Emitter Arrays

Evaluation of Single-Crystal CD-Reference Materials Consortium

Evaluation of Single-Crystal CD-Reference Materials Consortium

Improved SQUTD Magnetometer Measurement Testing

Evaluation of Single-Crystal CD-Reference Materials Consortium

Microwave CMOS Micromachined Power Systems

Rare-Earth-Doped Waveguide Laser Structures and Photosensitivity in Bulk Glass

Infrared Imaging with Microantenna Arrays

Semiconductor Technology and Processes

Scanning Capacitance and Electromagnetic Sensor Consortium

Evaluation of Single-Crystal CD-Reference Naterials Consortium

Transmission Line Characterization Using Time-Domain Instrumentation

MMIC Consortium

Optical Fiber Electric Field Sensors

General Agreements for Collaborative Research in Optical Electronics

MMIC Consortium

MMIC Consortium

Evaluation of Single-Crystal CD-Reference Materials Consortium

Thin Films Standard Reference Material Development 


\section{EEEL Laboratory Headquarters}

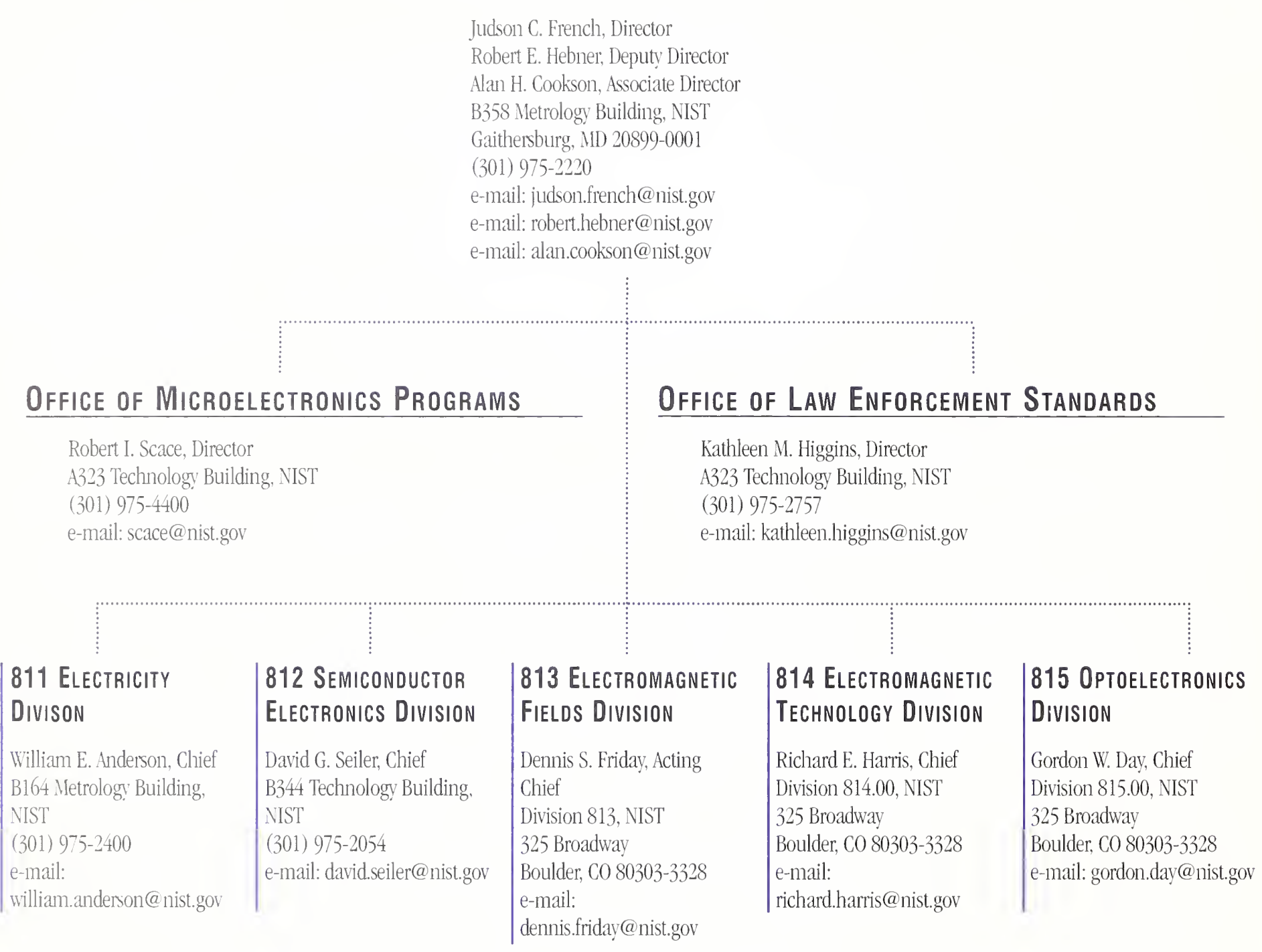

The Electronics and Electrical Engineering Laboratory comprises five divisions and two offices. Laboratory Headquarters, the Electricity Division, the Semiconductor Electronics Division, the Office of Microelectronics Programs, and the Office of Law Enforcement Standards are located in Gaithersburg, Maryland. The Electromagnetic Fields Division, the Electromagnetic Technology Division, and the Optoelectronics Division, which was formed in FY 1994, are located in Boulder, Colorado. 


\section{Laboratory Headquarters}

\section{Laboratory Headquarters}

2220 FrENCH, Judson C., Director

e-mail: judson.french@nist.gov

2220 PALLA, Jenilie C., Secretary

2220 HEBNER, Robert E., Deputy Director e-mail: robert.hebner@nist.gov

2220 COOKSON, Alan H., Associate Director e-mail: alan.cookson@nist.gov

2220 SACCHET, Linda I., Secretary

2220 MAYO-IVELLS, J. Franklin, Staff Asst.
2220 POWELL, Ronald MI. Scientific Asst.

2665 RLSSELd, Thomas J., Vigr., (optical Computing Coop. Prog.

5267 SURE'TEE, JoAnne M., Information Specialist

2228 HORNUT'H, James A., Exec. Officer

2220 GONZALEZ, Josephine A., Secretary

\section{Administrative Support-Gaithersburg}

2227 HAMILTON, Darlene, Admin. Ofr.

2229 JOHNSON, Margie I., Admin. Ofr.

2230 THOMAS, S. Michael, Admin. Ofr.

\section{Office Of Microelectronics Programs}

4400 SCACE, Robert I., Director e-mail:scace@nist.gov

4400 SETTLE-RASKIN, Alice, Secretary

2871 KNIGHT, Stephen, Senior Scientist

2040 GRAlATT, Cary, Assoc. Director

\section{Administrative Support-Boulder}

3813 ANDRUSKO, Gaynel k., Admin. Ofr.

3514 GLAZE, Terry L., Ofr. Asst.

3812 SCHUMP, Jeanne, Admin. Ofr.

3811 QUARTEMONT, Heidi, Admin. Asst.

5342 McCOLSKEY, Kathy, Admin. Ofr.

5123 DERR, Linda S., Admin Ofr. Asst.

\section{Office Of Law Enforcement Standards}

Office of Microelectronics Programs (OMP) matrixmanages a NIST-wide program responding to the measurement requirements of the semiconductor industry. It provides integrated circuit manufacturers, materials suppliers, and makers of semiconductor manufacturing equipment with a clear window on the entire NIST organization. OLP offers direct access to an enormously varied range of scientific and technical expertise. In addition, OMP manages NIST's strong working relationship with SEMATECH, the consortium of U.S. semiconductor manufacturers, and with many of its member firns. Research priorities are established on the basis of industry input and the Office's participation in domestic and international conferences and planning activities. The National Semiconductor Vletrology Program (NSIP), which was established in 1994, draws on the full range of NIST expertise in semiconductor electronics, manufacturing engineering, chemical and materials science engineering, and fundamental science. NSMP is also managed by the Office of Microelectronics Programs.

Office of Law Enforcement Standards (OLFS) supports law enforcement agencies through the development of measurement methods and techniques for testing devices used in such applications as tracking vehicles, speed monitoring, surveillance. communications, and counterterrorism efforts. The office develops minimum perfonnance standards for issuance by the National Institute of Justice as voluntary national standards. Its mission is to assist federal, state, and local law enforcement agencies to apply new technology efficiently; effectively: and safely. OLES draws upon the technical expertise and resources of all of NISH in its support missions for the National Institute of Justice (NIJ). NIJ is the research arm of the Department of Justice and the National Highway Traffic Safety Administration, which is part of the Department of Transportation.

The areas of research investigated by this Office include clothing. communication systems, emergency equipment, investigative aids. protective equipment, security systems, vehicles, weapons, and analytical techniques and standard reference materials used by the forensic science community: In the past fiscal year, OLES has focused on supporting .VI and law enforcement agencies in identifying those standards that are high priority requirements for providing direct support in counterterrorism efforts. In the year to come, the task will be to focus on expanding existing law: enforcement standards and testing prograns to include selected counterterrorism technologies and equipment. 


\title{
811.00-Electricity Division
}

\author{
2400 ANDERSON, William E., Chief \\ e-mail: william.anderson@nist.gov
}

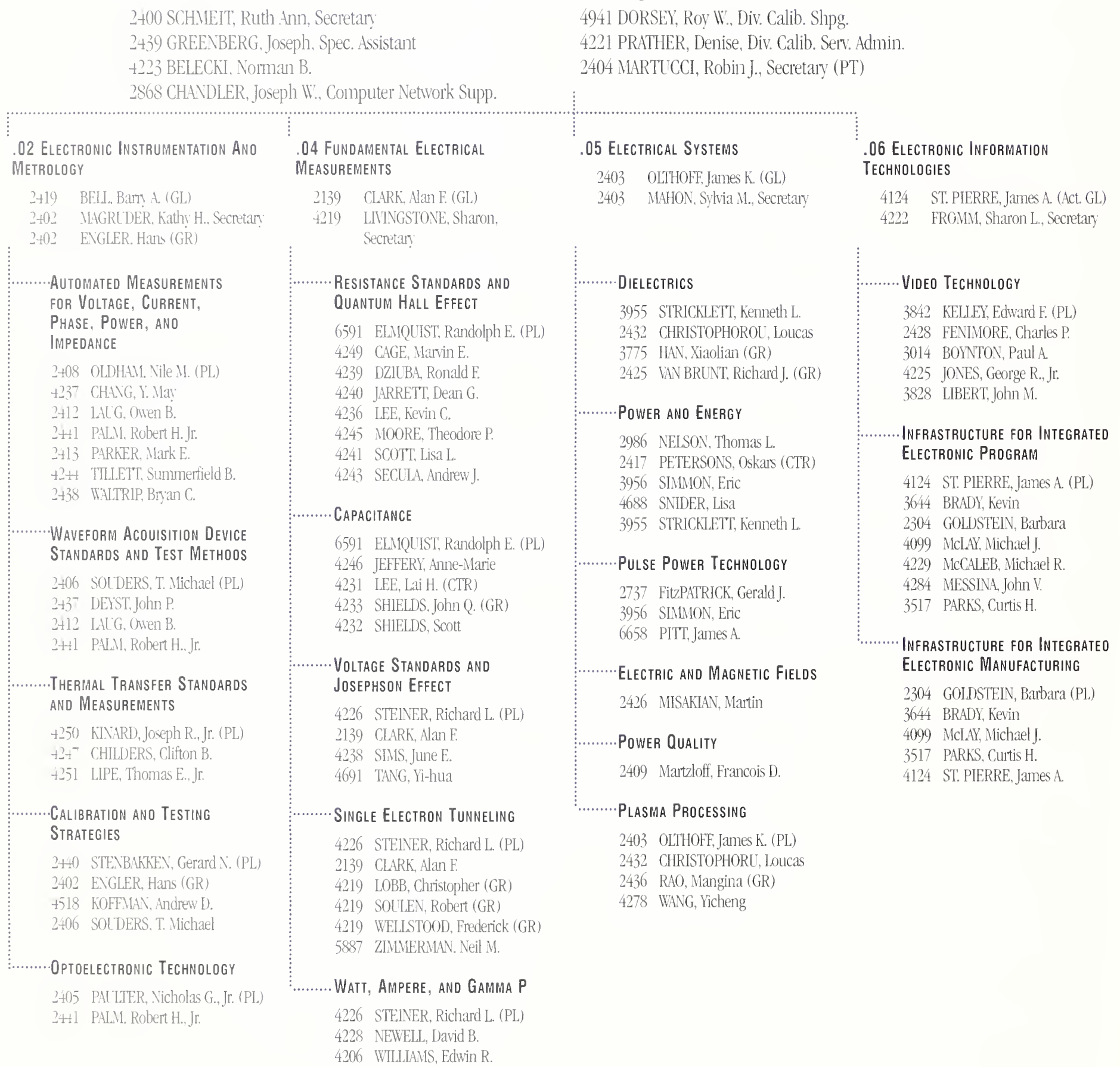

The Electricity Division maintains and improves the national standards of electrical measurement and develops stable standards for the dissemination of the units of electrical measure. Another major responsibility of this Division is to realize the electrical units in terms of the International System (SI) and determine the fundamental constants related to electrical units. The Division is responsible for providing calibration services, and developing and improving the measurement methods and services needed to support electrical materials, components, instruments, and systems used for the generation, transmission, and application of conducted electrical power. In addition, members of this division apply their expertise to selected scientific and technological problems in other areas of NIST research, including research on video technology and electronic product data exchange. 


\title{
Semiconductor Electronics Division
}

\subsection{0-Semiconductor Electronics Division}

\author{
2074 SEILER, David G., Chief \\ e-mail: david.seiler@nist.gor
}

\begin{abstract}
$205+$ MAIN, Brenda P., Secretary
2097 HARIAN, George G., NIST Fellow

2079 BENNETT, Herbert S., Senior Research Scientist

2054 CROWE, Cheryl D., Secretary (PT)

2242 BUCK, Laurence NI., Computer Facility Mgr.

(Property Officer)
\end{abstract}

2050 WALTERS, E. Jane, Lead Editorial Assistant

2296 ROHRBAI GH, Janet M., Editorial Assistant

2055 OETTINGER, Frank F. (GR)

2048 LOWNEI, Jereniah R. (GR)

\section{Materials technology}

$20^{\top} 9$ BENNE'T', Herhert S. (Act. GL)

2081 ROACH, Ramona K., Secretary

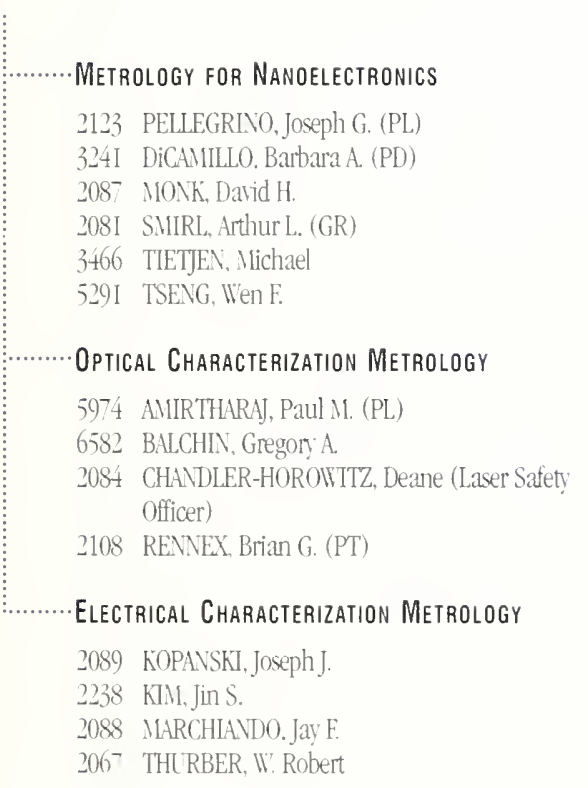

\section{.03 Device Technology}

2068 BLACKBLRN, David L.. (GL.)

2053 LAMBERT, Barbara Secretary

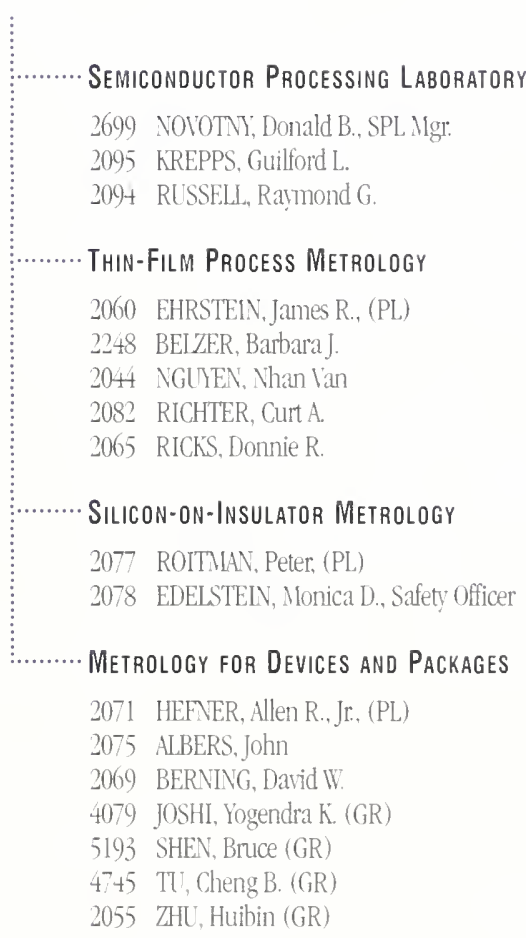

\begin{tabular}{|c|c|}
\hline \multicolumn{2}{|c|}{ LEGEND: } \\
\hline CON = CONSCLTANT & $\mathrm{GR}=$ GUEST RESEARCHER \\
\hline $\mathrm{CU}=$ CONTRACT WTH LNIERSITY & GS = GRADLATESTLDENT \\
\hline $\mathrm{CP}=$ COOPERATTIE EDLCATION PROG. & $\mathrm{N} / \mathrm{F}=$ NIST FELLOW' \\
\hline CTR $=$ CONTRACTOR & PD $=$ POSIDOCTORALAPPOINTMENT \\
\hline FH = FACUATY HIRE & PL $=$ PROJECT LEADER \\
\hline FTT = FUILTINE TE\P. & PT $=$ PART TINE \\
\hline GRF = GRADUATE RESEARCH FELLOW & $S=$ STLDENT \\
\hline $\mathrm{GL}=$ GROUP LFADER & $\mathbb{I I S}=\mathbb{W O R K S T U D Y}$ \\
\hline
\end{tabular}

The Semiconductor Electronics Division (SED) provides leadership in the derelopment of the semiconductor measurement infrastructure essential to improving U.S. economic competitiveness. The Division provides measurement methods, phrsical standards, and supporting data and technology; any associated generic technology; and fundamental research results to industry, goremment, and academia.
SED's primany focus is on mainstream silicon, but the Division's programs also respond to industry measurement needs related to compound semiconductors, power derices, and silicon-on-insulator derices. SED plans and implements its programs in cooperation with the semiconductor industry, its suppliers, and its customers to assure that the critical needs of the community are being addressed. To enhance the Division s effectiveness. SED collaborates and partners with industry: academia. other goremment agencies, and standards organizations.

\author{
.04 IC TeChnology \\ 2052 LINHOLWL, Lonen II. (Gl.) \\ 2052 IIILKkS, Jane VI. Secretary

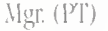 \\ 2820 OSEBANJO. Olanrewaju \\ $20^{72}$ CRESSWELL, Uichael IN: (PL.) \\ 5026 ALLE... Richard A. \\ $4+46$ GHOSHTAGORE: Rathindra V. (G,R) \\ 5623 ONEN. James C. \\ ....... Interconnect Reliability Metrology \\ 2234 SCHAFFT. Ham A. (PL) \\ 2045 WHAYO Santos \\ 2241 SCHISTER, Constance E.

\section{- Dielectric Reliability Metrology} \\ 2247 SLEHLE, John S. Suehle (PL) \\ 2III CHEX, lian (GR) \\ Microelectromechanical Systems \\ $20^{7} 0$ GATTAN, Wichael (PL) \\ 5484 GEIST, Jon ( $(\mathrm{iR})$ \\ 4739 HOPCROFT, Hatthew (GR) \\ 2049 . MARSHALL Janet C. (PT) \\ 4706 MIILANONIC, Velijko (GR) \\ t960 OZGLR. Hehmet (GR) \\ 5193 RAlLAl, Rajkumar (GR) \\ 2239 Z\$GHLOL L. Ylona F. (FH) \\ $20^{7} 3$ ZINCKE, Christian A. (GRF)
}




\subsection{0-Electromagnetic Fields Division}

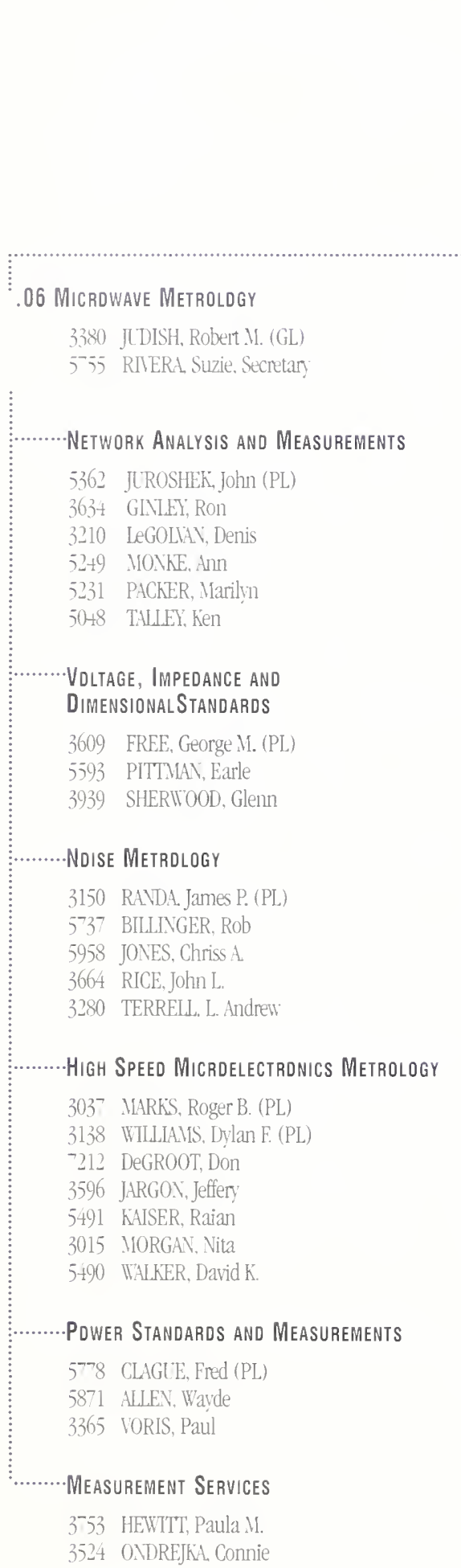

3131 FRIDAY, Dennis S., Act. Chief e-mail: demnis.friday@nist.gov

3132 LYONS, Ruth Marie, Secretary

3557 REEVE, Gerome R.

5284 DeLARA, Puanani L., Property Ofr.

\section{.07 Fields \& Interference Metroldgy \\ 5320 KANDA, Motohisa (GL) \\ 3321 HAAKINSON, Edit, Secretary

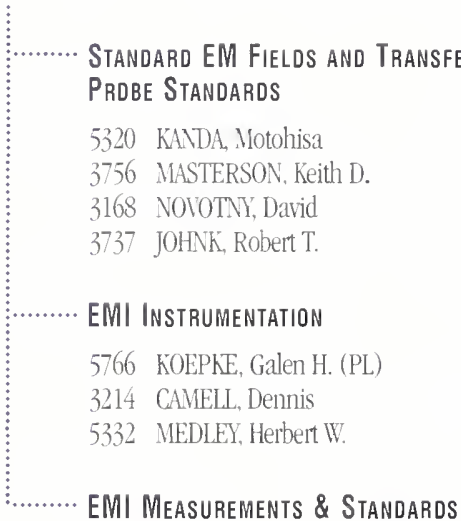 \\ 3472 HILL, David A. (PL) \\ 3995 CAYCEY, Kenneth A. \\ 5854 KAIVALKO, Stephen F. \\ 5372 LADBURY, John M. \\ .08 Antenna and Materials Metrology \\ 5703 REPJAR, Andrew G. (GL) \\ 3302 SANJERA, Sharon L., Secretary

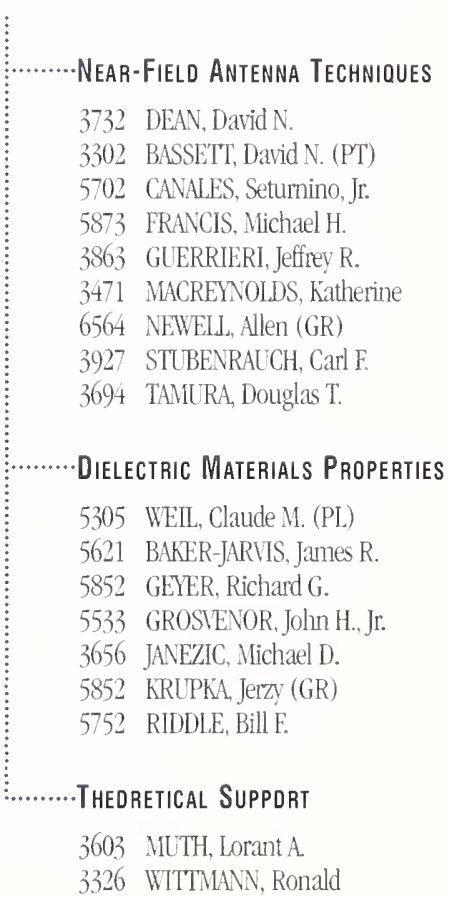

The Electromagnetic Fields Division develops and evaluates systems, devices, and methods for the measurement and analysis of radio-frequency electromagnetic fields, signals, noise, and interference. Other areas of investigation within the purview of this Division are the properties of materials for guided and freely propagated fields, including frequency and time-domain representation of electromagnetic fields and their interaction with materials and structures. The Division provides essential measurement and calibration services that enable industry and government to solve important national, commercial, industrial, and military problems. The Division routinely works with microwave and millimeter wave systems, components, and materials used in advanced radars, satellite and mobile communications, and automated test systems.
Assistance is also provided to other agencies to solve measurement-related issues, such as determining levels of nonionizing radiation and solving electromagnetic interference problems. The Division's principal program areas include microwave and millimeter wave metrology for continuous wave transmission line measurements, noise and dielectric measurements, antenna metrology, and fields and interference metrology. These services and associated standards provide a consistent base of measurements to enable contractors in the defense, aerospace, and communications industries to assemble complete systems and perform the stringent performance assessments which are required. 


\section{Electromagnetic Technology Division}

\subsection{0-Electromagnetic Technology Division}

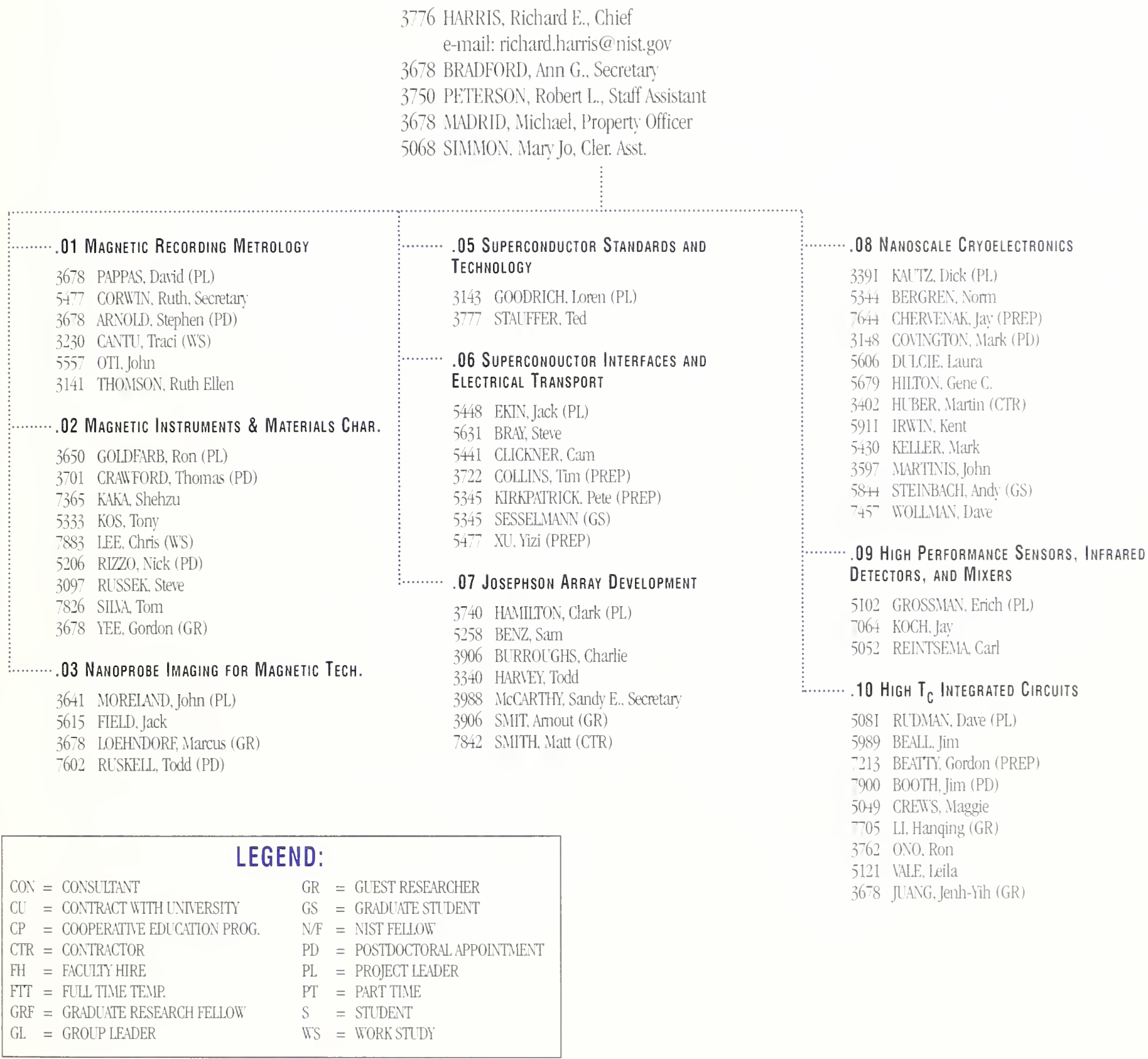

The Electromagnetic Technology Division develops and promotes adranced standards and measurement methods for the magnetics, cryogenic electronics, and superconductor industries and their scientific communities. The Dirision emplors phenomena based on magnetics, superconductivity. and cryoelectronics to create new standards, apparatus, and measurement technolog; advancing the state-of-the-art by basic research and the development of requisite materials, fabrication techniques, and metrolog: This Division leads the intemational community in setting standards for the measurement of superconductor parameters, and provides metrology infrastructure needed for the industrial derelopment of both large- and small-scale superconductors.
For the magnetics industry, the Dirision provides new measurements, instrumentation, imaging and characterization tools and standards. In addition, with support from theoretical studies and modeling, the Division develops measurement technolog! to determine basic properties of magnetic materials and structures. The Division collaborates with the magnetic recording industry in the development of metrology to support future recording heads and media with their erer-increasing data density: For the superconductor industry, the Division uses the unique properties of superconductors to invent and improve measurement methods for electromagnetic signals ranging from static voltages and magnetic fields through audio, microware, infrared, visible, and $\mathrm{x}$-ray frequencies. 


\subsection{0-Optoelectronics Division}

\begin{tabular}{|c|c|c|c|}
\hline & \multicolumn{2}{|c|}{$\begin{array}{l}5204 \text { DAl, Gordon W., Chief } \\
\text { e-mail:gordon.day@nist.gov } \\
\text { 5342 SuITH, Annie J., Secretary }\end{array}$} & \multirow[b]{2}{*}{$\begin{array}{l}.04 \text { Optoelectronic } \\
\text { Manufacturing } \\
3455 \text { HICKERNELL, Robert K. (GL) } \\
5187 \text { METZ, Sara E., Secretary } \\
3942 \text { AUST, Andy J. } \\
5069 \text { BERTNESS, Kristine A. } \\
3354 \text { CHRISTENSEN, David H. } \\
3289 \text { FUNK, David S. (PREP PD) } \\
3234 \text { HAYS, Scott (PREP GS) } \\
7368 \text { KNOPP, Kevin J. (PREP GS) } \\
7955 \text { MIRIN, Richard P. } \\
7300 \text { PETERS, Phil M. (GR) } \\
5420 \text { ROSHKO, Alexana } \\
5239 \text { SANFORD, Noman A. (PL) } \\
7953 \text { SLNAAN, Christopher C. (PT) } \\
5952 \text { VEASEY, David L. }\end{array}$} \\
\hline \multirow[t]{3}{*}{ 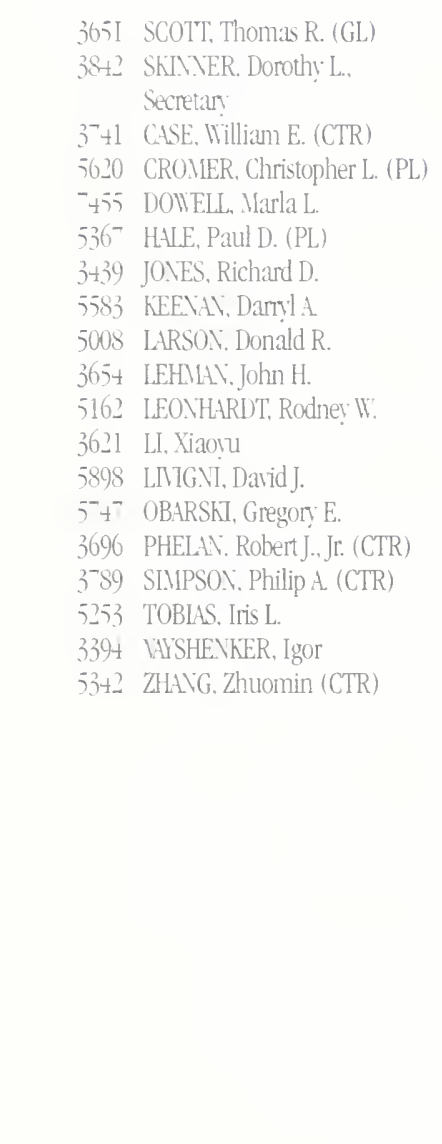 } & 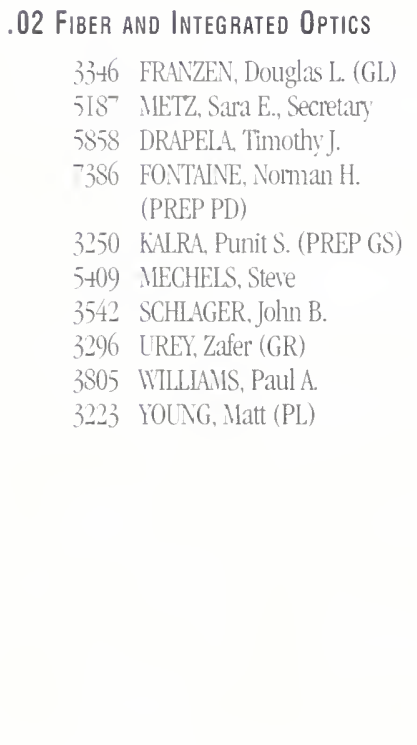 & 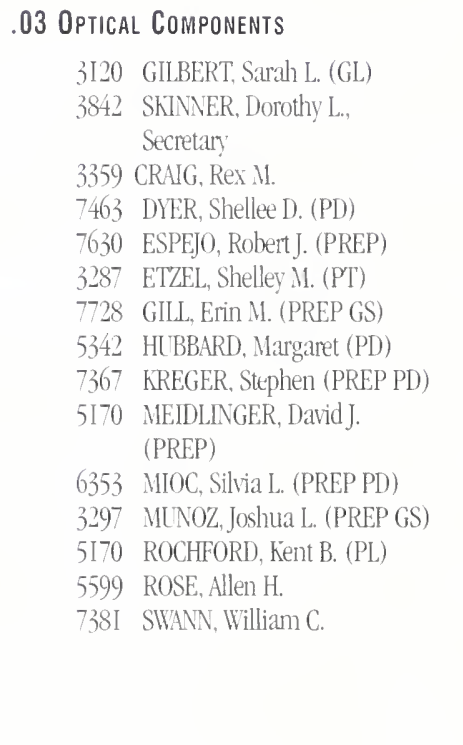 & \\
\hline & & \multicolumn{2}{|c|}{ LEGEND: } \\
\hline & & $\begin{array}{l}\text { CON = CONSLLTANT } \\
\text { CU = CONTRACT WITH LNIVERSITY } \\
\text { CP = COOPERATIVE EDLCATION PROG. } \\
\text { CTR = CONTRACTOR } \\
\text { FH = FACLLTY HIRE } \\
\text { FTT = FULL TINE TEMP. } \\
\text { GRF = GRADLATE RESEARCH FELLOW } \\
\text { GL = GROLP LEADER } \\
\text { GR = GLEST RESEARCHER }\end{array}$ & $\begin{array}{l}\text { GS = GRADUATE STUDENT } \\
\text { N/F = NIST FELLOW' } \\
\text { PD = POSTDOCTORAL APPOINTMENT } \\
\text { PL = PROJECT LEADER } \\
\text { PREP = PROFESSIONAL RES. } \\
\quad \text { EXPERIENCE PROG. } \\
\text { P'T = PART TIME } \\
S=\text { STLDENT } \\
\text { WS = WORK STUDY }\end{array}$ \\
\hline
\end{tabular}

The Optoelectronics Division is committed to providing the optoelectronics industry and its suppliers and customers with comprehensive and technically advanced measurement capabilities, standards, and traceability to those standards. The Division achieves these objectives by developing and evaluating measurement techniques, and by developing and disseminating reference data, standard reference materials and components. Providing measurement services and participating in industry-wide efforts toward measurement standardization are also part of this Division's strategy to support the characterization of materials, equipment and processes as required for design and manufacturing.
In keeping with these activities, the Division conducts basic research, develops new theoretical concepts and models as well as new and advanced devices, components, and associated technology. These actions are designed to further the equitable exchange of products in the marketplace, and the efficient, reliable, and economical application of such products. The Division also provides technical support to other government, industry, and academic organizations. 


\title{
Bibliographic Information
}

\author{
Abstract \\ The Electronics and Electrical Engineering Laboratory (EEEL), working in concert with \\ other NIST Laboratories, is providing measurement and other generic technology critical \\ to the competitiveness of the U.S. electronics industry and the U.S. electricity-equipment \\ industry. This report summarizes selected technical accomplishments and describes \\ activities conducted by the Laboratory in FY 1997. Also included are profiles of EEEL's \\ organization, customer interactions, and long-term goals.
}

\section{Keywords}

commercialization of technology, electrical-equipment industry, electronics industry, international competitiveness, measurement capability

\section{Ordering}

Copies of this document are available as Order No. PB981 14382 from the National Technical Information Service, 5285 Port Royal Road, Springfield, Virginia 22161, at (800) $553-6847$ or (703) 487-4650. 


\section{FOR ADDITIONAI INFORMATION, CONIACT NIST/EFEI \\ TELEPHONE: $\quad 301.975 .2220$ \\ FACSIMILE: $\quad 301.975 .4091$ \\ E-MAIL: EEEL@nist.gov}

WRITER/EDITOR: JoAnne SureHe

PHOTOGRAPHER: Geoffrey Wheeler

PRINTING COORDINATOR: Warren Overman

DOCUMENT PRODUCTION: EPI Communications, Inc. 